Florida International University FIU Digital Commons

11-19-2008

\title{
Effective Knowledge Integration in Emergency Response Organizations
}

Arvind Gudi

Florida International University

DOI: $10.25148 /$ etd.FI10022518

Follow this and additional works at: https://digitalcommons.fiu.edu/etd

\section{Recommended Citation}

Gudi, Arvind, "Effective Knowledge Integration in Emergency Response Organizations" (2008). FIU Electronic Theses and Dissertations. 203.

https://digitalcommons.fiu.edu/etd/203 


\section{FLORIDA INTERNATIONAL UNIVERSITY}

Miami, Florida

EFFECTIVE KNOWLEDGE INTEGRATION IN EMERGENCY RESPONSE ORGANIZATIONS

A dissertation submitted in partial fulfillment of the

requirements for the degree of

DOCTOR OF PHILOSOPHY

in

BUSINESS ADMINISTRATION

by

Arvind Gudi

2009 
To: Dean Joyce Elam

College of Business Administration

This dissertation, written by Arvind Gudi, and entitled Effective Knowledge Integration in Emergency Response Organizations, having been approved in respect to style and intellectual content, is referred to you for judgment.

We have read this dissertation and recommend that it be approved.

$\begin{array}{r}\hline \text { Weidong Xia } \\ \hline \text { Ronald Lee } \\ \hline \text { Shahid Hamid } \\ \hline \text { Irma Becerra-Fernandez, Major Profesor }\end{array}$

Date of Defense: November 19, 2008

The dissertation of Arvind Gudi is approved.

Dean Joyce Elam
College of Business Administration

Florida International University, 2009 


\section{DEDICATION}

I dedicate this dissertation to my mother Shashikala Gudi and late father Pralhad Gudi for their spiritual guidance in my life and to my wife Vandana and children Sumeet and Supriya, for being a fountain of joy and inspiration. 


\section{ACKNOWLEDGMENTS}

An academic undertaking of this magnitude can be successfully completed only by the support and assistance of many individuals and organizations to whom I would like to express my heartfelt appreciation.

I wish to thank my dissertation advisor Dr. Irma Becerra-Fernandez, for her unfailing guidance and encouragement throughout the research process and introducing me to the captivating field of knowledge management. I wish to thank my committee members for their help and support: Dr. Weidong Xia for always being accessible, giving me advice, and willing to help me in all the stages of the dissertation; Dr. Ronald Lee for being the "tough coach" and mentor particularly in the early research stages; and Dr. Shahid Hamid for his advice and suggestions regarding emergency management research. I am also grateful to my "Musketeers" colleagues for their support and willingness to listen to my ideas, provide feedback and suggestions, and helping me with the item sorting process in my methodology.

I would like to acknowledge the support of the personnel at Miami-Dade Emergency Operations Center which was the main site for the data acquisition process. I particularly acknowledge the help and support of Mr. Frank Reddish, Emergency Management Coordinator, Mr. David Perez, Government Affairs Coordinator, and Mr. Douglas Bass, Director, Miami-Dade Office of Emergency Management and Homeland Security. I also thank my colleague Jose Rocha for his support and friendship and David James for his timely assistance during the critical stages of data acquisition.

The financial support for part of this study was provided through the Doctoral Evidence Acquisition Fellowship 2008 of the University Graduate School at Florida 
International University. I also acknowledge the support of the National Science Foundation under grant CNS0452180.

This work would not have been possible without the love and support of my family. I thank our children Sumeet and Supriya for the special encouragement they always provided in their innocent yet unique ways. I am forever grateful to my wife, Vandana for her love, patience and inspiration throughout this journey. 


\title{
ABSTRACT OF THE DISSERTATION \\ EFFECTIVE KNOWLEDGE INTEGRATION IN EMERGENCY RESPONSE ORGANIZATIONS
}

\author{
by \\ Arvind Gudi \\ Florida International University, 2009 \\ Miami, Florida

\section{Professor Irma Becerra-Fernandez, Major Professor}

Natural and man-made disasters have gained attention at all levels of policymaking in recent years. Emergency management tasks are inherently complex and unpredictable, and often require coordination among multiple organizations across different levels and locations. Effectively managing various knowledge areas and the organizations involved has become a critical emergency management success factor. However, there is a general lack of understanding about how to describe and assess the complex nature of emergency management tasks and how knowledge integration can help managers improve emergency management task performance.

The purpose of this exploratory research was first, to understand how emergency management operations are impacted by tasks that are complex and inter-organizational and second, to investigate how knowledge integration as a particular knowledge management strategy can improve the efficiency and effectiveness of the emergency tasks. Three types of specific knowledge were considered: context-specific, technologyspecific, and context-and-technology-specific. 
The research setting was the Miami-Dade Emergency Operations Center (EOC) and the study was based on the survey responses from the participants in past EOC activations related to their emergency tasks and knowledge areas. The data included task attributes related to complexity, knowledge area, knowledge integration, specificity of knowledge, and task performance. The data was analyzed using multiple linear regressions and path analyses, to (1) examine the relationships between task complexity, knowledge integration, and performance, (2) the moderating effects of each type of specific knowledge on the relationship between task complexity and performance, and (3) the mediating role of knowledge integration.

As per theory-based propositions, the results indicated that overall component complexity and interactive complexity tend to have a negative effect on task performance. But surprisingly, procedural rigidity tended to have a positive effect on performance in emergency management tasks. Also as per our expectation, knowledge integration had a positive relationship with task performance. Interestingly, the moderating effects of each type of specific knowledge on the relationship between task complexity and performance were varied and the extent of mediation of knowledge integration depended on the dimension of task complexity. 


\section{TABLE OF CONTENTS}

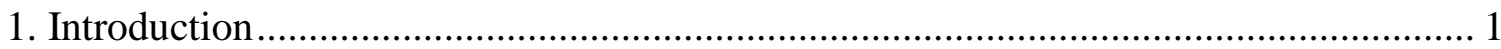

1.1 Emergency Operations Center activation facility................................................ 4

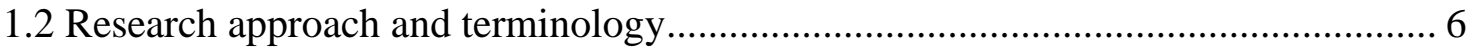

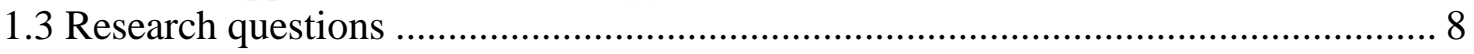

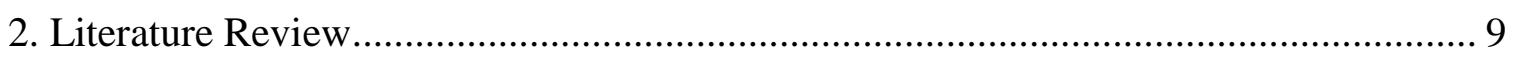

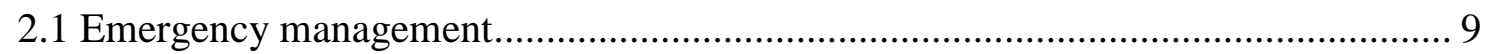

2.1.1 Link to knowledge management …………………....................................... 14

2.1.2 Challenges in emergency operations ............................................................. 18

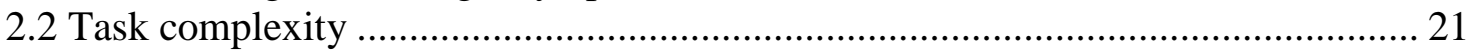

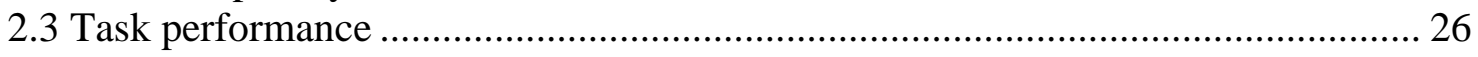

2.4 Normal Accident theory and organizational practices ............................................. 27

2.4.1 The Incident Command System ...................................................................... 29

2.5 Knowledge integration: The subtle link between task complexity \& performance 31

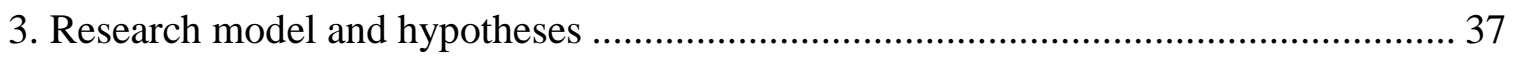

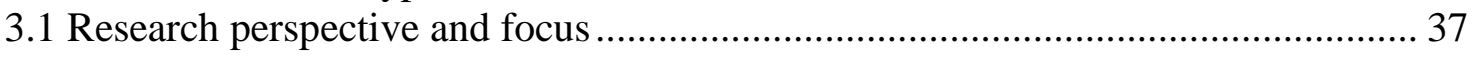

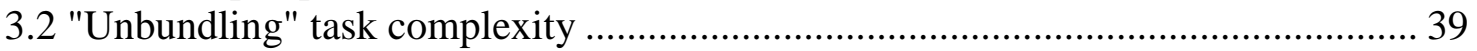

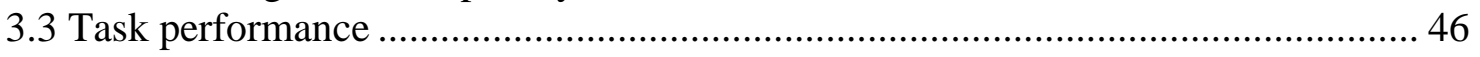

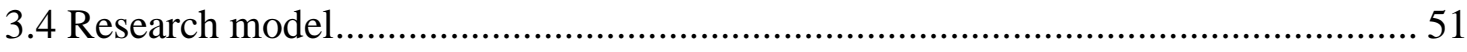

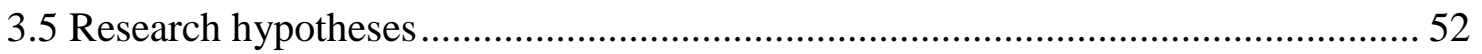

3.5.1 Research hypotheses for moderating effects ……………………………....... 55

3.5.2 Research hypotheses for mediating effects ......................................................... 64

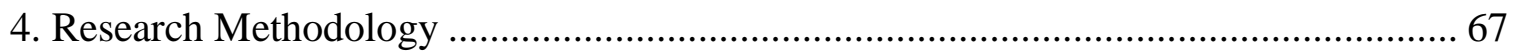

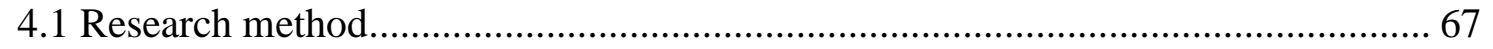

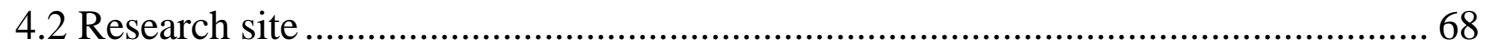

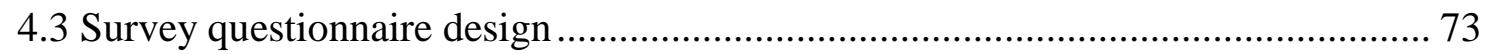

4.4 Generation and refinement of measurement items .............................................. 75

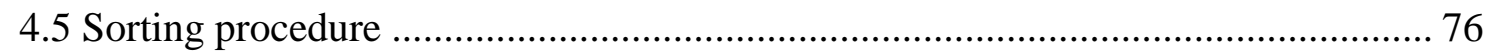

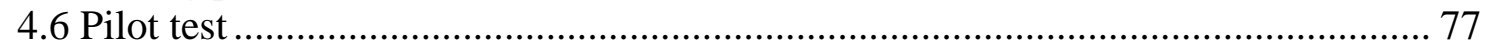

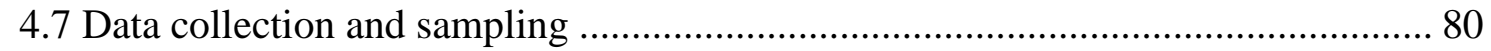

4.7.1 Sampling characteristics ................................................................................ 82

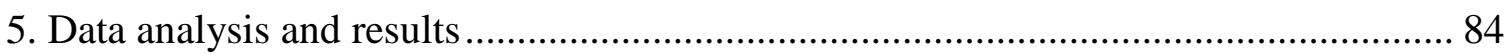

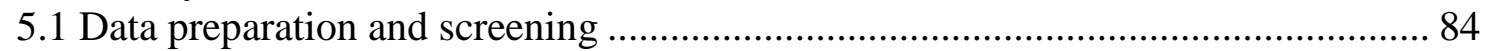

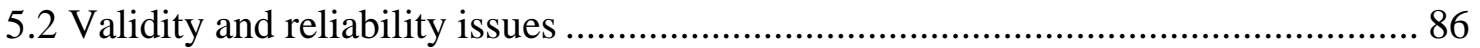

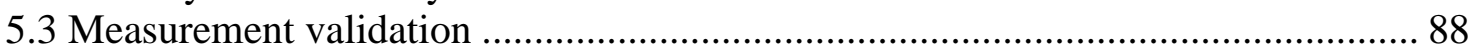

5.3.1 Task interactive complexity measurement ..................................................... 90

5.3.2 Task procedural rigidity measurement .............................................................. 91

5.3.3 Context-specific knowledge measurement.......................................................... 93 
5.3.4 Technology-specific knowledge measurement …………………….............. 94

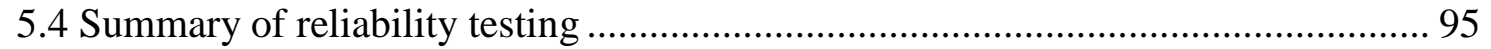

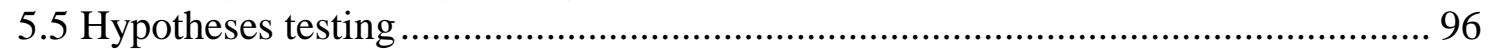

5.6 Summary of path analyses................................................................................... 98

5.7 Summary of path analyses with control variables ................................................ 103

5.8 Moderating effects of specific knowledge........................................................... 106

5.8.1 Moderating effects of context-specific knowledge .......................................... 107

5.8.2 Moderating effects of technology-specific knowledge .................................... 113

5.8.3 Moderating effects of context-and-technology-specific knowledge ................ 118

5.8.4 Summary of moderating effects hypotheses .................................................. 122

5.9 Mediating effect of knowledge integration ........................................................ 123

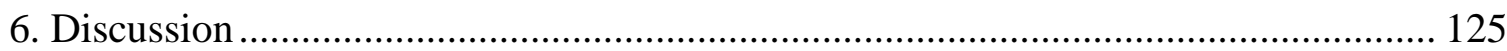

6.1 Relationship between task complexity, knowledge integration and performance 126

6.2 Implications of moderating effects of specific knowledge..................................... 129

6.3 Knowledge integration at Emergency Operations Center ..................................... 138

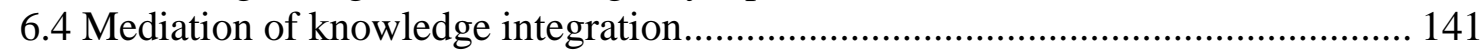

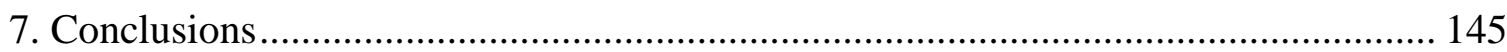

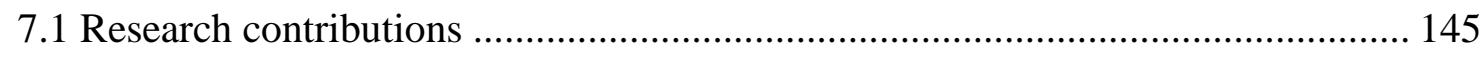

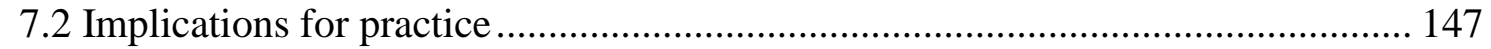

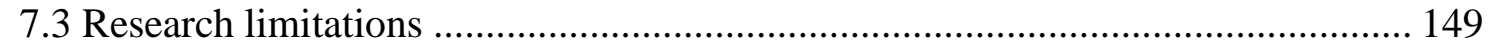

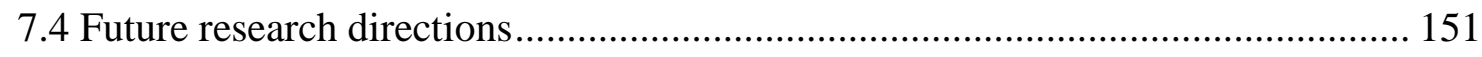

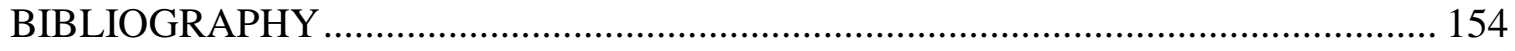

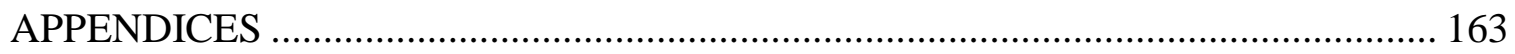

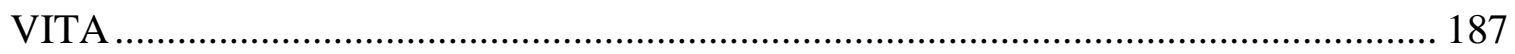




\section{LIST OF TABLES}

TABLE

PAGE

Table 1: Summary of task complexity literature review.......................................... 25

Table 2: Summary of knowledge integration literature review .................................. 36

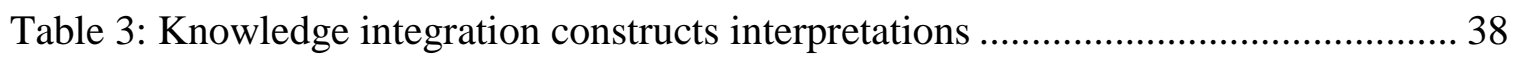

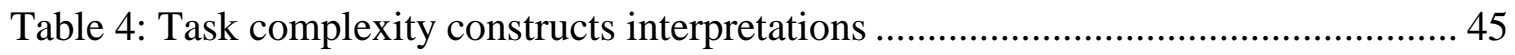

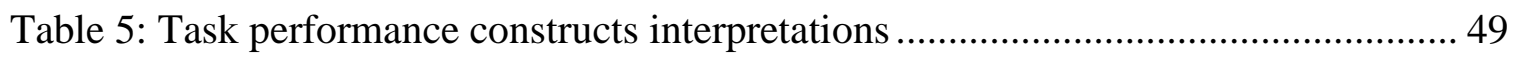

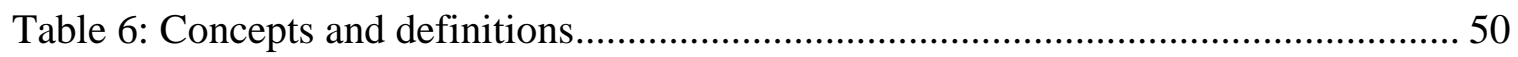

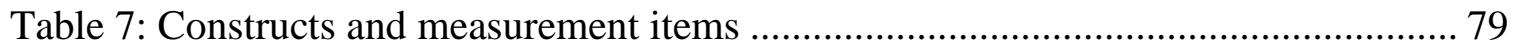

Table 8: Summary of tests to examine non-response bias ....................................... 85

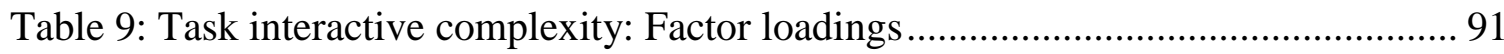

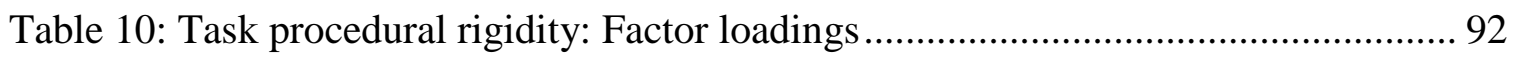

Table 11: Context-specific knowledge: Factor loadings ......................................... 94

Table 12: Technology-specific knowledge: Factor loadings .................................... 95

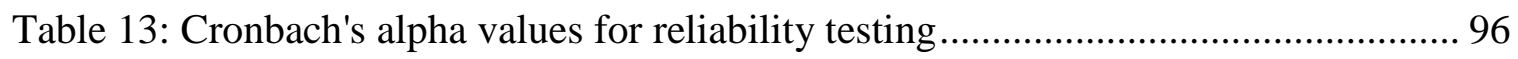

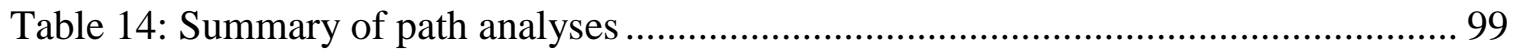

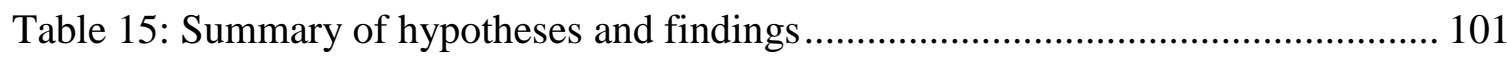

Table 16: Summary of path analyses with control variables ..................................... 104

Table 17: Path analyses knowledge integration and context-specific knowledge .......... 108

Table 18: Path analyses efficiency and context-specific knowledge ........................... 109

Table 19: Path analyses effectiveness and context-specific knowledge ...................... 111

Table 20: Path analyses knowledge integration and technology-specific knowledge.... 114

Table 21: Path analyses efficiency and technology-specific knowledge ...................... 115 
Table 22: Path analyses effectiveness and technology-specific knowledge

Table 23: Path analyses knowledge integration and context-and-technology-specific

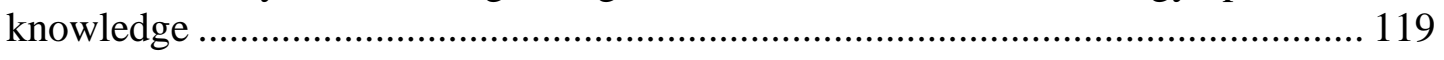

Table 24: Path analyses of task efficiency and context-and-technology-specific

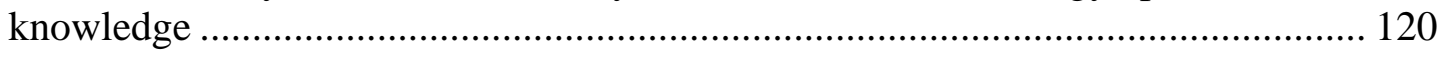

Table 25: Path analyses task effectiveness and context-and-technology-specific

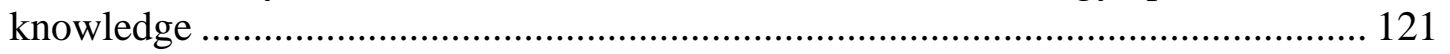

Table 26: Summary of moderating effects hypotheses .......................................... 122

Table 27: Context and technology specific knowledge within task performance .......... 130

Table 28: Task performance within specific knowledge ........................................ 133 


\section{LIST OF FIGURES}

FIGURE

PAGE

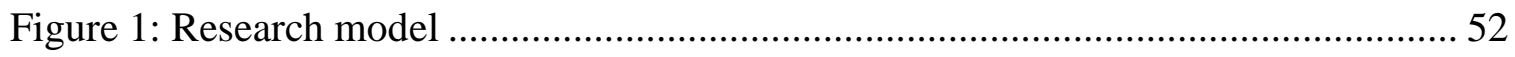

Figure 2: Moderation of context-specific knowledge on knowledge integration ............. 56

Figure 3: Moderation of context-specific knowledge on task efficiency ....................... 57

Figure 4: Moderation of context-specific knowledge on task effectiveness................... 58

Figure 5: Moderation of technology-specific knowledge on knowledge integration ....... 59

Figure 6: Moderation of technology-specific knowledge on task efficiency .................. 60

Figure 7: Moderation of technology-specific knowledge on task effectiveness.............. 61

Figure 8: Moderation of context-and-technology-specific knowledge on knowledge

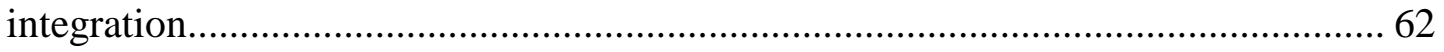

Figure 9: Moderation of context-and-technology-specific knowledge on efficiency....... 63

Figure 10: Moderation of context-and-technology-specific knowledge on task

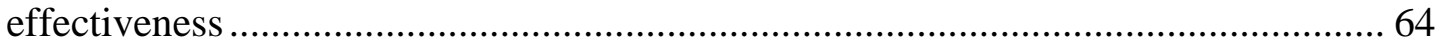

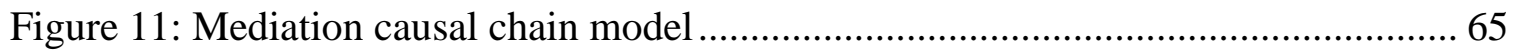

Figure 12: Emergency Operations Center activation floor plan ................................ 72

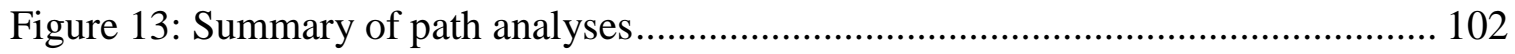

Figure 14: Summary of path analyses with control variables ................................... 105

Figure 15: Mediating effect of knowledge integration .......................................... 123

Figure 16: Conceptual framework moderating effects on efficiency ......................... 137

Figure 17: Conceptual framework moderating effects on effectiveness ...................... 137 


\section{Introduction}

Natural and man-made disasters have gained attention at all levels of policymaking particularly following the sobering lessons of Hurricane Katrina, one of the most significant natural disasters in the United States in recent history (Harris 2005).

Depending on the nature of the disaster, failure to successfully respond to the emergency incident can pose severe danger and risk to the community at-large and the personnel involved in the emergency response activities. Furthermore as our technology develops and expands in its applicability, experience shows that we create sophisticated systems and organizations for managing systems and tasks related to the operations in emergency response organizations. Analysis and investigations of the response activities and mechanisms following Hurricane Katrina, seem to indicate systemic flaws that existed even prior to the disaster (GAO, 2006) and there have been repeated failures in emergency response management at various levels (Becerra-Fernandez, Prietula, Madey, Rodriguez, Valerdi, Wright, 2008). Perhaps, what is even more disturbing is the observation that the lessons learned from Katrina were similar to those mentioned after Hurricane Andrew, which occurred ten years earlier (Becerra-Fernandez \& Prietula, 2006). As such, there is a critical need to try to minimize the impacts of disasters by improving the emergency response operations.

Emergency management tasks have become increasingly complex and interorganizational (Comfort et al., 2004; Becerra-Fernandez et al., 2007). Such tasks are more prone to failure and hence this complexity has made it difficult to manage the emergency tasks. In the face of such challenging situations, integration of the key areas 
of knowledge is the crucial requirement for successful task execution. Thus, effectively managing various knowledge areas and the organizations involved has become a critical emergency management success factor. However, there is a lack of theory and tools that organizations can use to assess and improve emergency management success through effectively managing task complexity and knowledge integration (Becerra-Fernandez, Xia, Gudi, \& Rocha, 2008). The purpose of this research is to fill that gap by examining how the integration of specific knowledge can improve the inter-organizational task performance in emergency operations.

This study is based on a review of relevant theoretical and empirical studies of disaster operations, knowledge management, knowledge integration, complex systems, and system accidents. Each of these areas is rich in its corresponding discipline but seems disconnected with the literature in the other areas. One of the theoretical motivations of this work will be to expand the emerging literature in the areas of task complexity and knowledge integration with a view to apply relevant theories in the field of emergency management.

For many years, researchers, practitioners, and thought-leaders have struggled with the notion of complex systems and how complexity theory might apply to social and organizational change. As research in these areas progresses, we might be able to gain a better understanding of the underlying issues in the management of inter-organizational tasks and how we can make better use of knowledge management in the domain of emergency response organizations. The steps proposed in this study will attempt to conceptualize the dimensions of task complexity and develop a research model that 
focuses on the relationships between task complexity, knowledge integration, and emergency task performance.

In the following sections of the paper, the various topics that are relevant for this study will be identified along with a review of the related literature. Emergency (or disaster) management functions need to be studied to better understand how the changing environment and development of technology is affecting the organization design and structure, and in turn how it affects inter-organizational task management. With regard to the possibility of risks of failures, we need to understand the nature of the tasks and how the task characteristics themselves might be making them more prone to failure. In later sections the research design will be explained along with proposed methodologies which were employed for this research.

Researchers have attempted to explain failures or accidents at a system level based on system characteristics of complexity and coupling (Perrow, 2004). Theories have been proposed to overcome some of the limitations to better cope with those issues and help improve the organizational reliability. This study views emergency response organizations from these perspectives and explores how the use of knowledge management (KM) strategies can improve their performance. Particularly, integration of specific knowledge has been proposed as a KM strategy in such environments. This study will further enable us to identify how the use of KM can benefit the organizations and which specific tools, processes or mechanisms can be applied.

The site for this research is the Miami-Dade County Emergency Operations Center. Current research has attempted to touch upon broad concepts that apply to emergency environments in different organization settings, but may not have reached the 
heart of the issues that we contemplate in this study. We expect that this work will provide useful insight and guidelines for emergency managers responsible for making crucial decisions in dynamic environments. We hope to provide them a methodology to evaluate their options, so that the choices they make are proactive, informed and deliberate, rather than simple enactments of past experiences. We anticipate that this research will allow us to contribute and offer insights towards improved and more effective performance.

\subsection{Emergency Operations Center activation facility}

We had the opportunity to visit the Miami-Dade EOC on a number of occasions for meetings and interviews with the emergency coordinators and other officials, as observers of their practice drills as well as activations in preparation for disaster events. In this section, we provide a snapshot of the EOC activation facility and our impressions of their work functions and environment. We highlight our experience of one particular visit that led to the epiphany which made us realize the significance and implications of our research project.

We were led into a fairly large room and a quick glance revealed that it was designed and furnished in special ways. Three large elongated tables were arranged in the center of the room; each table was equipped with 14-16 workstations and corresponding chairs, with two stations at the head of each table. Name plates of various organizations and agencies were neatly displayed at each workstation which was also equipped with a computer, two telephones (one conventional, and another customized), and a couple of manuals and instruction sets. One end of the room had seating 
arrangements for 8-10 people in each of two rows and the other end had a raised platform for four section managers, a podium with a microphone lending an aura of authority and orderliness. There were fifteen ceiling-mounted monitors and each of the adjoining walls was fitted with five television screens. The emergency management official who had sponsored the visit for our research team was beginning to explain that this was the central activation facility at the Miami-Dade EOC. Outside it was a typical warm summer day in South Florida.

Flash forward August 29, 2006. We were back in the same activation room -- this time as research observers for the activation procedures for Hurricane Ernesto. Most of the workstations were now manned by the representatives of the respective organizations and government agencies and regional EOC representatives were also present. The head of each table was occupied by the Miami-Dade EOC functional branch manager who also periodically updated the status boards on the overhead monitors. The television sets were muted but linked us to the outside world through different broadcast channels.

"Task complexity", "knowledge integration", and "emergency task performance" were no longer empty words on a sheet of paper or fancy ideas in a researcher's mind. These terms had sprung to life in this activation room and as we became aware of the gradual deterioration of the weather conditions outside, we realized there was serious work to be done. The faint buzz of telephone discussions, the chatter of computer keyboards, and the furtive glances at the television screens conveyed an ambiance of anxiety and apprehension; yet we could sense the urgency and intensity of purposive action that was evident in the expressions of these trained emergency professionals. The 
once hazy research concepts we had imagined had concretized on the landscape of South Florida.

\subsection{Research approach and terminology}

The aim of this research is to refine our understanding of how emergency response operations, undertaken by multiple organizations, are impacted by task characteristics such as complexity and process rigidity that are unique to emergency management and thereby present additional challenges for personnel working in these dynamic environments. Further, the intent is to identify knowledge management strategies which organizations could benefit from and improve their emergency management performance.

For the purpose of consistency of terminology and conceptual development, below are definitions of the terms introduced in this study. They will be explained in detail in later sections along with the logical and contextual ideology relating to prior literature as well as the context of this study.

Task complexity: This is the characteristic of the task complexity defined by three dimensions: component complexity (comprised of personnel, teams, organizations, machines, and computer systems), interactive complexity between different personnel and activities, and procedural rigidity (or lack of) of the processes involved in the task. Integration of specific knowledge: Integration of a particular area of knowledge represents the extent to which that knowledge is shared and applied across the organization and enables its members to better perform their tasks. In this study, three 
variations of specific knowledge are being considered: context-specific, technologyspecific, and context-and-technology specific knowledge.

Task performance: We choose to consider two dimensions of the task performance. One is task efficiency which refers to the extent to which the task was completed in the required time frame and within the allocated budget and resources. Second, task effectiveness refers to the extent to which the emergency incident requirements were met and completed satisfactorily for all participants and stakeholders.

The context of this study is the Miami-Dade County Emergency Operations Center. Emergency management organizations, like the Emergency Operations Center (EOC) at Miami-Dade County in the State of Florida, USA have some unique characteristics. They are knowledge-intensive organizations, in the sense that their operations deal with detailed scientific knowledge (such as meteorological systems) as well as inter-organizational management of skills and experience. Because of their mission, they must place a strong emphasis on safety, fraught with environmental uncertainty from different aspects -- technological, social, economical, and political. There is only so much that can be planned in advance for the possibility of occurrence of any disaster incident. What is critical in such an environment is for managers to know not only how their systems function, but also to learn how to quickly adapt to changing conditions (Haeckel 1999). Emergency management in these organizations will most likely have to deal with the issues which are the subject of this study.

The following two sets of research questions are posed. The first question deals with the exploration of the effects of complex inter-organizational tasks on emergency management operations. The literature related to complex systems and analysis of how 
failures can occur provides a useful and pragmatic perspective (Perrow 1999, 2004; Sagan 1993). An implicit understanding is that successful management of these tasks is critical for coping with the unique and distinctive issues faced in these environments. However this understanding alone is inadequate for managing emergency operations in a manner that will keep up with and address the emerging environmental and phenomenological realities. Hence the second question views these issues from a knowledge management perspective in an attempt to provide useful insights for the academic researcher as well as the practitioner.

\subsection{Research questions}

1. How are emergency management operations impacted by tasks that are complex and inter-organizational and could make them prone to failure?

2. How can knowledge management strategies be used for the successful management of the inter-organizational tasks in emergency operations?

a) How does integration of context-specific knowledge influence the performance of the tasks?

b) How does the integration of technology-specific knowledge influence the performance of the tasks?

c) How does the integration of context-and-technology specific knowledge influence the performance of the tasks? 


\section{Literature Review}

\subsection{Emergency management}

Emergency (or disaster) management has become an increasingly important topic of research. Natural disasters such as hurricanes, earthquakes, forest fires, floods, and other incidents can severely impact the lives of large numbers of people for extended periods of time (GAO, 2006). Hurricanes Katrina and Rita, which hit in succession in 2005 , caused the displacement of some 600,000 families from their homes. The damage caused by them extended over 90,000 square miles in five states, cost over $\$ 88$ billion, and resulted in more than 1,500 deaths (Stanton, 2007).

The literature on this topic has generally identified four phases of emergency management processes: preparedness, response, recovery, and mitigation (Mushkatel \& Weschler, 1985). The focus of this study is particularly on the response and short-term recovery phases. Preparedness includes those tasks that need to be initiated just prior to the disaster event. The goal is to minimize the possible damage that can be caused and includes planning activities, issuing warnings and other information to the public, and training. The activities undertaken immediately after the event, fall under the response phase. These usually include identification and relocation of severely affected victims, providing emergency assistance to victims, power restoration, etc. The next phase of

emergency management, recovery includes short-term and long-term recovery. Shortterm restoration activities and long-term reconstruction efforts are both intended to restore the conditions that existed prior to the disaster event. The purpose of the 
mitigation phase is to reduce the impact of any future disaster events based on the experience of the prior phases.

Scholars studying emergency management issues have adopted varied and at times diverse streams of research to analyze emergency incidents and the subsequent response activities. These research studies have included emerging trends and technologies such as emergency response information systems, the importance of the human-computer interaction and socio-technical systems, organizational structures and configurations, and management and coordination strategies. In the remainder of this section, we review the advances in emergency management literature over the past decade particularly about emergency management performance and how it might relate to notions of task complexity, complex systems, and knowledge management.

Emergency management environments are increasingly being characterized as complex involving multi-organizational settings. Researchers are examining the problems of inter-organizational coordination, how to increase the performance efficiency in disaster mitigation and response, and applications to public administration theory and practice (Comfort et al., 2004). They deal with issues related to identifying and sharing critical information among the organizational entities and how to design systems to achieve better coordination. The concept of complex adaptive systems is a useful theoretical framework to explain the dynamic processes in managing the complex technical operations. The goal of such organizations is not only to manage risk more effectively and efficiently in the organizations, but also for the community as a whole (Walle \& Turoff 2007). We note that this is an important consideration in the decisionmaking processes of emergency response organizations. 
Regarding organizational issues, a concern that has been reported repeatedly is that communication in large-scale emergencies has become a major challenge (Walle \& Turoff, 2007). Experience has shown that every major disaster event has the potential to spawn off new development of sophisticated systems and technologies and organization forms to potentially deal with future events. Since communication can prove to be a major barrier in such complex environments, research studies have identified three major categories that are key to developing and maintaining effective disaster communication systems: technological, sociological, and organizational (Manoj \& Baker, 2007). We briefly review the literature pertinent to these categories in the remainder of this section. However we believe that research studies confined to such categorizations may not be able to provide a comprehensive view of the research objectives that we address in this study.

Advocating the use of information and communication technology (ICT), new emergency response systems and processes have been proposed, the emphasis being on effective information systems which are able to provide timely and reliable information (Walle \& Turoff, 2007). A significant hurdle that emergency response organizations are faced with is how to gain useful information and make sense of it to arrive at meaningful decisions. Using technology as the basis, the proponents of this approach contend that emergency responders should be able to collect, analyze, disseminate and act on key information, thereby providing more timely and effective response for the emergency situation.

Fiedrich and Burghardt (2007) have identified two major research areas in application of agent technology: agent-based simulation systems which can create 
realistic post-disaster environments, and agent-based DSS which can support disaster managers operating at various levels. Again the emphasis here is on the timeliness and efficiency of the communication needs during disaster events. The authors argue that the application of agent technology can support more timely and enhanced data acquisition and coordination (Tate, 2006) which can support effective decision-making.

A research study that aims to address the critical needs of emergency response organizations is the Project Ensayo Virtual EOC (vEOC) (Becerra-Fernandez and Prietula, 2006; Becerra-Fernandez et al., 2007). The Ensayo vEOC project is a large, multidisciplinary effort that is focused on building a virtual computational infrastructure that simulates the various functions and processes of an emergency management event. One of the important contributions of this research will also help better educate emergency management personnel as to how to effectively and efficiently deal with such events, which inevitably will continue to occur.

Emphasizing the role of personnel in emergency response organizations, we note a research stream related to human factors and the interaction between humans and machines. Researchers are beginning to point out that design challenges for human factors and human-computer interaction are particularly relevant in emergency management systems (e.g., Carver \& Turoff 2007, Harrald et al. 2007). They contend that the human and the computer need to work together with other people and computer systems sharing information to manage the crisis and to support victims after the event. According to them, technological requirements should be driven by user requirements as a result of lessons learned originating from a user-centered systemic approach. This research stream also examines the attributes of automation and how it affects tasks, 
particularly the notion of situational awareness (Sarter \& Woods, 1995) which is considered a critical aspect in managing complexity. Automation undoubtedly will help to eliminate some routine aspects of the tasks, but ultimately the knowledge and experience of the emergency personnel lead to the successful execution of the tasks.

Thus human response to extreme events (or large-scale emergencies) is an important element in this research topic. Research has shown that the success of emergency response operations would depend on many considerations one of which is the recognition that response personnel need to undertake a range of tasks varying in their degree of improvisation (Mendonca et al. 2007). Understandably, the greater the degree of improvisation required for a task, the less the possible dependence of the personnel on automation. ICT systems can be built to support the personnel in accomplishing the tasks and an important consideration is the technological systems are built to enhance organizational agility (Harrald 2006). These systems should aid the personnel in their organizations to undertake the activities that underlie the tasks, some of which can be cognitive, behavioral, and communication (Mendonca et al. 2007).

Research in organization science is considering issues dealing with reliability in organizational working conditions that can be hazardous and unpredictable (Weick et al., 1999). Researchers are suggesting the possibility of new organizational forms for better control and efficiency such as the incident command system (ICS) (Bigley \& Roberts, 2001). The ICS is a particular approach to management of highly reliable temporary organizations that has been employed by many public safety professionals in emergency response organizations. It has enabled the organizations to be flexible and reliable in complex and volatile task environments. This approach is of particular interest in this 
study because the Miami-Dade Emergency Operations Center is structured following the ICS guidelines.

The National Incident Management System (NIMS) is the first standardized management approach that attempts to unify Federal, state, and local lines of government in times of emergency response activities (DHS, 2004). Researchers have reviewed the use and applications of this system with a focus on the ICS within NIMS (Anderson et al., 2004). One of the management characteristics of the ICS is modular organization, an organizational structure which develops in a top-down modular fashion based on the size and complexity of the incident. According to the authors, when situational complexity increases, the organization is able to respond by expanding from the top down adding functional responsibilities as required. For example, one of the procedures adopted at the Miami-Dade EOC is to ramp up (or down) the activation level depending on the severity of the disaster event thereby increasing (or decreasing) the personnel and resources available for the emergency response operation.

\subsubsection{Link to knowledge management}

Some research studies on emergency management have touched upon theories and applications of knowledge management. Since the nature of this work is using a knowledge-based perspective, we review some of the related literature in this section. In general, work related to knowledge management and knowledge management systems (KMS) has considered it important to manage both tacit and explicit knowledge (Nonaka \& Takeuchi, 1995; Polanyi, 1966). 
In emergency response environments the need to manage tacit knowledge is critical because there is seldom sufficient explicit knowledge that exists in databases or models to address all the events that can possibly arise (French \& Turoff 2007). Some suggested approaches are visualization aids to build a collaborative understanding of the situation and foster shared mental models among the emergency personnel (Weick \& Sutcliffe 2001). Through such techniques it is possible for emergency personnel with different skill sets to share their tacit knowledge expediently at critical times so that the emergency problem can be quickly resolved.

Researchers have examined the issues of coordination in rapidly evolving disaster response systems (Comfort et al., 2004). Increasing coordination in disaster management goes beyond just providing information to response agents. Hence the mechanisms used for coordination of information in normal circumstances would fall short in emergency situations. The authors point out that it is also important to identify the core information, including severity and time of incident, and share it with others. This is an important factor since in disaster situations the sooner the core information is identified and shared, the faster will be the response. This finding is of particular interest to us since this work aims to investigate the influence of knowledge integration on emergency task performance.

Organization theories have been examined to get a better understanding about emergent response groups and how they efficiently coordinate knowledge for improving disaster response (Majchrzak et al., 2007). Applying organization theory about knowledge coordination in groups, the authors in this study seek to learn about the internal dynamics of emergent response groups. From a theoretical perspective, they 
examine: the role of expertise in task assignment, how groups function when credibility cannot be validated, and how the expertise is coordinated. In emergency management, groups can be quickly assembled based on the disaster situation and the nature of response required. Different members of the group can have varied background in their professional experience and skills in dealing with emergencies. Hence emergency response organizations have to acknowledge that these groups need to function cohesively without prior validation of the credibility of each member and then provide the environment whereby the expertise is coordinated within the group effectively. We note that this is one of the challenges of the Miami-Dade EOC.

Effective knowledge and information management between government agencies and the public is important in emergency management (Schellong \& Langenberg, 2007). Presenting the case of Miami-Dade County, which implemented a multi-jurisdictional and channel environment (the 311-portal), the authors of this research study show how it was successfully used during Hurricane Wilma. They argue that such a setting enhances the organization's knowledge sharing effectiveness, which is important at all political levels, especially when disasters occur.

An important element of emergency response organizations is the responsibility of keeping the public informed about impending disaster situations, as well as issuing specific instructions and warnings to the community. Emergency response personnel often times depend on the cooperation of citizens for accomplishing their tasks (such as evacuations). Some interesting developments have been citizen-led online forums, public warning systems, and open source disaster management systems which are indicative of new avenues for knowledge management in unique emergency situations. 
A typical illustrative citizen-led online forum is one that emerged after the August 2005 Hurricane Katrina disaster (Palen et al., 2007). These forums were generated by the public to find missing people, to offer and seek shelter, employment, and other forms of relief. The authors point out that these forums are indicative of the reach of the Internet (Preece, 2000), and how public involvement can be expanded regardless of physical distance from the disaster area. From the knowledge management perspective, the forums create a means for sharing knowledge, learning from stories and experiences, and building the knowledge base which can be useful in preparation for future events.

The idea of public warning is about the sharing of information about threats and hazards. Botterell and Addams-Moring (2007) have discussed how public warning systems have developed in the networked-age serving the functions of warning others and enlisting help which become essential in the community during and after disasters. The challenges faced by emergency response organizations would be how to ensure the validity and authencity if such systems were freely deployed in the community.

A recent development in global disaster management is free and open source disaster management systems. In their assessment of "Sahana"1, the authors state that the key characteristics of the open-access approach are firstly low-cost deployment and secondly easy adaptability (Currion, De Silva, \& Van De Walle, 2007). Hence, they argue that open source emergency management systems will prove to be important in future humanitarian operations.

\footnotetext{
${ }^{1}$ Sahana is an open source disaster management system developed in Sri Lanka following the Tsunami disaster in 2004
} 


\subsubsection{Challenges in emergency operations}

When we consider work in highly dynamic environments and especially when the complexity is relatively high (such as in emergency management), some unique factors begin to surface which need consideration. These factors are related to organization structure, managerial strategies, technological infrastructure, and mechanisms of coordination. We describe below some of the key challenges in emergency environments and why further study and analysis and is called for in these research areas. These factors are significant for the following reasons:

1) The events that trigger emergency management operations are rare and diverse and there is no single comprehensive plan that can be devised ahead of time to cope with the next incident (Becerra-Fernandez et al. 2007). Emergency managers are faced with the dilemma that every event is unique and "one size does not fit all" when it comes to task management planning and methodology.

2) The Emergency Operations Center (EOC) is the organization which is the site for all emergency management operations and functional responsibilities. Many assumptions usually made in the organizational context with regard to issues such as resource planning, communications, chain of command, etc. may not hold here (Samii, Van Hassenhove, Kumar, \& Becerra-Fernandez, 2002a). During an emergency, the participation of representatives from different organizations is transitory. Communication mechanisms could be instituted formally, but the stressful conditions during an emergency might cause the participants to revert to informal means of communication (such as phone, e-mail etc.). For similar reasons, the welldefined chain of command at the EOC might be construed to be fluid and evolving. 
3) The nature of emergency situations is such that decisions have to be made quickly many decisions may have to be implemented immediately (Becerra-Fernandez \& Preitula 2006). Given this mandate, organizations would usually rely on policies and procedures dealing with communication, authority, delegation, decision criteria, etc. which have been established, distributed, and understood prior to the incident. Ironically many emergency events are unique and hence the extent of planning that can be done earlier is limited. For example, an event such as a hurricane can be unique in each occurrence in terms of speed of movement, wind speed, direction of motion, size, amount of rainfall, and so on. The number of variables that characterize an emergency event create practically an infinite number of possible combinations, such as the responses required for a fast moving "dry" hurricane versus a slow moving "wet" hurricane.

4) Many of the participants in the EOC for a particular incident may be "first time" entrants because emergency events do not have a regular pattern or schedule. They may have extensive knowledge and expertise in the organization they represent (such as water management, electric utility, phone services, etc.) without much experience of dealing with emergency situations. Additionally this might be the first time they are meeting and working with the other EOC members. This is a challenge because the situation would demand a high degree of interaction between the different organizational representatives with severe time constraints.

5) In emergency management environments involving multiple organizations, tasks will most likely have a high degree of complexity: component, interactive, and procedural rigidity. Many personnel representing different organizations and agencies need to 
come together and work on the emergency tasks. Such tasks will tend to be risky and prone to failure because decisions have to be made quickly in dangerous and stressful circumstances. This gives rise to additional challenges to compensate for these inherent characteristics by effective task management using adaptive techniques.

The convergence of the organizational and technological characteristics through knowledge integration we believe will be critical for successful management of these tasks. We believe effective integration of specific knowledge will be able to reduce the negative impact of task complexity on emergency task performance.

Current theory to address such questions remains sparse and our present level of understanding is inadequate when dealing with these issues (Comfort et al., 2004). When faced with the operational challenges of conducting such operations, typically practitioners continue to rely upon inefficient and ineffective methods such as trial and error, and imitation (Walle \& Turoff, 2007). We believe that this calls for both theoretical and applied research to help guide the academic scholar and also to inform the practitioner through new contributions in this research domain.

In summary, the emergency management processes before, during, and after the event are complex, can cross inter-organizational boundaries and jurisdictions (Samii et al., 2002a). The tasks undertaken by the emergency response organizations tend to be complex because of the interdependence among organizations as well as the systems involved (Comfort, Ko \& Zagorecki, 2004). Decision-makers are challenged to be flexible and adapt to the requirements of the situation as they unfold (Haeckel \& Nolan 1993). 
In a later section we review in more detail the principles and methodology of the Incident Command System (ICS), which is a particular approach of a highly reliable temporary organization employed by many public safety officials for management of emergency operations. Also in the Research Methodology chapter, we review the operations and structure of the Miami-Dade Emergency Operations Center (EOC).

The focus of this study is the operations of emergency organizations dealing with the phases related to response and short-term recovery. In the next section we review the literature on task complexity along with the rationale for viewing the "task" as the unit of analysis for research agendas pursuing related topics.

\subsection{Task complexity}

To be able to address the issues in such environments, we believe an understanding of task complexity is important for its potential implications for research in applied areas such as emergency response organizations. Prior literature on complexity theory (Bar-Yam, 2003), complex systems (Fryer 2003), and complex projects (Shenhar \& Dvir 1996; Xia \& Lee 2005) has attempted to develop strategies on how organizations in general can adapt to complex environments (P. Anderson, 1999). Simon (1996) defined a complex system as one made up of a large number of parts that have many interactions. Thompson (1967) explains a complex organization as a set of interdependent parts, which together make up a whole that is interdependent with some larger environment. 
In order to situate the concept of "task" and its attributes in the context of this work, we reflect upon Churchman's (1971) essay about "Leibnizian concept of a whole concept". As a systems thinker, Churchman explains:

"Present world's philosophy of system design, for almost all our conscious policy making is based on the idea of fixing up messy situations wherever they occur. ... No unit of nature can function unless implicitly it contains all the richness of nature -- a "unit" of nature contains all of the complexity of nature. To translate this into modern terminology, the idea is that in the design and evaluation of any functioning system the same set of considerations are always involved; to ignore any consideration is to design an incompletely functioning entity" (pp. 40-41).

We view task management as a core function in emergency operations and it is the nexus around which the requirements for all organizational units of emergency response organizations are conceptualized and eventually deployed. In other words, the concept of task implicitly contains the issues and complexities of emergency operations and the findings based on task analyses will lead us to solutions to the questions presented in the research objectives. Anticipating that these solutions potentially could have multiple and diverse applications in the organization, we adopt the "task" as the unit of analysis for this research study.

Literature on task complexity has attempted to explain the characteristics of complex tasks and identified a variety of dimensions to identify them. We review the significant contributions of Wood (1986) and Campbell (1988) to this research stream. Wood has defined three types of task complexity: component, coordinative, and dynamic. Component complexity of a task depends on the number of distinct acts that need to be executed and the number of distinct information cues that need to be processed for 
performing the acts. Coordinative complexity depends on the nature of the relationships between task inputs and task outputs. They are represented by the form and strength of the relationships between information cues, acts, and the products of the task. The difficulty for coordination increases as the requirements for timing, frequency, intensity, and location of acts become more complex.

Campbell (1986) proposes four fundamental task attributes that make a task complex. These are explained as: (1) multiple paths -- when there are potentially multiple ways (or paths) that lead to the goal, (2) multiple outcomes -- when there is more than one goal (or outcome) that is desired to be reached, (3) conflicting interdependence -- the paths and the outcomes have conflicting interdependencies, (4) uncertain linkages -- the relationship among the paths and the outcomes are not always clear.

The understanding of the concept of task complexity is important in such studies because we need to clarify the potential implications for the proposed research in applied areas such as emergency management. In a later section, we explain how we attempt to disaggregate or "unbundle" this concept as it relates to tasks undertaken in emergency operations. Also the primary feature that emerges in such a dynamic environment is that task management needs to hinge around the key ingredient of agility of purpose.

It is easy to see that the increased task complexity implies that no one individual or team can at a given time comprehend the entire disaster situation on hand. In a later section, we introduce some relevant knowledge management strategies useful in these conditions. Also we note that our ability to advance in science and technology continues 
unabated. This leads us to remain sanguine, that we can construct tools and design processes for managing this complexity.

In the next section, we discuss the conceptualization of task performance in emergency operations. The following table summarizes the various literature references that we draw from about complexity in general and more specifically about task complexity. 


\begin{tabular}{|c|c|}
\hline $\begin{array}{l}\text { Concept/ } \\
\text { construct }\end{array}$ & Literature references \\
\hline $\begin{array}{l}\text { Task } \\
\text { component } \\
\text { complexity }\end{array}$ & $\begin{array}{l}\text { Wood 1986, Campbell 1988, Perrow 1999, Marais, et al., 2004, Rijpma } \\
\text { 1997, Cooke \& Rohleder 2006, Shenhar \& Dvir } 1996 \\
\text { Component complexity represents the number of variables in the system; } \\
\text { how many business elements it needs to coordinate in the organization; the } \\
\text { size and number of elements and also the variety of elements. }\end{array}$ \\
\hline $\begin{array}{l}\text { Task } \\
\text { interactive } \\
\text { complexity }\end{array}$ & $\begin{array}{l}\text { Perrow (1984, 1999); Marais, et al., 2004; Rijpma 1997; Cooke \& Rohleder, } \\
2006 \\
\text { The measure of interactive complexity is the number of ways in which } \\
\text { components of the system can interact. It represents the number of variables } \\
\text { in the system, the number of relationships between the variables and the } \\
\text { number of feedback loops through which the variables interact. Typically, } \\
\text { interactive complexity increases with the technology incorporated into the } \\
\text { system. } \\
\text { Interactive complexity refers to the presence of unfamiliar or unplanned and } \\
\text { unexpected sequences of events in a system that is either not visible or not } \\
\text { immediately comprehensible. } \\
\text { Haeckel \& Nolan, } 1993 \\
\text { A company's complexity is a function of how many information sources it } \\
\text { needs, how many business elements it must coordinate and the number and } \\
\text { type of relationships that exist among those elements } \\
\text { Shenhar \& Dvir, } 1996 \\
\text { Complexity of a project depends on the size of the project, number of } \\
\text { elements, variety, and inter-connectedness of the parts. }\end{array}$ \\
\hline $\begin{array}{l}\text { Procedural } \\
\text { rigidity } \\
\text { OR } \\
\text { Coupling } \\
\text { (tight or } \\
\text { loose) }\end{array}$ & $\begin{array}{l}\text { Perrow (1984, 1999); Marais et al., 2004; Rijpma 1997; Cooke \& Rohleder, } \\
2006 \\
\text { A tightly coupled system is one that is highly interdependent: Each part of } \\
\text { the system is tightly linked to many other parts and therefore a change in } \\
\text { one part can rapidly affect the status of other parts. Tightly coupled systems } \\
\text { respond quickly to perturbations, but this response may be disastrous. } \\
\text { Loosely coupled or decoupled systems have fewer or less tight links } \\
\text { between parts and therefore are able to absorb failures or unplanned } \\
\text { behavior without destabilization. } \\
\text { Sanchez \& Mahoney, } 1996 \\
\text { Product designs composed of tightly coupled components will generally } \\
\text { require development processes carried out in a tightly coupled organization } \\
\text { structure coordinated by a managerial authority hierarchy, an organizational } \\
\text { design typically achieved within a single firm (p. 65) } \\
\text { Orton \& Weick, } 1990 \\
\text { Tightly coupled systems are portrayed as having responsive components } \\
\text { that do not act independently, whereas loosely coupled systems are } \\
\text { portrayed as having independent components that do not act responsively } \\
\text { (p.205) } \\
\text { Organizational outcomes of loose coupling are: persistence, buffering, } \\
\text { adaptability, satisfaction, and effectiveness (p. 213) }\end{array}$ \\
\hline
\end{tabular}

Table 1: Summary of task complexity literature review 


\subsection{Task performance}

In most prior studies concerned with tasks and their outcome, the focus is on the task in question. Measures dealing with the task performance tend to be centered on the nature of the specific task and usually not suitable for generic evaluation. A review of literature about project management and project success revealed approaches that are suitable for evaluating tasks in the emergency management arena.

Given that achieving targets of time, cost, scope, and quality are most highly rated as measures of success in project management (Freeman \& Beale, 1992), we need additional criteria for evaluating the success of the outcome of emergency tasks. This is partly due to the fact that this evaluation will also depend upon the "rater" of the task based on different viewpoints (Belout, 1998). This is especially true in dynamic environments when the nature of the emergency is such that amidst changing environmental factors, multiple organizations and agencies are involved, each potentially having their own accountabilities (PMBOK, 2000).

We propose two dimensions to evaluate the success of the task: task effectiveness and task efficiency based on the main criteria for measuring the success of projects as noted by Freeman and Beale (1992):

Task effectiveness refers to the extent to which the emergency incident requirements were met. It represents the extent to which the task outcome was satisfactory to all the participants. Equally important is how well the task was executed without disrupting other tasks. Task efficiency refers to the extent to which the task was completed in the required time frame and within the allocated budget and resources. 
With this background, we theorize that careful articulation of elements of task management leading to knowledge integration may inevitably be the most reasonable approach to turn the apparently contradictory forces riding on complexity to eventually converge on success for the task outcome.

In the following section, the principles of Normal Accident theory and related organizational practices are discussed along with their implications for managing complex tasks in organizations.

\subsection{Normal Accident theory and organizational practices}

The Normal Accident theory related to accidents and failures in systems and organizations further inform this research. Normal Accident theory (NAT) was initially formulated by Perrow (1984) and later reviewed by Sagan (1993) and states that accidents are inevitable in complex, tightly-coupled systems (such as nuclear power plants). Interactive complexity represents the number of ways in which the system components can interact with each other. It depends on the number of parts or components of the system, the possible relationships between them and the presence of feedback loops for the interactions. The premise for this theory is that system complexity will cause unpredictable interactions between the various parts of the system which can sometimes lead to failures, some of which can be catastrophic. Tight or loose coupling depends on the rigidity of the design of the system with respect to time or sequence of events. It will depend on presence of redundancies and backups, resource buffers, slack, and flexibility of the process. Tight coupling will allow breakdowns and failures in the system to quickly cascade to other parts. According to Perrow, a system that is complex 
and tightly-coupled is susceptible to failure and accidents; hence he calls them "normal accidents".

Theorists like La Porte and Consolini (1998) state that serious accidents and system failures can be prevented by implementing certain organizational practices. These organizations adopt several strategies which can increase their reliability (Roberts \& Bea, 2001), (Weick \& Sutcliffe, 2001) and these are summarized as follows: (1) Redundancy - maintaining backups for equipment so that if one part fails then there is another to replace it; keeping backup personnel available in case any one person is unable to accomplish his task. (2) Simultaneous centralized and decentralized operations -decentralized decision-making allows those who are most knowledgeable about the problem to quickly solve them. Decentralization needs to be supported by an organizational culture of reliability which imparts to its members a clear understanding of the operational goals and the decision premises with the underlying assumptions. The latter is achieved by a centralized organizational structure. (3) Culture of safety and reliability throughout the organization and a sense of high priority from management; (4) Organizational learning -- includes knowledge of the operations, processes, and technology. Emphasis is given on "trial-and-error" learning which implies learning from past mistakes, constant training and a forgiving culture which can allow its members to learn from past failures.

We draw from the principles discussed above to identify which knowledge management strategies would be appropriate to improve performance in emergency response organizations. The notion of knowledge integration in emergency situations is particularly relevant for an organization to be simultaneously centralized and 
decentralized in its operations. This, we believe is in part a solution for how an organization attempts to become adaptive to respond to complex environments as explained in the following section.

\subsubsection{The Incident Command System}

To deal with complex and volatile task environments, organizations have emphasized the need for reliability as well as being flexible and adaptive to respond to changing conditions (Haeckel 1999). The Incident Command System (ICS) is a particular approach of a highly reliable temporary organization employed by many public safety officials for management of emergency operations (Bigley \& Roberts, 2001). Department of Homeland Security defines ICS as "a management system designed to enable effective and efficient domestic incident management by integrating a combination of facilities, equipment, personnel, procedures, and communications operating within a common organizational structure" (DHS, 2004).

The ICS approach is of particular interest in this work since it implies a solution that holds the dual promise of being adaptive in a turbulent environment and at the same offering reliable practices. One of the key themes supporting such an organizational system is "integration" of various organizational capabilities as stated in the above definition. In general the ICS is constructed around five major functions: command, planning, operations, logistics, and finance/ administration. To some extent, the ICS is a bureaucratic system which is formalized, characterized by rules, procedures, policies, and instructions (A. I. Anderson, Compton, \& Mason, 2004). The Incident commander is the 
highest ranking position within the ICS who is ultimately responsible for all activities that take place at an incident.

Interestingly, despite being bureaucratic, the ICS serves as the basis for providing a high degree of organizational flexibility which is required for reliable performance in uncertain and risky circumstances (Bigley \& Roberts, 2001). This is accomplished by the ability of ICS-based organizations to rapidly coordinate diverse resources required to complete emergency tasks characterized by high complexity and rigid time-constrained conditions.

Researchers have explained this capability as "constrained improvisation" (A. I. Anderson et al., 2004). First, there is acknowledgement that the incident commander and other supervisors may not understand enough about all the details of the situations that their subordinates may be facing. Second, to reduce problems that can be created due to centralized structuring, supervisors provide the subordinates with a degree of latitude to improvise since they possess the required experience, training, and resourcefulness to adapt to the particular problem on hand. We advocate knowledge management strategies, particularly integration of specific knowledge as vital for supporting such organizational capabilities which entail improvisation with tools, rules, and routines, and coordination amongst individuals, teams, and organizations.

In the following section we review the literature on knowledge integration, specificity of knowledge, types of specific knowledge, and propose how the theory of knowledge integration can be applied to emergency management. 


\subsection{Knowledge integration: The subtle link between task complexity \& performance}

This research study proposes that improved performance in emergency response organizations can be achieved not merely by a technological solution (e.g. sophisticated databases and access mechanisms) or a personnel-related solution (e.g. hire smarter and more experienced people), but rather by a structural approach to address performance issues (Myers, 1996). For example an engineer will have studied the fundamentals of physics when designing a bridge and a doctor is trained to study the basic structures of the human body. Similarly emergency management professionals need to understand the underlying concepts and phenomenon and how they interrelate to identify specific issues and solutions. In particular, they need to understand the fundamental processes involved in their operations and the dynamics of the organizations that they are part of.

We also draw from project management literature which views project related issues from a knowledge management perspective. We see similarities between multiproject organizations and the environments in which emergency management personnel need to work in. For example, projects are unique and each project might be significantly different from the other in terms of being relatively self-contained and of a finite nature of the project tasks (Bresnen et al., 2003). In the emergency management environment, each disaster incident is unique (i.e. in the course of a year, one may encounter the threat of a hurricane, a wild fire, or a medical emergency of a contagious disease) and calls for the appropriate kind of response with the required resources and personnel with necessary expertise and experience. As outlined below, project management scholars have proposed strategies to manage the flow of knowledge and establish processes to enhance organizational learning. 
Acknowledging that knowledge management efforts in project organizations may not be mature, researchers are recommending that in order to avoid knowledge fragmentation and loss of organizational learning, project organizations require systematic and effective knowledge management (Kasvi et al., 2003). For example, they propose the concepts of Project Organization Memory (knowledge stored from an organization's past projects), and Project Organization Memory System (means by which Project Organization Memory is realized). For multidisciplinary project teams, Fong (2003) has researched the underlying processes and their interrelationships in knowledge creation and provides a conceptual model of knowledge creation viewing collective project learning as the nucleus of all three knowledge processes (i.e. sharing, generation, and integration). In their research on knowledge management in project-based settings, Bresnen et al. (2003) emphasize the importance of the social aspects of knowledge retention and transfer. The authors examine the significance of social factors in enhancing knowledge management capabilities in such environments proposing a community-based approach to managing knowledge. Scholars have attempted to address the question of what kind of social engagements are relevant in project work for acquisition and sharing of tacit knowledge (Koskinen et al., 2003) using the Holistic Concept of $\mathrm{Man}^{2}$ as the analytical tool.

We note that although some project management work has touched upon the notion of knowledge integration, it needs further development which we intend to expand upon in this review. In complex development projects, expertise needs to be drawn from

\footnotetext{
${ }^{2}$ This is a concept which consists of an individual's three basic modes of existence: consciousness, situationality, and corporeality. Consciousness is existence as a psychical-mental phenomenon, as
} 
diverse sources, so it is required to find a balance between differentiation and integration (Garrety et al., 2004). The authors view differentiation as teams working separately and integration as teams meeting and exchanging knowledge ${ }^{3}$. They apply a communities of practice perspective to propose how to enable project managers to achieve a balance between differentiation and integration in complex development projects. Huang and Newell (2003) examine in their research within large organizations, the dynamics of knowledge integration in the context of cross-functional project implementation. Their findings suggest that in these cases knowledge integration is a process of engaging organizational members, creating awareness of the value of the project for all stakeholders, the management of social networks, and developing the social capital for all members.

Among strategies of knowledge management, our focus is knowledge integration which is needed to satisfy the conflicting demands for specialization and collaboration in organizations (Grant, 1996). Understanding how to promote the integration of specific knowledge can become a critical emergency management success factor and as mentioned earlier it can be the key element for enabling the organization to become adaptive in uncertain environments.

In this study we adopt the following definition: Integration of a particular area of knowledge represents the extent to which that knowledge is shared and applied across the organization and enables its members to better perform their tasks (Sabherwal \& Becerra-Fernandez, 2005). The need for integration arises because of the increased

experiencing (the mind), situationality is existence in relation to a certain part of reality i.e. the world or the environment (the situation), corporeality is existence as an organism with organic processes (the body). 
specialization of the knowledge which can be one of its inherent characteristics. Grant (1996) explains that "firms need to reconcile specialization in the production domain while remaining integrated in the knowledge domain" (pp. 609). We review the concept of specific knowledge particularly as it applies to managing emergency response organizations.

To conceptualize the specialization of knowledge, Jensen and Meckling (1996) consider it as the knowledge that is possessed by a very limited number of persons and is expensive to transfer. Other theorists have proposed component knowledge (knowledge that already exists in one industrial complex but not known in firms from other industries) and architectural knowledge (combining or integrating different types of component knowledge into a new configuration) (Boer et al. 1999).

Prior literature has identified three types of specific knowledge: context-specific, technology-specific, and context-and-technology specific (Sabherwal \& BecerraFernandez, 2005). Context-specific knowledge refers to the knowledge of particular circumstances of time and place in which work is performed (Hayek, 1945). On the other hand, technology-specific knowledge is knowledge of the particular scientific or theoretical discipline, which comprises of rules of cause and effect and the tools and techniques used to address problems in that area (Choudhury \& Sampler, 1997). Advances in this theory have discerned a type of specific knowledge called context-and technology-specific knowledge which is high in both context and technical specificity (Sabherwal \& Becerra-Fernandez, 2005).

\footnotetext{
${ }^{3}$ Our conceptualization of knowledge integration goes beyond teams meeting and exchanging knowledge as will be explained later in the section.
} 
In this review we consider all three types of specific knowledge since prior research suggests that knowledge integration is a process of engaging organizational members and the management of social networks (Huang \& Newell, 2003). The aspect of engaging organizational members is particularly relevant in emergency response operations comprising of several organizations and government agencies. The following table summarizes the various literature references about knowledge integration and types of specific knowledge. 


\begin{tabular}{|c|l|l|}
\hline $\begin{array}{l}\text { Concept/ } \\
\text { construct }\end{array}$ & $\begin{array}{l}\text { Literature references } \\
\text { technology } \\
\text { specific } \\
\text { knowledge }\end{array}$ & $\begin{array}{l}\text { 1) Choudhury \& Sampler, 1997 } \\
\text { Specific knowledge has 2 attributes: (1) it is possessed by a very } \\
\text { limited number of individuals and (2) it is expensive to transfer } \\
\text { For example, the professional medical knowledge possessed by a } \\
\text { doctor is specific knowledge gained by relatively few individuals in } \\
\text { the medical profession } \\
\text { 2) Sabherwal \& Becerra-Fernandez, 2005 } \\
\text { Specific knowledge is knowledge of the particular scientific or } \\
\text { theoretical discipline. It comprises of rules of cause and effect and } \\
\text { the tools and techniques used to address problems in that area. } \\
\text { 3) Grimaldi \& Torrisi, 2001 } \\
\text { (In software industry) This is the specific knowledge concerning } \\
\text { new technologies, platforms and standards } \\
\text { 4) Grant 1996; Huang \& Newell, 2003 } \\
\text { Efficiency of knowledge integration }\end{array}$ \\
\hline 2 & $\begin{array}{l}\text { Context } \\
\text { specific } \\
\text { knowledge }\end{array}$ & $\begin{array}{l}\text { 1) Choudhury \& Sampler, 1997 } \\
\text { This is specific knowledge that is gained in a given context. For } \\
\text { instance, the detailed knowledge that a doctor possesses about the } \\
\text { idiosyncrasies of a particular patient, that he/she has treated for a } \\
\text { number of years } \\
\text { 2) Hayek 1945 } \\
\text { This is Idiosyncratic knowledge, knowledge of context, or } \\
\text { knowledge of particular circumstances of time and place } \\
\text { 3) Carlile 2004 } \\
\text { Specialization in different problem-solving domains found in Weber } \\
\text { (1924/1947) between actors. This creates differences in levels of } \\
\text { experience, terminologies, tools, and incentives that are unique to } \\
\text { each specialized domain. } \\
\text { 4) Grimaldi \& Torrisi, 2001 } \\
\text { (In software industry) linked to particular markets, users and } \\
\text { applications } \\
\text { 5) Grant 1996; Huang \& Newell, 2003 } \\
\text { Scope of knowledge integration }\end{array}$ \\
\hline $\begin{array}{l}\text { Context and } \\
\text { technology } \\
\text { specific }\end{array}$ & $\begin{array}{l}\text { 1) Sabherwal \& Becerra-Fernandez, 2005 } \\
\text { Knowledge that is high in both contextual and technical knowledge } \\
\text { specificity as explained above } \\
\text { 2) Grant 1996; Huang \& Newell, 2003 } \\
\text { Flexibility of knowledge integration }\end{array}$ \\
\hline 1
\end{tabular}

Table 2: Summary of knowledge integration literature review 


\section{Research model and hypotheses}

\subsection{Research perspective and focus}

Based on the analysis and the review of related theories and empirical research (Chapter 2), the research perspective and focus are presented in this section. We acknowledge that other concepts and their relationships might be relevant for this topic of research and will be mentioned as possible avenues for consideration in future research undertakings.

As discussed earlier, work in the highly complex environment of emergency management is particularly challenging and is the focus of this study. We reviewed the literature in relevant areas such as emergency management, complex systems, task complexity, knowledge management, knowledge integration, and task performance. Based on the literature review and our observations at the Miami-Dade EOC, we further develop the conceptualization of task complexity in the context of emergency operations as described in the following section. We argue that considering "task" as the unit of analysis, the study of the underlying task attributes in terms of complexity is a useful approach to frame this study. Essentially these are the attributes which make the execution of these tasks difficult and despite these challenges emergency management personnel have to ensure the success of the tasks.

We examined knowledge-based perspectives which might be useful in this study in improving task performance in general and more particularly in mitigating the impact of task complexity on performance. We expect that the study of knowledge integration is 
appropriate in emergency response organizations for task management and for improving task performance. We consider the three fundamental concepts in this work as task complexity, integration of specific knowledge, and task performance and the relationships between these concepts will be explored. In the following table we summarize the knowledge integration related constructs and our interpretations in this study.

\begin{tabular}{|c|l|l|}
\hline 1 & Concept/ construct & \multicolumn{1}{|c|}{ Interpretations in this study } \\
\hline $\begin{array}{l}\text { Scientific or technology } \\
\text { specific knowledge }\end{array}$ & $\begin{array}{l}\text { For emergency response organizations, this represents the } \\
\text { kind of specific knowledge required to perform a task that } \\
\text { needs scientific or engineering expertise and experience in } \\
\text { special tools and techniques. } \\
\text { The engineering and technical knowledge of the power grid } \\
\text { system in FPL for supply and distribution of electricity is an } \\
\text { example of this type of specific knowledge. }\end{array}$ \\
\hline $\begin{array}{l}\text { Context specific } \\
\text { knowledge }\end{array}$ & $\begin{array}{l}\text { For emergency response organizations, this represents the } \\
\text { kind of specific knowledge required to perform a task that is } \\
\text { unique to the context and depends on the time and } \\
\text { location. } \\
\text { For example one of the tasks related to hurricane } \\
\text { preparation is the evacuation of citizens in risk-prone } \\
\text { areas. The context-specific knowledge required in this task } \\
\text { is the experience of the use of the County transit system } \\
\text { prior to a hurricane, which roads to shut down, what are } \\
\text { traffic conditions, which are the critical expressways, etc. }\end{array}$ \\
\hline $\begin{array}{l}\text { Context and } \\
\text { kechnowlogy specific }\end{array}$ & $\begin{array}{l}\text { For emergency response organizations, this represents the } \\
\text { kind of specific knowledge required to perform a task that is } \\
\text { both technology and context specific. } \\
\text { Immediately after a hurricane, the engineering expertise to } \\
\text { restore the power in a particular community with the } \\
\text { understanding that some critical facilities need to be } \\
\text { prioritized is an example of this type of specific knowledge. }\end{array}$ \\
\hline
\end{tabular}

Table 3: Knowledge integration constructs interpretations 


\section{2 "Unbundling" task complexity}

In this study three dimensions of task complexity have been identified as being relevant for tasks typically undertaken in emergency environments: component complexity (represents number and variety of resources and activities required to complete the task), interactive complexity (degree of interactions and interdependencies), and procedural rigidity (also called as extent of tight coupling -- rigidity of activities in terms of timing or sequence).

Prior literature on complex systems and organizations has identified these factors which increase complexity: number of variables in the system (Perrow, 1984), number of information sources and business elements to be coordinated (Haeckel \& Nolan, 1993), size, number of elements, and their variety (Shenhar \& Dvir, 1996). By observing the tasks in emergency operations, we propose the concept Component complexity to represent the task characteristics of number of people assigned, organizations being represented, computer systems being accessed and used, machines required, and variety of resources required to complete the task.

We observed that for a given activation at the Miami-Dade EOC, there are approximately 130 people directly involved in the efforts related to responding to a disaster incident in one operation shift. These individuals represent their organizations, government agencies, and the regional EOC's and are high enough in their respective organizational hierarchy to take decisions in crisis situations. Often times the EOC operates in two 12-hour shifts and there can be 250 to 300 people involved in the EOC activation. The sheer numbers of personnel, organizations, and the resources they depend 
on (e.g. computer systems, machine elements) can be staggering particularly when they need to assemble and work together within hours' notice of the call for activation.

The second dimension we consider is task Interactive complexity. Researchers have viewed this concept fairly consistently with slight variations depending on the context of the problem. According to Perrow (1984), interactive complexity is the number of ways in which the components of the system can interact. It depends on the number of relationships between the variables and the number of feedback loops through which the variables interact. Interactive complexity will increase with the presence of unplanned, unfamiliar and unexpected sequences of events which are either not visible or immediately comprehensible. Haeckel \& Nolan (1993) contend that complexity of the company will depend upon the number and type of relationships that exist between the different elements, and Shenhar \& Dvir (1996) point to the inter-connectedness of the elements. As explained earlier, in his conceptualization of task complexity, Wood (1996) has defined three types of task complexity: component, coordinative, and dynamic. Campbell (1998) proposes four fundamental task attributes that make a task complex: multiple paths, multiple outcomes, conflicting interdependence and uncertain linkages. We draw support for the dimension of interactive complexity based on the high degree of inter-relationships and inter-dependencies that we observed between the three functional branches at the Miami-Dade EOC and the related organizations and agencies that they coordinate. The three branches are Public Safety, Human Services, and the Infrastructure functional group. Although the physical layout of the groups is spatially separate during the activation, their mode of operations is anything but. A high degree of coordination, communication and feedback is achieved by the following mechanisms: 
ceiling-mounted display monitors that are periodically updated by each branch coordinator showing current status, E-Team computer software system, conventional email, IAP reports, telephone, break-out planning sessions, and periodic status update broadcasts. Perhaps the most telling episode of the degree of inter-connectedness in these operations was demonstrated when one of the branch managers answered a phone call, briskly walked over to the station of an individual in another branch and directly made an urgent resource request. He explained later that based on the nature of the critical urgency, there simply was no time to follow the procedures and communication protocol that would normally be adhered to for similar resource requests.

The term Procedural rigidity is also referred to as tight coupling in other studies (Sanchez \& Mahoney 1996, Orton and Weick 1990, Perrow 1984). A tightly coupled system is one that is highly interdependent: each part of the system is tightly linked to many other parts and therefore a change in one part can rapidly affect the status of other parts. Tightly coupled systems respond quickly to perturbations, but this response may be disastrous. Loosely coupled or decoupled systems have fewer or less tight links between parts and therefore are able to absorb failures or unplanned behavior without destabilization. From an organizational perspective, tightly coupled systems are portrayed as having responsive components that do not act independently, whereas loosely coupled systems ${ }^{4}$ are portrayed as having independent components that do not act responsively (Orton \& Weick, 1990). Two important organizational outcomes of loose

\footnotetext{
${ }^{4}$ The authors explain buffering in loosely coupled systems will prevent the spread of problems. For example in software design, modularity reduces the occurrence of ripple effects caused by bugs in one module spreading to other modules. Whereas this is how the impact of change is neutralized, adaptability on the other hand, will allow the system to assimilate and accommodate the change.
} 
coupling in emergency management are buffering and adaptability. Sanchez and Mahoney (Sanchez \& Mahoney, 1996) use the principles of nearly decomposable systems to facilitate loose coupling of organizational structures, which increase the adaptive coordination. The chances of failure will increase with higher degrees of procedural rigidity which might make the processes less adaptive.

The dimension of procedural rigidity needs special consideration in the emergency management environment. Some tasks must adhere to extremely strict time constraints failing which can lead to fatal consequences. For example evacuation orders are given for a particular community based on possible risk related to flooding during a hurricane. Once the order is issued the evacuation needs to be conducted in an orderly fashion so that all the residents can reach the designated shelters safely. A delay in this activity can expose the evacuees to dangerous circumstances since the rain, wind and in general the weather conditions will continue to deteriorate. In addition there can be important economic and political consequences related to such tasks as explained to us by one of the emergency managers. The raising of expressway tolls is a critical decision to ease the flow of traffic for evacuation procedures. However, if executed hastily or prematurely, it can quickly result in potential loss of revenue sometimes to the tune of millions of dollars.

We observe that these dimensions might have conflicting demands: for example, to reduce procedural rigidity (or tight coupling) and increase redundancy, we may need to add more parts and interconnect them; but this might increase the component complexity since we are increasing the number of personnel and resources associated with them. At the same time this might also increase the interactive complexity since the number of 
ways in which these parts might interact and provide feedback to each other is increased. Conversely to reduce the component and interactive complexity, we may choose to reduce the number of personnel and resources, but this may result in fewer redundancies and backup personnel which might increase the procedural rigidity.

In summary, for emergency response organizations, a task with a high degree of complexity is one which possesses one or more of the following characteristics: component complexity (has many parts such as personnel, machines, computer systems); interactive complexity (components can interact in many different ways); procedural rigidity (processes are rigid or tightly coupled). We illustrate below how these dimensions are particularly applicable for the study and analysis of emergency tasks.

As an example, consider a typical emergency task undertaken during preparations for a hurricane: evacuating people with special medical needs before a hurricane. This operation involves many personnel from varied organizational units in the EOC (transport, medical facilities, electric utility, etc.) and the technology systems they rely on. Before the operation begins, the people who require the evacuation need to be identified and put on the "call down" list so they can be informed ahead of time about the evacuation plans. The receiving facilities have to be prepared with the necessary equipment and medical professionals and backup provisions in case of loss of power. Transport vehicles have to arranged, some of which might need specialized equipment, along with available drivers who need to be knowledgeable of the evacuation routes. These personnel and the organizations they represent need to interact with each other in unfamiliar circumstances with a high degree of uncertainty since many of the activities 
might vary with the changing weather conditions. Hence, such a task conceptually is representative of a high degree of component complexity and interactive complexity.

We also note that in this task, the different units are very tightly dependent on each other. In addition the task has to be completed successfully within strict time deadlines; otherwise it might result in severe damage to life and/or property. Any change in a particular event (such as the flooding of a roadway or an evacuation route made inaccessible due to debris) will immediately impact several other activities forcing the responsible personnel to adapt quickly, make alterations to the plan, and continue working the task. Hence this task is conceptually representative of a high degree of procedural rigidity.

In the following table we summarize the task complexity constructs and the interpretations of these constructs in this study: 


\begin{tabular}{|l|l|}
\hline \multicolumn{1}{|c|}{$\begin{array}{c}\text { Concept/ } \\
\text { construct }\end{array}$} & \multicolumn{1}{c|}{ Interpretations in this study } \\
\hline $\begin{array}{l}\text { Task component } \\
\text { complexity }\end{array}$ & $\begin{array}{l}\text { For emergency response organizations, a task with a high degree of } \\
\text { component complexity is one which has many parts: personnel, } \\
\text { teams, organizations, computer systems, machines, and any other } \\
\text { resources required to accomplish the task. }\end{array}$ \\
\hline $\begin{array}{l}\text { Task interactive } \\
\text { complexity }\end{array}$ & $\begin{array}{l}\text { For emergency response organizations, a task with a high degree of } \\
\text { interactive complexity is one which the personnel and activities can } \\
\text { interact in many different ways. }\end{array}$ \\
\hline $\begin{array}{l}\text { Procedural rigidity } \\
\text { OR } \\
\text { Coupling (tight or } \\
\text { loose) }\end{array}$ & $\begin{array}{l}\text { Forample a task for evacuating people with special medical } \\
\text { needs before a hurricane involves many organizational units in the } \\
\text { EOC (transport, medical facilities, electric utility etc.) and the } \\
\text { technology systems they rely on. In addition they need to interact } \\
\text { with each other in unfamiliar circumstances and a high degree of } \\
\text { uncertainty. } \\
\text { whether the processes are closely dependent on each other in terms } \\
\text { of time and sequence. A task in which the activities have to be } \\
\text { executed in a rigid sequence and adhere to strict timelines will have } \\
\text { a high degree of procedural rigidity. } \\
\text { For example, a task for evacuating people with special medical } \\
\text { needs before a hurricane involves many organizational units in the } \\
\text { EOC (transport, medical facilities, electric utility etc.) and the } \\
\text { technology systems they rely on. In this task, the different units are } \\
\text { very tightly dependent on each other. In addition the task has to be } \\
\text { completed within strict time deadlines; otherwise it might result in } \\
\text { severe damage to life and/or property. }\end{array}$ \\
\hline
\end{tabular}

Table 4: Task complexity constructs interpretations 


\subsection{Task performance}

As discussed in the literature review section (Section 2.3) we propose two dimensions to evaluate the performance of emergency management tasks: task effectiveness and task efficiency. These relate generally to the main criteria that are important success factors in emergency organization centers that we observed and how they have been communicated in support documents that we describe below.

Standard Operating Procedures (SOP) ${ }^{5}$ documents are published and distributed on a yearly basis by the Miami-Dade EOC. The documents are categorized based on the area of responsibility such as Public Works and Engineering (ESF \#3), Energy (ESF \#12), Communication (ESF \#2), and so on. These documents contain the definition of the area of responsibility, objectives of the operations, processes, roles and responsibilities, procedures, direction and control, planning and information, response, and proposed checklists. Particularly they outline the tasks that they are responsible for, the planned response activities, and an overall plan for accomplishing the tasks.

At a general level, the successful completion of these tasks would be a fair assessment of task performance. However, depending on the nature of the disaster event and how it develops, the teams need to change and adapt their responses to be effective in volatile circumstances. For example some of the objectives for Public Works and Engineering ESF \#3 (p. 3) are: "The emergency repair of potable water utilities, sanitary

\footnotetext{
5 "The SOP is intended to provide an instructional manual for those involved in the preparedness, response, and recovery phase of an incident or disaster. (It is) a basic foundation from which sound decisions can be made. The SOP is a living document, requiring constant review and update. Revisions to the base document will be made as necessary. However, a formal, for distribution, comprehensive revision will be made on an annual basis to be included... no later than October $30^{\text {th }}$ each year". Public Works and Engineering ESF \#3
} 
sewer, storm water collection facilities, generators and electrical distribution systems;

perform the initial damage assessment survey and prioritize preliminary repair to the infrastructure; perform a preliminary vulnerability survey and assessment of damage to hazardous waste storage, generation, distribution, and disposal sites". Further, the guidelines provided are (Public Works and Engineering ESF \#3, p. 3): "Prioritization of ESF-3 resource requests will be based upon the primary objective of protecting the life, health, and welfare of the community. During the emergency response period it may be necessary for ESF-3 to rely on local resources and agencies to act individually, based upon their individual disaster action plans".

This goes to show that a certain amount of flexibility is built into the objectives and proposed guidelines for the plans and procedures of the emergency tasks. Hence in the emergency environment, in addition to purely objective measures, it is important to incorporate perceptual elements of satisfaction of all participants and how the incident requirements were met for a given task. As mentioned in the literature review (Section 2.3), we also draw from success criteria in project management (Freeman \& Beale 1992) and how the evaluation will also depend upon the "rater" of the task based on different viewpoints (Belout 1998). Based on these analyses and observations, we describe below the two dimensions we propose to assess emergency task performance.

Task effectiveness refers to the extent to which the emergency incident requirements were met. It represents the extent to which the task outcome was satisfactory to all the participants and stakeholders. Equally important is how well the task was executed without disrupting other tasks and how well the team managed and resolved any possible conflicts. For example, consider a task for delivering a backup 
generator to a medical facility within one hour for emergency medical care. The effectiveness will depend on: whether the right equipment was delivered to the right facility and whether the equipment had the correct specifications as requested. In the event that if the task depends on special personnel and equipment (such as transportation), the effectiveness will be evaluated based on how well the team managed the task in terms of potential conflicts and usage of scarce resources.

Task efficiency refers to the extent to which the task was completed in the required time frame and within the allocated budget, personnel, and resources. For example, consider once again the task for delivering a backup generator to a medical facility within one hour for emergency medical care. The efficiency will depend on whether the task was completed on time using the available personnel and resources. Perhaps in such a situation the timing consideration would be critical and in adverse conditions, the team would make a paramount effort to comply with this request within the allotted time requirements, even if it meant tapping into personnel and/or resources which were not originally included in the plan for this task.

In the following table we summarize the task performance constructs and the interpretations of these constructs in this study: 


\begin{tabular}{|l|l|}
\hline \multicolumn{1}{|c|}{$\begin{array}{c}\text { Concept/ } \\
\text { construct }\end{array}$} & \multicolumn{1}{c|}{ Interpretations in this study } \\
\hline Task efficiency & $\begin{array}{l}\text { Refers to the extent to which the task was completed in the required } \\
\text { time frame and within the allocated budget and resources. } \\
\text { For example, a task for delivering a backup generator to a medical } \\
\text { facility within one hour for emergency medical care. The efficiency will } \\
\text { depend on whether the task was completed on time using the available } \\
\text { resources. }\end{array}$ \\
\hline $\begin{array}{l}\text { Task } \\
\text { effectiveness }\end{array}$ & $\begin{array}{l}\text { Refers to the extent to which the emergency incident requirements } \\
\text { were met. It represents the extent to which the task outcome was } \\
\text { satisfactory to the participants. } \\
\text { For example, a task for delivering a backup generator to a medical } \\
\text { facility within one hour for emergency medical care. The effectiveness } \\
\text { will depend on: whether the equipment was delivered to the right } \\
\text { facility, whether the equipment had the correct specifications as } \\
\text { requested, and how well the task was executed without disrupting } \\
\text { other tasks. }\end{array}$ \\
\hline
\end{tabular}

Table 5: Task performance constructs interpretations 
The following table summarizes the main concepts in this study and the definitions of the terms as conceptualized based on the literature review and our observations:

\begin{tabular}{|l|l|}
\hline \multicolumn{1}{|c|}{ Concept } & \multicolumn{1}{c|}{ Definition } \\
\hline $\begin{array}{l}\text { Context specific } \\
\text { knowledge }\end{array}$ & $\begin{array}{l}\text { Type of specific knowledge that is characterized as idiosyncratic } \\
\text { knowledge, } \\
\text { knowledge of context, localized knowledge, or knowledge of particular } \\
\text { circumstances of time and place }\end{array}$ \\
\hline $\begin{array}{l}\text { Technology } \\
\text { specific } \\
\text { knowledge }\end{array}$ & $\begin{array}{l}\text { Type of specific knowledge characterized as of the particular scientific } \\
\text { or theoretical discipline. It comprises of rules of cause and effect and } \\
\text { the tools and techniques used to address problems in that area. }\end{array}$ \\
\hline $\begin{array}{l}\text { Context and } \\
\text { technology } \\
\text { specific } \\
\text { knowledge }\end{array}$ & $\begin{array}{l}\text { Type of specific knowledge that is characterized by both contextual } \\
\text { and technological specificity }\end{array}$ \\
\hline $\begin{array}{l}\text { Task component } \\
\text { complexity }\end{array}$ & $\begin{array}{l}\text { Represents number and variety of resources and activities required to } \\
\text { complete the task }\end{array}$ \\
\hline $\begin{array}{l}\text { Task interactive } \\
\text { complexity }\end{array}$ & $\begin{array}{l}\text { Represents the number of ways in which components of the task can } \\
\text { interact, have inter-dependencies, and feedback loops. It also } \\
\text { represents uncertain links between the paths and the outcome. }\end{array}$ \\
\hline $\begin{array}{l}\text { Task procedural } \\
\text { rigidity }\end{array}$ & $\begin{array}{l}\text { Represents rigidity of processes with respect to time and sequence } \\
\text { and the degree of impact of change. It also represents lack of } \\
\text { redundancies, backups, and process flexibility. }\end{array}$ \\
\hline $\begin{array}{l}\text { Task efficiency } \\
\text { satisfied, and other tasks were not impacted }\end{array}$ \\
\hline $\begin{array}{l}\text { Extent to which task was completed in the required time, within the } \\
\text { allocated budget and resources }\end{array}$ \\
\hline
\end{tabular}

Table 6: Concepts and definitions 


\subsection{Research model}

In the prior sections we discussed the research problems and reviewed the literature related to the topics of interest on past theoretical and empirical findings. Using the conceptual development as a basis for this study, we present a research model and a preliminary set of hypotheses to formulate the relationships between the concepts that were introduced and explained. The hypotheses at this point, also represent our observations of the workings of the Miami-Dade Emergency Operations Center. They build upon prior research in domains that we touched upon in the literature review sections, and extend them to task complexity and knowledge integration strategies in the emergency organization. Further pruning of the space of the hypotheses may be required as the study progresses.

One of the focal constructs to analyze work in emergency organizations is task complexity which consists of three dimensions: component complexity, interactive complexity, and procedural rigidity. Task performance or outcome is comprised of two dimensions: effectiveness and efficiency. Hypotheses (1a) through (1c) are concerned about the relationships between the dimensions of task complexity and task effectiveness. Hypotheses (2a) through (2c) explain the relationships between task complexity and task efficiency. We propose that strategies of integration of the three types of specific knowledge will improve emergency task performance. The construct for integration of specific knowledge has three dimensions: one each for integration of context-specific, technology-specific, and context-and-technology specific knowledge. Hypotheses (3a) through (3c) describe the relationships between knowledge integration and task effectiveness and hypotheses (4a) through (4c) describe the relationships between 
knowledge integration and task efficiency. At this stage of the research we intend to explore the possible relationship between dimensions of task complexity and integration of three types of specific knowledge.

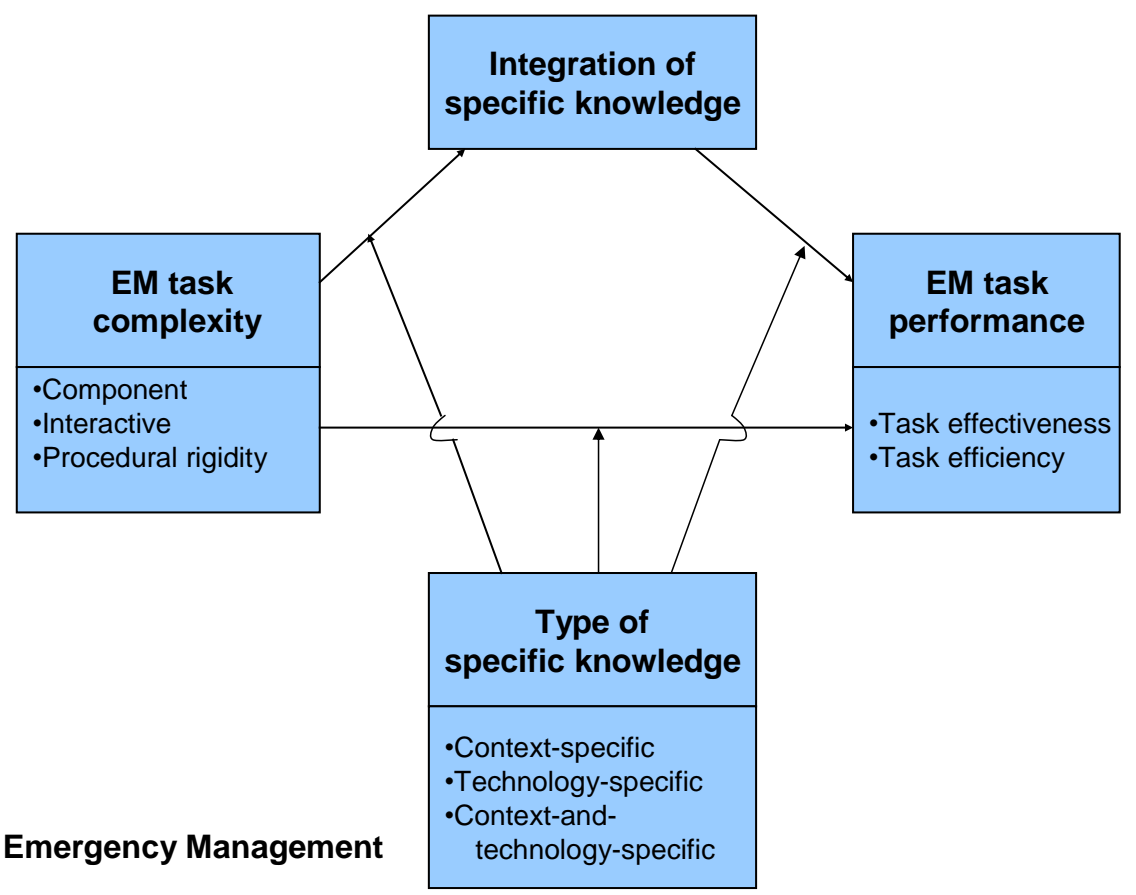

Figure 1: Research model

\subsection{Research hypotheses}

We have argued that emergency tasks with inherent attributes which increase the complexity will be more difficult to control and manage. Higher degrees of component complexity imply there are greater numbers of personnel, organizations, computer systems and other resources involved. An increased level of interactive complexity would imply a greater need for interactions amongst the activities, some of which might be unforeseen and unpredictable. In addition if the task also has higher procedural 
rigidity, the emergency team would be under increased pressure to deliver and mistakes and failures are more likely to occur. If these factors are not properly managed, they will reduce the extent to which the task requirements are met and overall the participants will not be completely satisfied with the task outcome. Hence we propose:

H1a) Component complexity of tasks is negatively associated with task effectiveness H1b) Interactive complexity of tasks is negatively associated with task effectiveness H1c) Procedural rigidity of tasks is negatively associated with task effectiveness Most tasks in emergency situations need to be completed successfully within stipulated time constraints and sometimes using the available resources. Resources which include equipment, personnel, and machines cannot be easily and quickly transported without adequate planning and preparation. Complex tasks with higher degrees of component, interactive and/ or procedural rigidity will impose greater demands on the emergency team and will reduce the extent to which the task might be successfully completed within the requirements of time and budget. Hence we propose: H2a) Component complexity of tasks is negatively associated with task efficiency H2b) Interactive complexity of tasks is negatively associated with task efficiency H2c) Procedural rigidity of tasks is negatively associated with task efficiency An important ingredient of the response activities during or after an emergency event involves dynamic decision-making (Samii, Van Hassenhove, Kumar, \& BecerraFernandez, 2002b). Situations in complex task environments are beyond the capacity of any one individual's prior experience and problem solving abilities (Comfort, Dunn, Johnson, Skertich, \& Zagorecki, 2004). Integration of specific knowledge becomes crucial for quickly and adequately sharing knowledge and completing the task 
successfully. This serves as the basis for creating organizational flexibility required for reliable performance in such circumstances (Bigley \& Roberts, 2001). Hence we propose:

H3a) Integration of context-specific knowledge is positively associated with task effectiveness

$\mathrm{H} 3 \mathrm{~b}$ ) Integration of technology-specific knowledge is positively associated with task effectiveness

H3c) Integration of context-and-technology-specific knowledge is positively associated with task effectiveness

Coordination between diverse personnel and organizations is difficult to achieve in emergency environments (Comfort et al., 2004). Members need to know which individual or organization possesses the skill or expertise that is required for the task on hand and strategies that support the exchange of critical information need to be implemented. A strategy that enhances the integration of a type of specific knowledge will improve coordination thereby making the emergency organization more responsive and adaptive (Coakes, Willis, \& Clarke, 2002) Hence we propose:

H4a) Integration of context-specific knowledge is positively associated with task efficiency

H4b) Integration of technology-specific knowledge is positively associated with task efficiency

H4c) Integration of context-and-technology-specific knowledge is positively associated with task efficiency 
The above hypotheses represent our expectations about the impact of task complexity on the task outcome and also how the integration of specific knowledge might influence the task outcome. At this stage of the research we intend to explore the possible relationship between dimensions of task complexity and integration of three types of specific knowledge.

\subsubsection{Research hypotheses for moderating effects}

We adopt the working definition of moderation as explained by Baron and Kenny (1986): A moderator is a "variable that affects the direction and/or strength of the relation between an independent or predictor variable and a dependent or criterion variable" (p.1174). This implies that a variable can be considered to be a moderator if the relationship between the independent and dependent variable depends on the level of the moderator variable (Saks, 1995). In this study we expect that the relationship between task complexity and emergency task performance depends on the level of each type of specific knowledge we have considered, namely context-specific, technology-specific, and context-and-technology-specific.

To conceptualize the understanding of the term "level of specific knowledge", we draw from prior research which theorizes general knowledge as being low in specificity (Sabherwal \& Becerra-Fernandez, 2005). Thus if the area of knowledge required to complete an emergency task was not context-specific or technology-specific, it would be categorized as general knowledge. Our expectation is that the nature of the relationships between task complexity, knowledge integration, and task performance will be different 
depending on the extent to which the area of knowledge is general (low-specificity) or context-specific or technology-specific.

Hence we propose the following models and the related hypotheses for the moderating effects of each type of specific knowledge:

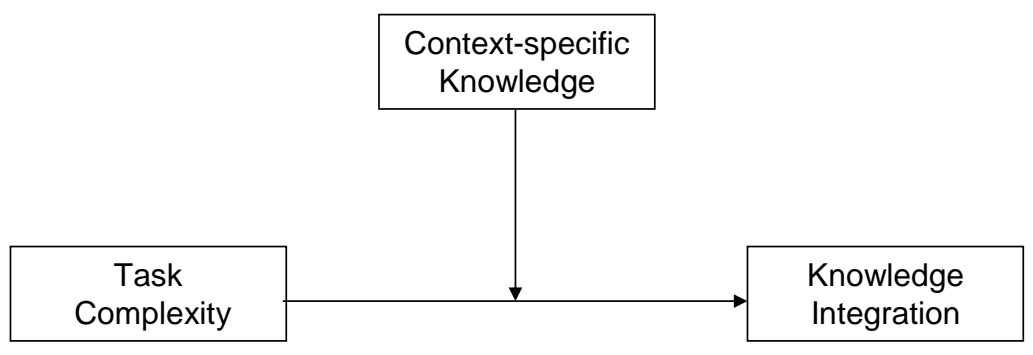

Figure 2: Moderation of context-specific knowledge on knowledge integration

H5a) The level of context-specific knowledge will moderate the relationship between task component complexity and knowledge integration

H5b) The level of context-specific knowledge will moderate the relationship between task interactive complexity and knowledge integration

H5c) The level of context-specific knowledge will moderate the relationship between task procedural rigidity and knowledge integration 


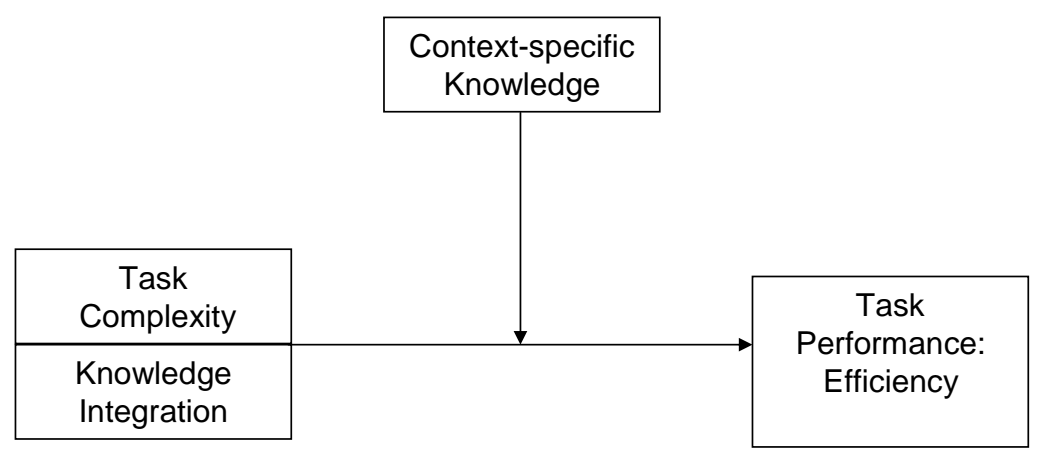

Figure 3: Moderation of context-specific knowledge on task efficiency

In Figure 3, we present the moderating effects of context-specific knowledge. First, we examine the moderating effects of context-specific knowledge with task complexity dimensions (component, interactive, and procedural rigidity) along with knowledge integration as independent variables. Task efficiency is the dependent variable. Thus, we propose the following:

H6a) The level of context-specific knowledge will moderate the relationship between task component complexity, knowledge integration, and task efficiency

H6b) The level of context-specific knowledge will moderate the relationship between task interactive complexity, knowledge integration, and task efficiency

H6c) The level of context-specific knowledge will moderate the relationship between task procedural rigidity, knowledge integration, and task efficiency 


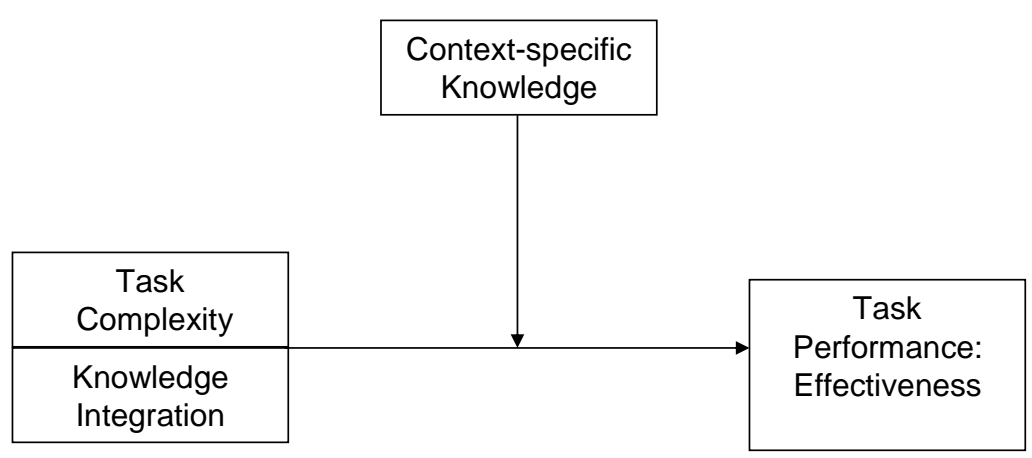

Figure 4: Moderation of context-specific knowledge on task effectiveness

In Figure 4, we present the moderating effects of context-specific knowledge. We examine the moderating effects of context-specific knowledge with task complexity dimensions (component, interactive, and procedural rigidity) along with knowledge integration as the independent variables. Task effectiveness is the dependent variable. Thus, we propose the following:

H7a) The level of context-specific knowledge will moderate the relationship between task component complexity, knowledge integration, and task effectiveness H7b) The level of context-specific knowledge will moderate the relationship between task interactive complexity, knowledge integration, and task effectiveness H7c) The level of context-specific knowledge will moderate the relationship between task procedural rigidity, knowledge integration, and task effectiveness 


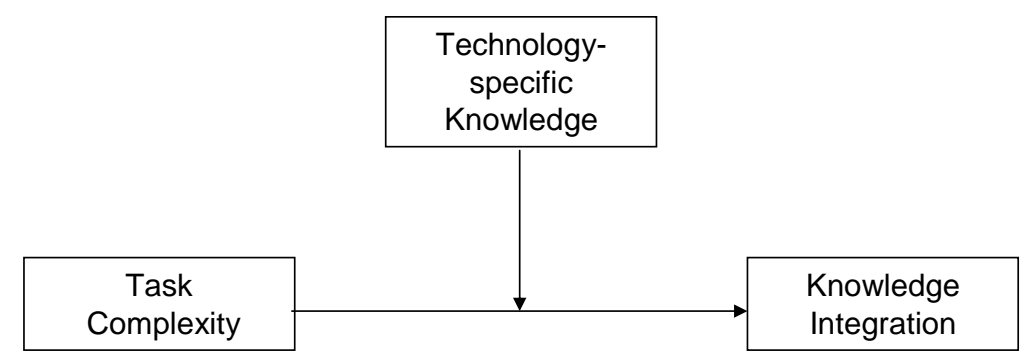

Figure 5: Moderation of technology-specific knowledge on knowledge integration

In Figure 5, we present the moderating effects of technology-specific knowledge. We examine the moderating effects of technology-specific knowledge with task complexity dimensions (component, interactive, and procedural rigidity) as the independent variables. Knowledge integration is the dependent variable. Thus, we propose the following:

H8a) The level of technology-specific knowledge will moderate the relationship between task component complexity and knowledge integration

H8b) The level of technology-specific knowledge will moderate the relationship between task interactive complexity and knowledge integration

H8c) The level of technology-specific knowledge will moderate the relationship between task procedural rigidity and knowledge integration 


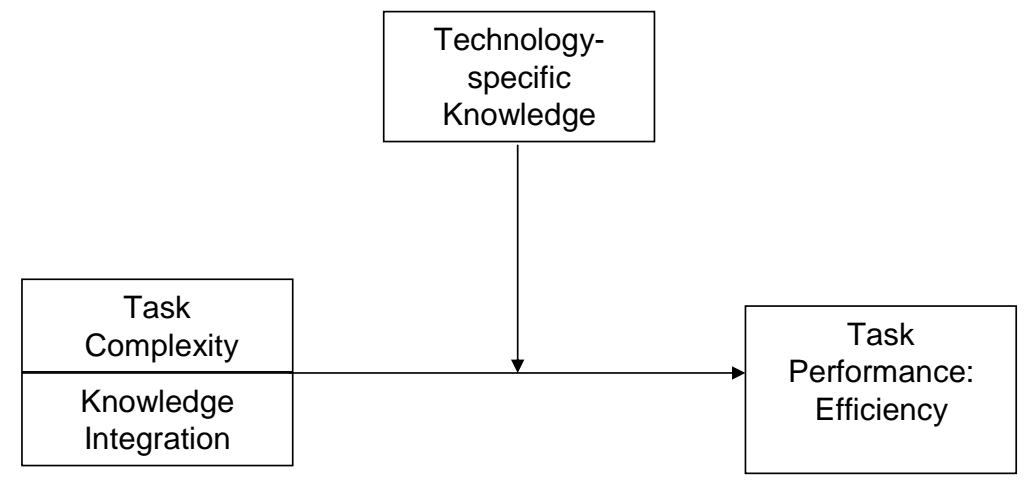

Figure 6: Moderation of technology-specific knowledge on task efficiency

In Figure 6, we present the moderating effects of technology-specific knowledge. We examine the moderating effects of technology-specific knowledge with task complexity dimensions (component, interactive, and procedural rigidity) along with knowledge integration as the independent variables. Task efficiency is the dependent variable. Thus, we propose the following:

H9a) The level of technology-specific knowledge will moderate the relationship between task component complexity, knowledge integration, and task efficiency

H9b) The level of technology-specific knowledge will moderate the relationship between task interactive complexity, knowledge integration, and task efficiency

H9c) The level of technology-specific knowledge will moderate the relationship between task procedural rigidity, knowledge integration, and task efficiency 


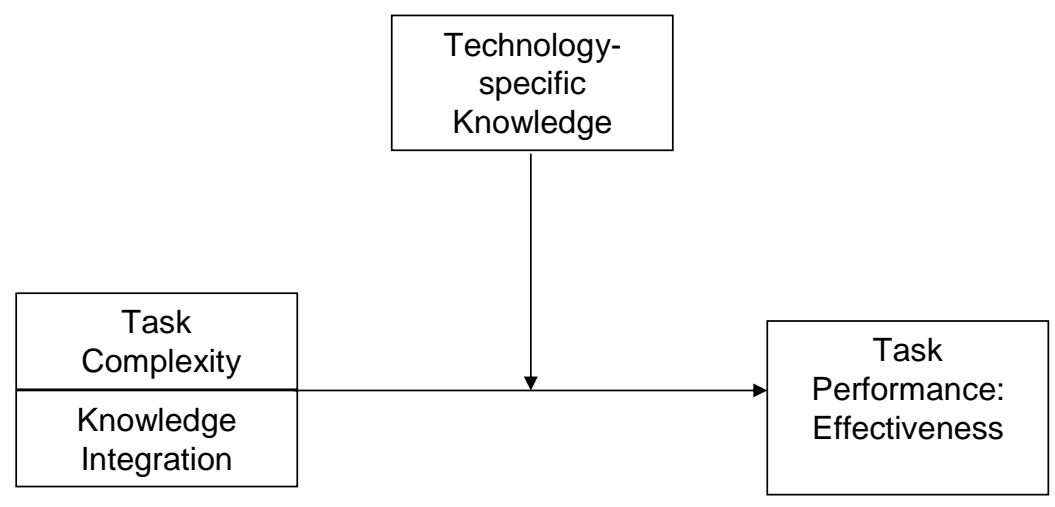

Figure 7: Moderation of technology-specific knowledge on task effectiveness

In Figure 7, we present the moderating effects of technology-specific knowledge. We examine the moderating effects of technology-specific knowledge with task complexity dimensions (component, interactive, and procedural rigidity) along with knowledge integration as the independent variables. Task effectiveness is the dependent variable. Thus, we propose the following:

H10a) The level of technology-specific knowledge will moderate the relationship between task component complexity, knowledge integration, and task effectiveness H10b) The level of technology-specific knowledge will moderate the relationship between task interactive complexity, knowledge integration, and task effectiveness H10c) The level of technology-specific knowledge will moderate the relationship between task procedural rigidity, knowledge integration, and task effectiveness 
(In the following figures and descriptions, the term "Context-and-technology-specific knowledge" has been abbreviated to "C-and-T-specific knowledge").

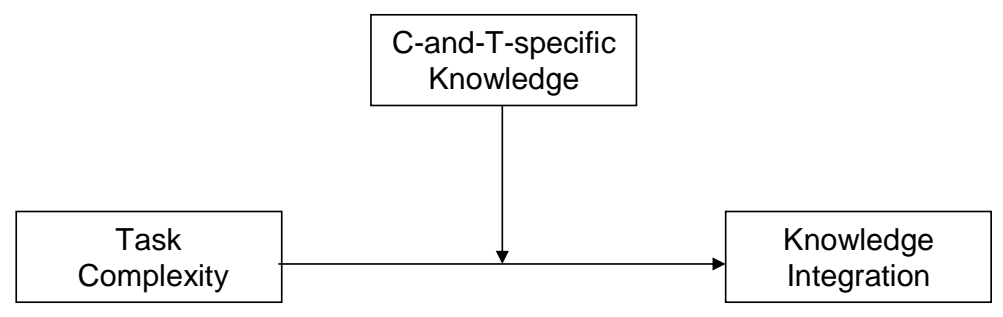

Figure 8: Moderation of context-and-technology-specific knowledge on knowledge integration

In Figure 8, we present the moderating effects of C-and-T-specific knowledge. We examine the moderating effects of $\mathrm{C}$-and-T-specific knowledge with task complexity dimensions (component, interactive, and procedural rigidity) as the independent variables. Knowledge integration is the dependent variable. Thus, we propose the following:

H11a) The level of C-and-T-specific knowledge will moderate the relationship between task component complexity and knowledge integration

H11b) The level of C-and-T-specific knowledge will moderate the relationship between task interactive complexity and knowledge integration

H11c) The level of C-and-T-specific knowledge will moderate the relationship between task procedural rigidity and knowledge integration 


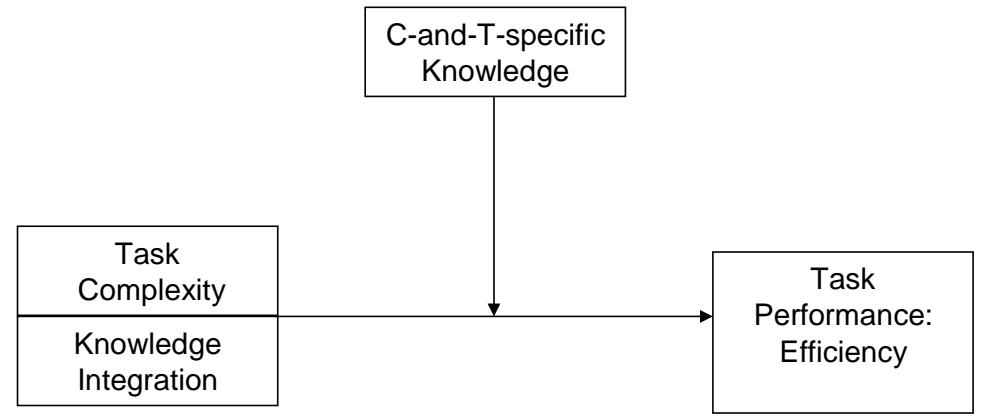

Figure 9: Moderation of context-and-technology-specific knowledge on efficiency

In Figure 9, we present the moderating effects of C-and-T-specific knowledge.

We examine the moderating effects of $\mathrm{C}$-and-T-specific knowledge with task complexity dimensions (component, interactive, and procedural rigidity) along with knowledge integration as the independent variables. Task efficiency is the dependent variable.

Thus, we propose the following:

H12a) The level of C-and-T-specific knowledge will moderate the relationship between task component complexity, knowledge integration, and task efficiency

H12b) The level of C-and-T-specific knowledge will moderate the relationship between task interactive complexity, knowledge integration, and task efficiency

H12c) The level of C-and-T-specific knowledge will moderate the relationship between task procedural rigidity, knowledge integration, and task efficiency 


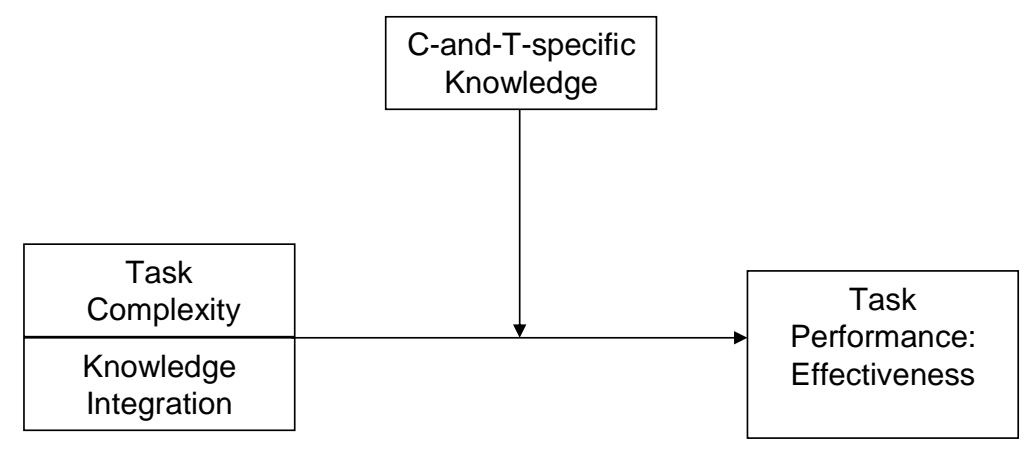

Figure 10: Moderation of context-and-technology-specific knowledge on task effectiveness

H13a) The level of C-and-T-specific knowledge will moderate the relationship between task component complexity, knowledge integration, and task effectiveness

$\mathrm{H} 130 \mathrm{~b})$ The level of C-and-T-specific knowledge will moderate the relationship between task interactive complexity, knowledge integration, and task effectiveness

H13c) The level of C-and-T-specific knowledge will moderate the relationship between task procedural rigidity, knowledge integration, and task effectiveness

\subsubsection{Research hypotheses for mediating effects}

Our initial proposition of mediation was derived by the notion that knowledge integration may be an important process construct for understanding the true nature of the relationship between task complexity and task performance. We adopt the working definition of mediation as explained by Baron and Kenny (1986): "In general, a given 
variable may be said to function as a mediator to the extent that it accounts for the relation between the predictor and the criterion" (p. 1176). The mediating variable explains how or why the predictor (independent variable) affects the criterion (dependent variable) (Saks, 1995). In this study, one set of hypotheses deal with the impact of task complexity dimensions on the outcome, task performance variables. The mediating hypotheses help us understand how this relationship occurs by treating knowledge integration as the mediating or intervening variable.

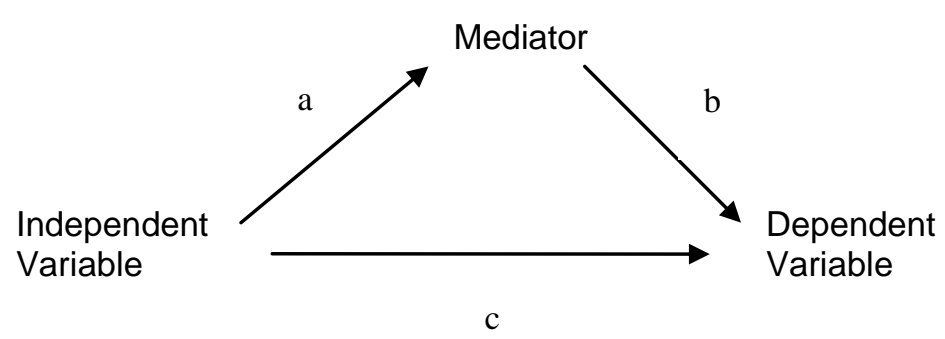

Figure 11: Mediation causal chain model

(Adapted from Baron and Kenny, p. 1176)

The above path diagram is introduced to depict the causal chain model and for clarifying the meaning of mediation in the research study (Baron \& Kenny, 1986). This represents the basic causal chain which includes the mediating variable. There are three variables in the system: independent variable (the three dimensions of task complexity -component, interactive, and procedural rigidity), dependent variable (two dimensions of task performance -- efficiency and effectiveness), and mediating variable (integration of specific knowledge). There are two paths which feed into the outcome or dependent variable: the direct impact of the independent variable (path c) and the impact of the 
mediating variable (path b). In addition, there is also the path from the independent variable to the mediator which we consider.

The overall hypothesis can be stated as: Integration of specific knowledge mediates the relationship between task complexity and task performance. We propose the following:

H14a) Integration of specific knowledge mediates the relationship between task component complexity and efficiency.

H14b) Integration of specific knowledge mediates the relationship between task interactive complexity and efficiency.

H14c) Integration of specific knowledge mediates the relationship between task procedural rigidity and efficiency.

H15a) Integration of specific knowledge mediates the relationship between task component complexity and effectiveness.

H15b) Integration of specific knowledge mediates the relationship between task interactive complexity and effectiveness.

H15c) Integration of specific knowledge mediates the relationship between task procedural rigidity and effectiveness. 


\section{Research Methodology}

\subsection{Research method}

The research method is planned to consist of five phases: (1) conceptual development, (2) generation and refinement of measurement items, (3) data collection, (4) data analysis and measurement validation, and (5) research model and hypothesis testing (Xia \& Lee, 2005). The research setting for this study is the Miami-Dade County Emergency Operations Center (EOC) located in Miami in the state of Florida.

The basis of the overall research model of this study is of an exploratory nature rather than confirmatory. Although many research studies exist in the discipline of knowledge management in general, there is a lack of theories in the specific areas which are of interest in this study. Hence the nature of this work is deemed exploratory since we view this work as being at the early stage of theory development.

Prior to designing the survey questionnaire, we met with EOC staff on different occasions over the past two years to gain understanding about the typical emergency tasks, computer systems and technologies, and coordination mechanisms as they pertain to this research. For example, we scheduled meetings and interviews with key management staff and emergency coordinators. We also were invited to attend several day-long simulation "drill"-- an exercise designed by the EOC for all participating organizations and agencies to simulate events based on a prior hurricane and to practice coordination and response activities required to accomplish the tasks. This was part of the preparation and planning program before the onslaught of the hurricane season in June 2007. As a team of researchers, we participated as observers at the EOC when it 
was activated for hurricane Ernesto (later downgraded to tropical storm) in late August 2006 for three days (prior, during, and after the event).

A qualitative review and analysis has been conducted based on these OEM/EOC archives: Standard Operations Procedures (SOP), Local Response Protocols, Situation Reports and Incident Action Plans (IAP) of Hurricanes Katrina, Rita, and Wilma which occurred in 2005 .

\subsection{Research site}

The research setting for this study was the Miami-Dade County Emergency Operations Center (EOC). The state of Florida is currently considered one of the most effective in disaster management. The State Emergency Response Team (SERT) has identified eighteen types of hazards that pose an emergency threat to Florida. These are: wildfires, thunderstorms, tornadoes, lightning, flood, terrorism, drought, heat waves, hurricanes, cold, animals, nuclear, hazardous materials, cyber attacks, information warfare, aircraft, and bombs. The division is organized into four bureaus: compliance planning and support, policy and planning, preparedness and response, and recovery and mitigation. Of these, the Bureau of Preparedness and Response is responsible for developing and maintaining the State's ability to effectively respond to a wide variety of threats and has two sections, namely preparedness and response. The Response Section coordinates emergency response at the state level, and provides the necessary technical assistance to county governments. The Miami-Dade County Office of Emergency Management (OEM) is the lead agency in an emergency event and the Emergency Operations Center (EOC) is the site for all of the emergency management operations. 
The EOC is organized under the guidelines of Incident Command System (ICS) with Operations, Planning, Logistics, and Finance and Administration (BecerraFernandez et al. 2007). Figure 12 depicts the floor plan organization for the operation of the EOC. Furthermore, Operations depends on a large array of organizations that are organized into three branches: the Public Safety Functional Group Branch, the Human Services Functional Group Branch, and the Infrastructure Functional Group Branch:

1. Public Safety Group Branch. The Public Safety Functional Group Branch includes, but is not limited to, the following organizations: National Park Service, Florida Fish and Wildlife Conservation Commission, US Coast Guard, the Department of Environmental Resources Management (DERM), Miami-Dade Fire Rescue Dept., Florida National Guard, Animal Services, Miami-Dade Corrections Dept., Florida Dept. of Law Enforcement, Florida Highway Patrol, and Miami-Dade Police Dept. The Public Safety Manager Branch Director coordinates the activities of the public safety functional group, with the assistance of the Public Safety Assistant.

2. Human Services Group Branch. The Human Services Functional Group Branch consists of, but is not limited to, the following organizations: Dept. of Human Services, Team Metro, Salvation Army, Greater Miami Convention and Visitors Bureau, American Red Cross, Miami-Dade County Public Schools, Miami-Dade Voluntary Organizations Active in Disaster (VOAD), Dept. of Mental Health, Miami-Dade Housing Agency, Florida Dept. of Children and Families, Miami-Dade County Health Dept., Florida Agency for Health Care Administrators (AHCA), and the Miami-Dade Fire Rescue Emergency Management Services. The Human Services Manager Branch Director coordinates the activities of the Human Services Functional 
Group Branch, with the assistance of the Human Services Assistant and the Special Needs Coordinator.

3. Infrastructure Group Branch. The Infrastructure Functional Group Branch consists of, but is not limited to, the Miami-Dade Solid Waste Dept, Miami-Dade Water and Sewer, South Florida Water Management District, Miami-Dade Transit-Regular Services, Miami-Dade Transit Evacuation, Miami-Dade Public Schools, Miami-Dade Public Works, Florida Dept. of Transportation, Miami-Dade Parks Dept., Agriculture Extension, City Gas Comcast, Miami-Dade Enterprise Technology Services Dept. (ETSD), BellSouth, and Florida Power \& Light, the airports, and the Port of Miami. The Infrastructure Manager Branch Director coordinates the activities of the Infrastructure Manager Branch with the assistance of the Infrastructure Assistant. The Operations Section Manager coordinates the activities of the three functional groups branches, with the assistance of the EOC Support Manager, the Operations Section Assistant, and the Planning Situation Assessment Assistant.

A number of additional organizations are represented in the periphery of the EOC: Florida Division of Emergency Management (DEM), neighboring county's emergency management liaisons (including Monroe County, Broward County, Florida City, Martin County, and Collier County), and the Divisional EOCs (Miami Beach, North Miami, North Miami Beach, Homestead, Coral Gables, Hialeah, and the city of Miami). In addition, representatives from Homestead Air Force Reserve Base and FEMA are also included. Many other agencies are called upon following a disaster event. 
The EOC depends on a number of state-of-the-art tools that it uses to manage emergencies: (1) Hurrevac, a software developed jointly by the National Hurricane Center, the U.S. Army Corps of Engineers and FEMA to track tropical cyclones and provide a continuous flow of information to emergency managers; (2) SLOSH II, software developed jointly by the National Hurricane Center Storm Surge Group, the U.S. Army Corps of Engineers, USGS and FEMA with input from the state of Florida and several local emergency managers including Miami-Dade County. It demonstrates probable storm surge based on size, direction and forward speed of a storm; (3) SALT (Storm Action Lead Time), software developed by Miami-Dade County OEM and ETSD to provide a check-list of pre- and post-storm activities; (4) Snapshot, software developed by Miami-Dade OEM to provide virtually instant information on damages caused by a storm or flood event; and (5) E-Team, a collaborative software for crisis management provided by NC4.

During such events, critical decisions must be made that involve crossorganizational and cross-agency coordination, and sharing of data, information and knowledge (Becerra-Fernandez \& Prietula 2006). As these events and their contexts are infrequent and varied, the nature of the decisions, where they are made, who makes them, the data and information resources required to make and monitor them, and the location of available knowledge to drive them may sometimes be unknown, unavailable, or both. At the Miami-Dade EOC decisions are thoroughly documented via after action reports that cover a period of twelve hours before, during, and after the hurricane. But even though the Miami-Dade EOC is disciplined about recording the necessary documentation to prevent loosing their corporate memory, these after action reports may 
not cover every issue that needs to be dealt with during an emergency, as frequently unique and unanticipated events arise during each emergency (Becerra-Fernandez et al. 2008). Furthermore, people may leave the organization, due to attrition or retirement, and some of the informal rules that serve as the "glue" that affords the very ability to function may be lost (Becerra-Fernandez et al. 2007).

\section{Esjis

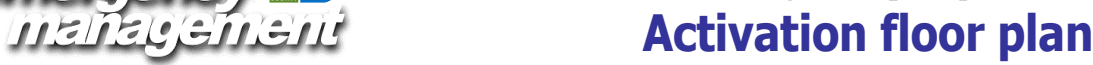
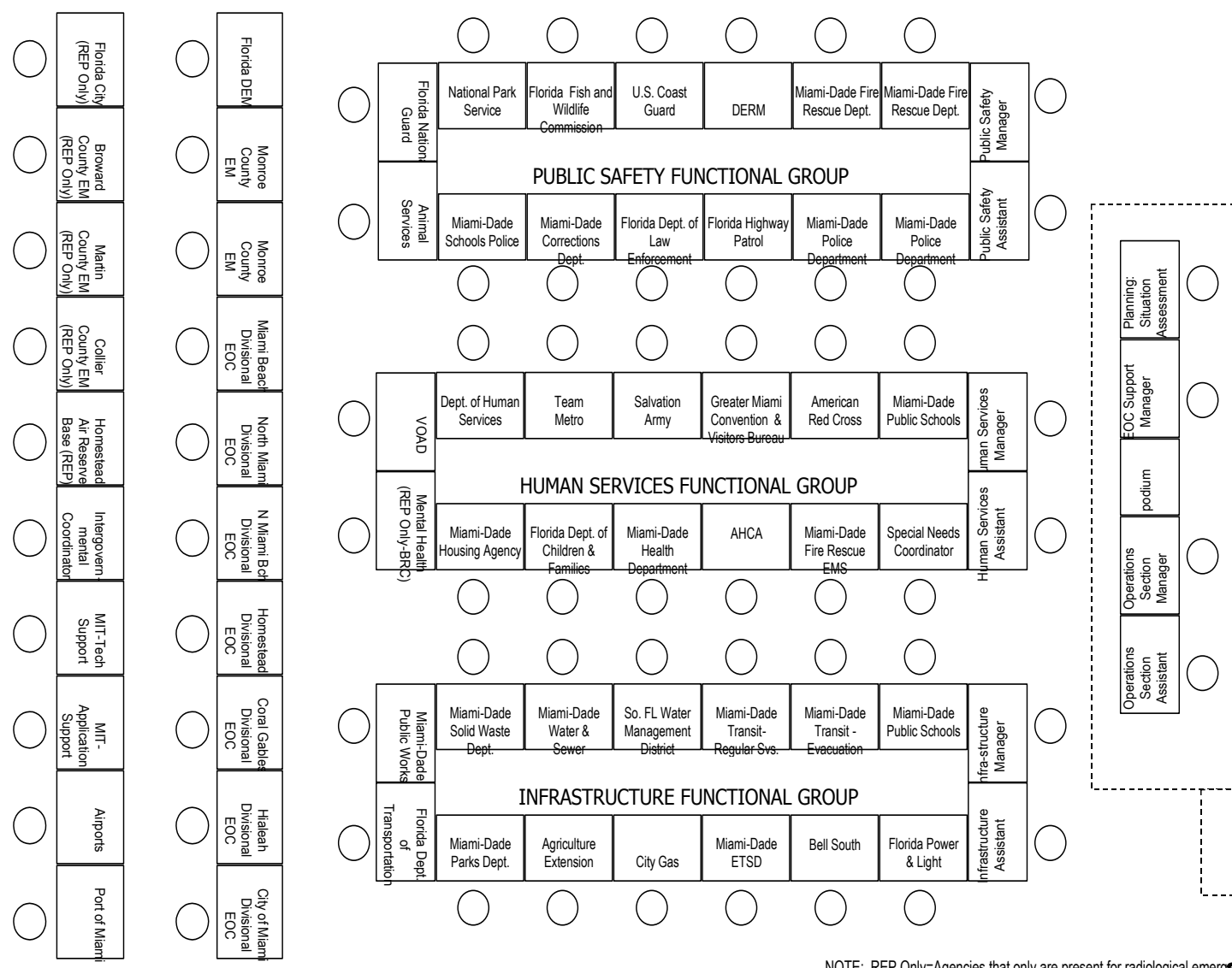

Figure 12: Emergency Operations Center activation floor plan 


\subsection{Survey questionnaire design}

The survey design consists of three main sections: section (1) asks for information about the characteristics of the emergency management task that the respondent was recently involved; section (2) is about the characteristics of a relevant knowledge area that was used to accomplish the task; and section (3) asks for background information about the respondent which will be useful for data segmentation and analysis.

In section (1), we ask the respondent to answer the questions about the task as representatives of their respective organizations. We provide guidelines for the task selection by listing some sample task descriptions related to response and recovery efforts during an incident such as a hurricane, which were explained to us by the EOC Point-ofcontact. The list is certainly not meant to be exhaustive, and the respondent can specify a task they worked on recently which is not on the list. Overall, we expect these tasks to cover a wide range with variations in the degree of complexity (relatively low to relatively high). In this section there are groups of items to assess the task characteristics: degree of component complexity, interactive complexity, and procedural rigidity. In addition there are measurement items to assess the degree of task effectiveness and efficiency. Participants responded on a 7-point Likert-type scale ranging from 1 (strongly disagree) to 7 (strongly agree) to questions such as "The different activities in the task interacted with each other in unpredictable ways during the execution of the task" as one of the measures of task interactive complexity. A high value of response for such a question $(5,6$, or 7$)$ will indicate a relatively high degree of interactive complexity for the task. They responded to questions such as "How many organizations were 
involved in the task" by filling in the appropriate number as one of the measures of task component complexity. The larger the number of organizations involved in the task, it would indicate a relatively high degree of task component complexity.

The research design and hence the questionnaire is developed around the pivotal notion that the integration of a specific area of knowledge is critical for the successful completion of the task. In the second section, we ask the respondent to identify one specific area of knowledge that they would consider critical for executing the task that they have identified in section (1). We intend to study three categories of specific knowledge: Context-specific (knowledge of particular circumstances of time and place in which work is performed), Technology-specific (knowledge of a particular scientific or theoretical field, which includes the rules, tools and techniques that may be used to solve problems in that area), and Context-and-Technology-specific knowledge (knowledge that is both context-specific and technology-specific (Sabherwal \& Becerra-Fernandez, 2005). We have provided examples of each type of specific knowledge and attempted to list the corresponding knowledge areas for the emergency tasks. The respondent can either choose one from any of these examples or describe one of their own as relevant for the task.

The questionnaire includes six items for assessing the integration of each type of knowledge (Sabherwal \& Becerra-Fernandez, 2005). There are four items each to assess whether the type of specificity is context or technology related. In addition there are items to assess the characteristics of the area of knowledge: degree of knowledge sharing, codifiability, teachability, and common knowledge. Participants responded on a 7-point Likert-type scale ranging from 1 (strongly disagree) to 7 (strongly agree) to questions 
such as "This knowledge makes use of tools and techniques specific to a particular discipline" as one of the measures of technology-specific knowledge.

In the third section, we ask for background information about the respondent. Primarily this is information about their title, work experience in their own organization (if different from the EOC), and in the field of emergency management, and educational background. They were assured that the information will be treated as confidential and no personal information will be reported. In return for their collaboration, we committed to provide each respondent an executive report of our findings at the end of the study.

\subsection{Generation and refinement of measurement items}

The initial items for the 3 dimensions of task complexity (component, interactive, and rigidity) were generated through review of the literature and field observations. These are new measures because we found no established measures for these constructs in prior studies that were especially suitable for our intended use in the field of emergency management. Measures for the constructs related to integration of specific knowledge were adapted from well-established measures which were used in prior knowledge management studies (Sabherwal \& Becerra-Fernandez 2005). Most measures for task performance in prior studies were found to be narrowly focused on the specific task being performed in the context of the study. Hence the measures for task effectiveness and task efficiency were adapted from well-established studies in prior literature on project management which were found to be suitable for this work (Freeman \& Beale 1992; Belout 1998). 
Based on the conceptual development and the related review of current literature, the initial pool of measurement items was first developed. As clarified above, whenever possible we adapted the items from prior studies in related fields of the literature. We confirmed the initial conceptual model and the measurement items through field interviews, meetings, discussions, and observations, which were modified whenever necessary.

\subsection{Sorting procedure}

The initial pool of measurement items for the 8 constructs were further refined and modified through a sorting procedure and pilot tests (Xia \& Lee, 2005). The purpose of the sorting procedure is to qualitatively assess the face validity and the construct validity of the initial measurement items (Moore \& Bebasat, 1991). Four separate sessions of the sorting procedure were conducted with four judges: one faculty member, and three Ph.D. candidates in the College of Business in the University. Each one of the judges was well advanced in their research and had several years of work experience in their respective fields.

Each measurement item was printed and pasted on 3x5 inch card. The judge was explained the research problem addressed in this study and a brief explanation of the eight constructs being used in the research model. During the sorting process, each judge was asked to carefully read the measurement item on each card and place it in one of the eight constructs. An additional category "ambiguous/ unclear" was created for the judge to use if they felt the item did not belong to any of the eight categories. 
The judge's categorization was compared with the standard groupings for each construct as was originally intended for the measurement items. On an average each judge grouped two items differently during the sorting process and they explained why their perception of the measurement item was different. This indicated an agreement level greater than a threshold of eighty percent for the complete set of measurement items. After each session, we carefully reviewed the discrepancies and accordingly made modifications to the measurement items in the questionnaire. These mostly included minor revisions regarding usage of terms or emphasis on certain phrases in order to improve clarity. The detailed instructions used for the sorting procedure, the forms used for the sorting results and two sample result sheets have been included in the appendix.

\subsection{Pilot test}

Once the Q-sorting procedure was completed, the next step was to conduct a pilot test of the instrument at the research site, the Miami-Dade County Emergency Operations Center (EOC). The purpose of the pilot test was to further validate the relevance, coverage, and clarity of the items, particularly in the context of emergency management. The test was conducted with five managers and coordinators at the EOC, who represented different areas of responsibility across the Center. First, the participants were given an overview of the research project and then they were asked to provide their feedback as they filled the questionnaire.

Several important suggestions were noted in the course of the discussions with the participants. We particularly benefited from their ideas related to the emergency task typology and the corresponding area of specific knowledge they used to work on the task. 
We revised the task typology to show a variety of sample tasks under two categories -low task complexity, and high task complexity. In the section describing the different knowledge areas, we included examples for each of the three types of specific knowledge: context, technology, and context-and-technology. We also noted their estimates as to how long it might take a participant to complete the questionnaire, given that we are aiming for an average of twenty minutes. Other than a few editorial changes, no major revisions were deemed necessary to the measuring items themselves.

The following table describes the final list of constructs and measurement items planned in this study: 
Table 7: Constructs and measurement items

\begin{tabular}{|c|c|}
\hline Construct & Measurement Items \\
\hline $\begin{array}{l}\text { Task attribute: } \\
\text { Component } \\
\text { complexity }\end{array}$ & $\begin{array}{l}\text { How many people were assigned to this task } \\
\text { How many machines were used to execute this task } \\
\text { How many computer systems were used to execute this task } \\
\text { How many organizations were involved in this task } \\
\text { The extent to which personnel involved in this task were under the jurisdiction of } \\
\text { one organization }\end{array}$ \\
\hline $\begin{array}{l}\text { Task attribute: } \\
\text { Interactive complexity }\end{array}$ & $\begin{array}{l}\text { The different activities in the task interacted with each other in unpredictable } \\
\text { ways during the execution of the task } \\
\text { Different activities in this task provided feedback to each other during the } \\
\text { execution of the task } \\
\text { There was interdependence among the various activities in the task } \\
\text { There were uncertain relationships between the activities and the task outcome } \\
\text { A change in one activity had significant impacts on other activities during } \\
\text { execution of the task }\end{array}$ \\
\hline $\begin{array}{l}\text { Task attribute: } \\
\text { Procedural rigidity }\end{array}$ & $\begin{array}{l}\text { The various activities in the task were very rigid with respect to time } \\
\text { The sequence by which the various activities were performed was very rigid } \\
\text { There were sufficient backup personnel in the executions of the task } \\
\text { There were sufficient redundancies of machines that were required for the task } \\
\text { There were sufficient slack in the time required for completing the task }\end{array}$ \\
\hline $\begin{array}{l}\text { Integration of } \\
\text { Technology-specific } \\
\text { knowledge }\end{array}$ & $\begin{array}{l}\text { This knowledge was frequently used by yourself in performing your tasks } \\
\text { This knowledge was frequently used by your organization in performing its tasks } \\
\text { This knowledge was frequently used by the EOC in performing its tasks } \\
\text { This knowledge improved your overall effectiveness } \\
\text { This knowledge improved the overall effectiveness of your organization } \\
\text { This knowledge improved the EOC's overall effectiveness }\end{array}$ \\
\hline $\begin{array}{l}\text { Integration of } \\
\text { Context-specific } \\
\text { knowledge }\end{array}$ & $\begin{array}{l}\text { This knowledge was frequently used by yourself in performing your tasks } \\
\text { This knowledge was frequently used by your organization in performing its tasks } \\
\text { This knowledge was frequently used by the EOC in performing its tasks } \\
\text { This knowledge improved your overall effectiveness } \\
\text { This knowledge improved the overall effectiveness of your organization } \\
\text { This knowledge improved the EOC's overall effectiveness }\end{array}$ \\
\hline $\begin{array}{l}\text { Integration of } \\
\text { Context-and- } \\
\text { Technology-specific } \\
\text { knowledge }\end{array}$ & $\begin{array}{l}\text { This knowledge was frequently used by yourself in performing your tasks } \\
\text { This knowledge was frequently used by your organization in performing its tasks } \\
\text { This knowledge was frequently used by the EOC in performing its tasks } \\
\text { This knowledge improved your overall effectiveness } \\
\text { This knowledge improved the overall effectiveness of your organization } \\
\text { This knowledge improved the EOC's overall effectiveness }\end{array}$ \\
\hline Task efficiency & $\begin{array}{l}\text { The task was completed within the planned time schedule } \\
\text { The task was completed within the allocated budget } \\
\text { The task was completed within the planned number of person-hours } \\
\text { The task was completed with efficient use of all available resources }\end{array}$ \\
\hline Task effectiveness & $\begin{array}{l}\text { The task was completed satisfactorily for all participants } \\
\text { All incident requirements were met when the task was completed } \\
\text { The task was completed successfully without negatively impacting other tasks } \\
\text { The task was effectively completed despite any conflicting task requirements }\end{array}$ \\
\hline
\end{tabular}




\subsection{Data collection and sampling}

The target respondents of the survey questionnaire were all the personnel who are associated with the EOC as well as employees of other organizations and government agencies that are called upon to participate in the EOC activities to respond to a disaster event (such as a hurricane or wildfire). These respondents are experienced professionals in their own organizations (such as FPL, BellSouth, etc.), who would typically have participated in one or more emergency incidents at the EOC, and are familiar with how to coordinate and manage some of the emergency tasks. They include the members of the organizations who participate in the three branches mentioned in Section 4.6 (Human Services group branch, Public Safety group branch, and Infrastructure group branch) and those which are in the periphery of the EOC. Hence we deem this data collection approach as a non-probability type of sampling method ${ }^{6}$.

The original list of numbers of potential participants that we obtained from the EOC was as follows: Human Services group branch $=266$, Public Safety group branch $=$ 125 , Infrastructure group branch $=75, \mathrm{EOC}$ staff $=19$, other contacts $=12$ giving a total of 497. The contact information consisted of the individual's name, company name, department, title, contact phone number(s), and email address. We found that some of the personnel had retired, moved, were no longer associated with the EOC activation procedures, or had old email addresses or contact phone numbers and in such cases we were not able to reach them. The number of potential participants we were finally able to establish contact with was 311. The final number of responses we received was 120

\footnotetext{
${ }^{6}$ As per our original expectations, the number of potential participants of the study was between 400 and 500 -- which would be a non-probability type of sampling.
} 
which gives an effective response rate of about 39\%. Of these, 84 responses were filled through the online web-based version and the remainder were obtained from other sources such as mail-in of the paper version, faxes, etc.

One of the challenges in this research has been the limited number of potential respondents to our survey since they have to be personnel involved in disaster operations and who have had prior experience in emergency management tasks. Also past research in emergency management with a knowledge management perspective has been sparse and we have not been able to find prior procedures of evidence acquisition which can be reused. Hence the data acquisition activity needed to be very timely and focused and we planned three varied and flexible approaches.

We developed a web-based online version of the questionnaire using SurveyMonkey, an online survey software tool, which provided us a professional, userfriendly design and a secure URL link for the participants to access the questionnaire. We initially contacted them via a personalized email message requesting them to complete the survey either through the online link or by filling out the paper-based version that we sent as an attachment with the email. They were asked to complete the questionnaires as part of a two-phase study on emergency management tasks and knowledge management. They were told that their individual responses would be kept strictly confidential and any results that were reported would be either anonymous without personal details or in summary/aggregate form. Along with the email, we also enclosed a letter of sponsorship and endorsement from the EOC coordinator to further emphasize that the survey request was genuine and required for the research study. If we did not receive a response, we followed up with another email message after every two 
weeks as a reminder for our original request. In many cases, we spent considerable time towards responding to questions from the respondents by email and also discussing their unique task assignments and specialized knowledge work by phone to expedite the survey process.

The second approach we adopted was to send the potential participants mail packages through the university bulk mail system, consisting of a personalized cover letter, the paper version of the survey, copy of the EOC endorsement letter, and stamped return envelopes so they could conveniently fill out the survey and mail it back to us. This approach required additional time since we needed to call the offices of the participant and speak to someone who could provide us the correct mailing address including nuances such as department name, office building and so on. The third approach was to personally meet the participants, briefly explain the purpose of the study and the relevance to their work, and request them to fill out the paper-based version. In some cases, the participants offered to delegate the questionnaire to someone else in their unit who was more familiar with the work in Miami-Dade EOC activations. We were able to help them complete the survey process expediently.

\subsubsection{Sampling characteristics}

We present below the characteristics of the data in terms of the respondent profiles. We developed the respondent profiles in terms of two attributes: (1) the position of the respondent in their respective organization and (2) number of years of emergency 
management experience. We categorized the respondent organizational position as follows and noted the corresponding response percentages:

1) Senior management which corresponds to the organizational positions such as chief, commander, president, and other executive and top management titles (20\%)

2) Middle management which corresponds to organizational positions related to managerial, supervisory, and coordination responsibilities (66\%)

3) Other which captures all other positions (14\%)

We categorized the number of years of emergency management experience as follows and noted the corresponding response percentages:

1) Less than 5 years $(35 \%)$

2) From 5 to 14 years $(37 \%)$

3) More than 15 years $(28 \%)$

We see that most of the respondents had organizational positions entailing significant amount of authority and responsibilities in their respective organizations. Also many of the respondents had a considerable amount of experience in the emergency management field. These attributes when viewed together suggest that it is important for the personnel working on the emergency tasks to have sufficient knowledge, skills and experience in their particular field as well as in emergency management. 


\section{Data analysis and results}

\subsection{Data preparation and screening}

The survey data was carefully screened for unusual patterns, non-response bias, and outliers. The responses were reviewed to see if the survey participants were careful and serious in completing the questionnaires. To examine non-response bias, we planned to examine the dates on which the responses are received and make comparisons of early responses and later responses on key demographic and item scores to see whether any significant differences are revealed. If there were no significant differences, then we would be able to conclude that response bias was not likely to be a problem.

We split the data into two halves based on the date the response was received. Using the key variable for demographics (number of years worked in current organization), Independent-Samples $t$ test were conducted and the means for the two groups of data for the main constructs were compared. These constructs are task component complexity, task interactive complexity, task procedural rigidity, knowledge integration, task efficiency, and task effectiveness. 


\begin{tabular}{|l|l|l|}
\hline \multicolumn{1}{|c|}{ Construct } & \multicolumn{1}{|c|}{ Result of $\boldsymbol{t}$ test } & \multicolumn{1}{c|}{ Comments } \\
\hline $\begin{array}{l}\text { Years worked in current } \\
\text { organization (yrs_worked) }\end{array}$ & Not significant & \\
\hline Knowledge Integration KI & Not significant & $\begin{array}{l}\text { Mean difference is }-0.47 \\
\text { (Mean values: } 4.97 \text { and } 5.44)\end{array}$ \\
\hline Efficiency & Significant at .05 level & \\
\hline Effectiveness & Not significant & \\
\hline Component complexity CC & Not significant & $\begin{array}{l}\text { Mean difference is -.53 (Mean } \\
\text { values: } 4.25 \text { and } 4.78 \text { ) }\end{array}$ \\
\hline Interactive Complexity IC & Not significant & Significant at .05 level \\
\hline Procedural Rigidity PR & &
\end{tabular}

Table 8: Summary of tests to examine non-response bias

The results of the tests to examine non-response bias are explained as follows. Five of the key constructs used in the research model indicate a difference in the mean values of the two halves of the dataset to be non-significant. These constructs are: years worked in current organization, knowledge integration, task efficiency, task effectiveness, task component complexity, task interactive complexity, and task procedural rigidity. This is a reasonably good measure to indicate that response bias is not likely to be a problem in the survey data.

The two half sets of data are considered to represent the group of early and late respondents respectively, the latter group serving as a proxy for the group that failed to respond. The purpose of this test is to validate whether there is a possibility of the presence of any systematic differences between the responses of the group that participated in the survey and the group who we attempted to contact but failed to respond. The tests indicate that overall there are no significant differences between the 
responses of the two groups of early and late respondents and therefore between the two groups, one that responded and the other being the group that did not respond.

The measurement items were analyzed for possible outlier values. Our consideration for an outlier value is based on the value beyond the mean plus/minus 3

SDs (Standard Deviations). In most cases we did not observe any outlier values. In the few cases where we found outliers, we determined that the value was not a mistake, but could actually be the value intended by the respondent for the particular task or knowledge area.

\subsection{Validity and reliability issues}

As explained in sections 4.3,4.4, and 4.5, issues related to content validity (or face validity) were addressed by following the guidelines for interviews with the site managers, field observations, and the appropriate use of Q-sorting techniques.

\section{Data Reliability}

To assess the reliability of the measures indicated for the variables, Cronbach's alpha coefficient will be estimated using SPSS for Windows application program. The purpose of performing the analyses for reliability is to examine whether the items in the instrument consistently represent the construct that is being measured (Green \& Salkind, 2005). Thus for each set of measurement items for a specific variable (for example five items for component task complexity, six items for integration of specific knowledge, four items for task performance effectiveness, etc.), Cronbach's alpha will be computed using SPSS and we will determine whether the value is adequate for judging the reliability of the measures. 
This technique is based on the idea of split half reliability -- the dataset is split into two halves randomly and for several participants the correlation between the two halves is computed, the indicator of reliability being a large correlation (Field, 2005). Cronbach's alpha is the average value obtained by computing the correlation coefficient for every possible way in which the dataset can be split. Cronbach's alpha is defined as

$$
\frac{N}{N-1}\left(\frac{\sigma_{X}^{2}-\sum_{i=1}^{N} \sigma_{Y_{i}}^{2}}{\sigma_{X}^{2}}\right)
$$

where $N$ is the number of components (items or testlets), $\sigma_{X}^{2}$ is the variance of the

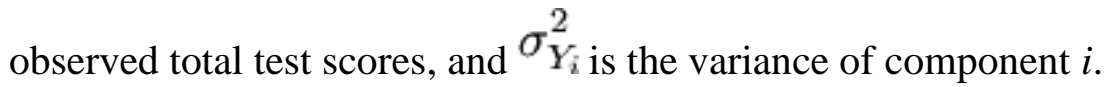

We note that some of our measurement items are reverse scored. For example the item "There were sufficient backup personnel in the execution of the task" for the task attribute of Procedural Rigidity is phrased the opposite way for measuring the degree of procedural rigidity of the task. A high score on this item (on the scale of 1 through 7) actually indicates a low degree of procedural rigidity for the task. Before conducting the reliability analysis, we will reverse the scale for such items which can be achieved in SPSS by using the Transform and Compute options. We also note that there are two versions of alpha: the normal and the standardized versions which we will use per these guidelines. The normal alpha is considered appropriate when a single score for a scale is produced by summing the items on the scale, and the standardized alpha is used when the items on the scale are summed after they are standardized (Field, 2005).

The SPSS Reliability Analysis will provide the required statistics one of which is the Corrected Item-Total Correlation. These values are the correlations between each 
item and the total score from the questionnaire (Green \& Salkind, 2005). We expect that if the scale is reliable, all items should correlate with the total and we will look for items that don't correlate with the overall score from the scale. Then we will need to consider whether items with low correlations may have to be dropped from the scale. We will also examine the values labeled Alpha if Item is Deleted (which is the value of the overall alpha if that item is not included in the calculation) and the value of Alpha which is the Cronbach's alpha. Our expectation is that a value of more than 0.7 will be considered adequate for judging the reliability.

\subsection{Measurement validation}

Factor analysis was conducted using SPSS for Windows software to identify factors that statistically explain the variation and covariation among the measures that have been identified in the study. For the purpose of this study, we plan exploratory factor analysis to describe and summarize data by grouping together variables that are correlated (Tabachnick \& Fidell, 1996). We expect that exploratory factor analysis will provide the tools to describe and understand the relationships among the variables in preparation for testing the research hypotheses.

In this study, the research design is based on different sets of measures reflecting the different dimensions of broader concepts: emergency task complexity, integration of specific knowledge, and emergency task performance; factor analysis can yield factors that represent these dimensions. As described in Table 5, we have identified five items each for task component complexity, task interactive complexity, and task procedural rigidity, six items for integration of specific knowledge, and four items each for task 
effectiveness and task efficiency. All measurement items associated with the same construct should have high loadings on the same factor and relatively low loadings on other factors (Green \& Salkind, 2005).

We plan two stages for factor analysis: factor extraction and factor rotation (Green \& Salkind, 2005). The objective of the first stage is to make an observation about the number of factors that underlie a set of measured variables. The purpose of the second stage is to statistically manipulate the previous results to make the factors more interpretable in the context of our study.

The analysis will be conducted using SPSS for Windows application. Based on the techniques mentioned above, the following is a possible outline of the process using the SPSS application program.

For factor extraction, we start with the options for Analyze, Data Reduction, and then Factor, which takes us to the "Factor Analysis" dialog box. The initial statistics from the factor extraction procedure show the eigenvalues for each factor component (an eigenvalue is the amount of variance of the variables accounted for by a factor), which are helpful in deciding how many factors should be used. A possible criterion will be to retain all factors that have eigenvalues greater than 1 (this is the default value in SPSS).

The next stage after factor extraction is factor rotation. A possible outline of the process using SPSS is conducting the analysis by choosing the menu option "Maximum Likelihood", and the Varimax option for an orthogonal rotation of factors, assuming the rotated factors may be uncorrelated. The resulting rotated factor matrix will show the factor loadings, which are the correlations between each of the variables and the factors selected for the rotation. 
This analysis also allows us to assess the convergent and discriminant validity of the measurement items and the constructs. As mentioned earlier, all items associated with the same construct should have high loadings on the construct (convergent validity) and relatively low loadings on other factors (discriminant validity). This will support the measure's validity that items should be more highly correlated with their own scales than with other scales.

The tables below summarize the results of factor analysis conducted for the constructs task interactive complexity, task procedural rigidity, context-specific knowledge, and technology-specific knowledge.

\subsubsection{Task interactive complexity measurement}

The dimensionality of the 5 items used to measure task interactive complexity was analyzed using maximum likelihood factor analysis. We determined the number of factors to rotate based on the a priori hypothesis that the construct was unidimensional, the eigenvalues, and interpretability of the factor solution. The initial hypothesis of unidimensionality was incorrect and two factors were rotated using a Varimax rotation procedure. The rotated solution yielded two interpretable factors: uncertainty and interdependence. The first factor combines the items related to the "uncertainty" component and the second factor has the items related to the "interdependence" component. Table 9 shows the final results we obtained.

Further, coefficient alphas were computed to obtain internal consistency estimates of reliability for the measures in each of the two factors. The values of Cronbach's Alpha and Standardized Item Alpha for the "interdependence component" were .407 and .425 
respectively. It was decided to drop these items for following reasons: 1) The relatively low value of Cronbach's Alpha for the measures being dropped indicates a low level of internal reliability for these items and (2) the value of correlation between the two subconstructs is very low (less than 0.1 ).

In summary, the 2 items tc_int 2 and tc_int 3 were dropped for the construct Task Interactive Complexity. The three items tc_int1, tc_int4, and tc_int5 will be retained for further analysis. Table 9 summarizes these results.

Table 9: Task interactive complexity: Factor loadings

\begin{tabular}{|l|c|}
\hline \multicolumn{1}{|c|}{ Task Interactive Complexity ltems } & Factor Loadings \\
\hline & .721 \\
\hline $\begin{array}{l}\text { tc_int1: The different activities in the task interacted with each } \\
\text { other in unpredictable ways during the execution of the task }\end{array}$ & .676 \\
\hline $\begin{array}{l}\text { tc_int4: There were uncertain relationships between the activities } \\
\text { and the task outcome }\end{array}$ & .428 \\
\hline $\begin{array}{l}\text { tc_int5: A change in one activity had significant impacts on other } \\
\text { activities during execution of the task }\end{array}$ & \\
\hline \multicolumn{2}{|c|}{ Note: } \\
Extraction Method: Maximum Likelihood \\
Rotation Method: Varimax with Kaiser Normalization
\end{tabular}

\subsubsection{Task procedural rigidity measurement}

The dimensionality of the 5 items used to measure task procedural rigidity was analyzed using maximum likelihood factor analysis. We determined the number of factors to rotate based on the a priori hypothesis that the construct was unidimensional, the eigenvalues, and interpretability of the factor solution. The initial hypothesis of unidimensionality was incorrect and two factors were rotated using a Varimax rotation procedure. The rotated solution yielded two interpretable factors: rigid and noslack. The 
first factor combines the items related to the "rigid" component and the second factor has the items related to the "lack of slack" component. Table 10 shows the final results we obtained.

Further, coefficient alphas were computed to obtain internal consistency estimates of reliability for the measures in each of the two factors. The values of Cronbach's Alpha and Standardized Item Alpha for the "lack of slack" component were .494 and .499 respectively. It was decided to drop these items for the following reasons: 1) The relatively low value of Cronbach's Alpha for the measures being dropped indicates a low level of internal reliability for these items and (2) the value of correlation between the two sub-constructs of task procedural rigidity is very low (less than 0.1).

In summary, the three items tc_pr3, tc_pr4, and tc_pr5 will be dropped for the construct Task Procedural Rigidity and the two items tc_pr1 and tc_pr2 will be retained for further analysis. Table 10 summarizes these results.

Table 10: Task procedural rigidity: Factor loadings

\begin{tabular}{|l|c|}
\hline \multicolumn{1}{|c|}{ Task Procedural Rigidity Items } & Factor Loadings \\
\hline \multicolumn{1}{|c|}{} \\
\hline $\begin{array}{l}\text { tc_pr1: The various activities in the task were very rigid with } \\
\text { respect to time }\end{array}$ & .907 \\
\hline $\begin{array}{l}\text { tc_pr2: The sequence by which the various activities were } \\
\text { performed was very rigid }\end{array}$ & .722 \\
\hline Note: \\
Extraction Method: Maximum Likelihood \\
Rotation Method: Varimax with Kaiser Normalization
\end{tabular}




\subsubsection{Context-specific knowledge measurement}

The dimensionality of the 4 items used to measure degree of context-specific knowledge was analyzed using maximum likelihood factor analysis. We determined the number of factors to rotate based on the a priori hypothesis that the construct was unidimensional, the eigenvalues, and interpretability of the factor solution. The initial hypothesis of unidimensionality was supported and the rotated solution yielded one interpretable factors. Table 11 shows the final results we obtained.

Further, coefficient alphas were computed to obtain internal consistency estimates of reliability for the measures of this construct. These values were computed first for all 4 items and then for 3 items after dropping sk_cxt3. We found that the value of Cronbach's Alpha obtained for all 4 items was 0.677 indicating a low level of internal reliability. After dropping 1 item, the value of Cronbach's Alpha (and the value of Standardized Item Alpha) improved to .798 which will be considered as acceptable for internal reliability.

In summary, the item sk_cxt3 was dropped for the construct Context-specific knowledge and the three items sk_cxt1, sk_cxt2, and sk_cxt4 will be retained for further analysis. Table 11 summarizes these results. 


\begin{tabular}{|l|c|}
\hline \multicolumn{1}{|c|}{ Context-specific Knowledge Items } & Factor Loadings \\
\hline $\begin{array}{l}\text { sk_cxt2: This knowledge is related to particular situations and } \\
\text { place }\end{array}$ & .871 \\
\hline $\begin{array}{l}\text { sk_cxt4: Application of this knowledge is contingent upon } \\
\text { particular circumstances \& events }\end{array}$ & .825 \\
\hline $\begin{array}{l}\text { sk_cxt1: This knowledge is related to particular circumstances of } \\
\text { time }\end{array}$ & .798 \\
\hline \multicolumn{1}{|c|}{$\begin{array}{l}\text { Note: } \\
\text { Extraction Method: Maximum Likelihood } \\
\text { Rotation Method: Varimax with Kaiser Normalization }\end{array}$} \\
\hline
\end{tabular}

Table 11: Context-specific knowledge: Factor loadings

\subsubsection{Technology-specific knowledge measurement}

The dimensionality of the 4 items used to measure the degree of technologyspecific knowledge was analyzed using maximum likelihood factor analysis. We determined the number of factors to rotate based on the a priori hypothesis that the construct was unidimensional, the eigenvalues, and interpretability of the factor solution. The initial hypothesis of unidimensionality was incorrect and two factors were rotated using a Varimax rotation procedure. The rotated solution yielded two interpretable factors and Table 12 shows the final results we obtained.

Further, coefficient alphas were computed to obtain internal consistency estimates of reliability for the measures for the first factor and then for all 4 items. The value of Cronbach's Alpha obtained for all 4 items was 0.483 indicating a low level of internal reliability. After dropping 1 item, the value of Cronbach's Alpha and the Standardized Item Alpha improved to some extent (.629 and .630 respectively) which will be considered as marginally acceptable for internal reliability. 
In summary, the item sk_tech4 was dropped for the construct Technology-specific knowledge and the three items sk_tech1, sk_tech2, and sk_tech3 were retained for further analysis. Table 12 summarizes these results.

\begin{tabular}{|l|c|}
\hline \multicolumn{1}{|c|}{ Technology-specific Knowledge Items } & Factor Loadings \\
\hline $\begin{array}{l}\text { sk_tech3: This knowledge makes use of tools \& techniques } \\
\text { specific to a particular discipline }\end{array}$ & .832 \\
\hline $\begin{array}{l}\text { sk_tech2: This knowledge has rules specific to a particular } \\
\text { discipline }\end{array}$ & .818 \\
\hline $\begin{array}{l}\text { sk_tech1: This knowledge can be taught through formal training } \\
\text { \& education }\end{array}$ & .614 \\
\hline $\begin{array}{l}\text { Note: } \\
\text { Extraction Method: Maximum Likelihood }\end{array}$ \\
\hline
\end{tabular}

Table 12: Technology-specific knowledge: Factor loadings

\subsection{Summary of reliability testing}

To assess the reliability of the measures of each of the multi-scale items associated with the constructs, we estimated the value of Cronbach's alpha coefficient using SPSS 1.4 for Windows application program. This analyses will indicate whether the items in the instrument consistently represent the construct that is being measured (Green \& Salkind, 2005).

Thus for each set of measurement items for a specific construct (for example five items for component task complexity, six items for integration of specific knowledge, four items for task performance effectiveness, etc.), Cronbach's alpha was computed using SPSS and we determined whether the value is adequate for judging the reliability of the measures using a threshold value of 0.7 . 
Table 13 summarizes these results:

\begin{tabular}{|l|l|l|l|l|}
\hline \multicolumn{1}{|c|}{$\begin{array}{c}\text { Construct and } \\
\text { Measures }\end{array}$} & $\begin{array}{c}\text { Cronbach's } \\
\text { Alpha }\end{array}$ & $\begin{array}{l}\text { Standardized } \\
\text { Item Alpha }\end{array}$ & $\begin{array}{c}\text { N number } \\
\text { of items }\end{array}$ & Comments \\
\hline $\begin{array}{l}\text { Knowledge Integration KI } \\
\text { (ki1, ki2, ki3, ki4, ki5, ki6) }\end{array}$ & 0.764 & 0.786 & 6 & Satisfactory \\
\hline $\begin{array}{l}\text { Task Efficiency } \\
\text { (t_efcy1, t_efcy2, t_efcy3, } \\
\text { t_efcy4) }\end{array}$ & 0.824 & 0.821 & 4 & Satisfactory \\
\hline $\begin{array}{l}\text { Task Effectiveness } \\
\text { (t_efts1, t_efts2, t_efts3, } \\
\text { t_efts4) }\end{array}$ & 0.844 & 0.845 & 4 & Satisfactory \\
\hline $\begin{array}{l}\text { Task Component Complexity } \\
\text { CC - Standardized } \\
\text { (nbr_people, nbr_mach, } \\
\text { nbr_sys, nbr_org) }\end{array}$ & 0.739 & 0.714 & 4 & Satisfactory \\
\hline $\begin{array}{l}\text { Task Interactive Complexity } \\
\text { IC (tc_int1, tc_int4, tc_int5) }\end{array}$ & 0.623 & 0.621 & 3 & Marginally \\
\hline $\begin{array}{l}\text { Task Procedural Rigidity PR } \\
\text { (tc_pr1, tc_pr2) }\end{array}$ & 0.786 & 0.786 & 2 & Satisfactory \\
\hline
\end{tabular}

Table 13: Cronbach's alpha values for reliability testing

The reliability tests indicate a satisfactory value of Cronbach's Alpha (greater than 0.7) for the key constructs in the research model. The value of Cronbach's Alpha for Task Interactive Complexity is 0.623 and will be considered as marginally acceptable.

\subsection{Hypotheses testing}

In order to test the level of support for each hypothesis, a series of multiple regression analyses will be performed using SPSS for Windows at a 5\% level of significance $(\alpha=0.05)$. The purpose of the model testing is for path analysis and not for testing the measurement and structure of the model. 
As indicated earlier in the research model, the independent (predictor) variable is task complexity (TC) which we treat as a multidimensional construct of three dimensions -- component task complexity (CC), interactive task complexity (IC), and procedural rigidity (PR). The dependent (criterion) variable is emergency task performance (TP) of two dimensions -- task effectiveness and task efficiency. The mediating variable is knowledge integration (KI) that partially accounts for the relationship between the independent and dependent variables (Cohen \& Cohen, 1983). The measurement for each of these constructs was obtained by calculating the mean of the response values of the measurement items used for the corresponding construct. For the task component complexity construct, we calculated the mean of the standardized values of the responses for the corresponding measurement items.

The summaries of the regression test analyses that were conducted are described below. Treating task complexity as a multidimensional construct, we examined the effects of the three task complexity dimensions as well as knowledge integration on task effectiveness and task efficiency.

The hypotheses based on the research model (which were explained in Chapter 3) are reproduced here for the reader's convenience.

H1a) Component complexity of tasks is negatively associated with task effectiveness H1b) Interactive complexity of tasks is negatively associated with task effectiveness H1c) Procedural rigidity of tasks is negatively associated with task effectiveness H2a) Component complexity of tasks is negatively associated with task efficiency $\mathrm{H} 2 \mathrm{~b})$ Interactive complexity of tasks is negatively associated with task efficiency $\mathrm{H} 2 \mathrm{c})$ Procedural rigidity of tasks is negatively associated with task efficiency 


\subsection{Summary of path analyses}

In this section we describe how the path analysis was conducted for the main constructs of task complexity, knowledge integration, and task performance. Three sets of multiple regression tests were conducted to explore the relationships between task complexity, knowledge integration, and task performance. In the first set, the independent variables were task component complexity, task interactive complexity, and task procedural rigidity, while the dependent variable was knowledge integration. In the second set, knowledge integration was included as the independent variable along with the three constructs for task complexity, while the dependent variable was task efficiency. In the third set of regression testing, the independent variables were the same as the second set, while the dependent variable was task effectiveness.

1) Regression of Task Complexity and Knowledge Integration

2) Regression of Task Complexity, Knowledge Integration, and Efficiency

3) Regression of Task Complexity, Knowledge Integration, and Effectiveness as represented by the following equations:

$$
\begin{aligned}
& \mathrm{KI}=\mathrm{f}(\mathrm{CC}, \mathrm{IC}, \mathrm{PR}) \\
& \text { Efficiency }=\mathrm{f}(\mathrm{CC}, \mathrm{IC}, \mathrm{PR}, \mathrm{KI}) \\
& \text { Effectiveness = } \mathrm{f}(\mathrm{CC}, \mathrm{IC}, \mathrm{PR}, \mathrm{KI})
\end{aligned}
$$

The following table summarizes the results of these analyses showing the individual values of standardized beta coefficients, t-statistic and the statistically significant level. 


\begin{tabular}{|c|l|l|l|l|l|l|}
\hline $\begin{array}{c}\text { Independent } \\
\text { Variable }\end{array}$ & \multicolumn{5}{c|}{ Dependent Variable } \\
\hline & \multicolumn{2}{|c|}{ KI } & \multicolumn{2}{c|}{ Efficiency } & \multicolumn{2}{c|}{ Effectiveness } \\
\hline & $\begin{array}{l}\text { Standardized } \\
\beta \text { coefficient }\end{array}$ & t-statistic & $\begin{array}{l}\text { Standardized } \\
\beta \text { coefficient }\end{array}$ & t-statistic & $\begin{array}{l}\text { Standardized } \\
\beta \text { coefficient }\end{array}$ & t-statistic \\
\hline & & & & & & \\
\hline CC & $0.187^{*}$ & 2.039 & $-0.169^{*}$ & -1.963 & $-0.241^{* *}$ & -2.794 \\
\hline IC & 0.048 & 0.505 & $-0.334^{* * *}$ & -3.808 & $-0.209^{*}$ & -2.385 \\
\hline PR & -0.008 & -0.082 & $0.224^{*}$ & 2.557 & $0.157^{+}$ & 1.794 \\
\hline KI & -- & -- & $0.243^{* *}$ & 2.816 & $0.341^{* * *}$ & 3.957 \\
\hline & \multicolumn{7}{l}{ Adj $R^{2}=0.155 ; F=6.429^{* * *}$ Adj $R^{2}=0.156 ; F=6.473^{* * *}$} \\
\hline
\end{tabular}

Table 14: Summary of path analyses

Based on the above table we now describe the results of our analyses and how they tie back to our hypotheses. The standardized $\beta$ coefficient between task component complexity and task effectiveness was negative and significant $(-0.241, \mathrm{p}<.01)$. This result provides support for the hypothesis that task component complexity is negatively associated with task effectiveness. The standardized $\beta$ coefficient between task interactive complexity and task effectiveness was negative and significant $(-0.209, \mathrm{p}<$ $.05)$, which provides support for the hypothesis that task interactive complexity is negatively associated with task effectiveness. The standardized $\beta$ coefficient between task procedural rigidity and task effectiveness was positive and marginally significant $(0.157, \mathrm{p}<.1)$. This did not support our expectation that task procedural rigidity is negatively associated with task effectiveness.

The standardized $\beta$ coefficient between task component complexity and task efficiency was negative and significant $(-0.169, \mathrm{p}<.05)$. This result provides support for 
the hypothesis that task component complexity is negatively associated with task efficiency. The standardized $\beta$ coefficient between task interactive complexity and task efficiency was negative and significant $(-0.334, \mathrm{p}<.001)$, which provides support for the hypothesis that task interactive complexity is negatively associated with task efficiency. The standardized $\beta$ coefficient between task procedural rigidity and task efficiency was positive and significant $(0.224, \mathrm{p}<.05)$. This did not support our expectation that task procedural rigidity is negatively associated with task efficiency.

The value of standardized $\beta$ coefficient between knowledge integration and task effectiveness was positive and significant $(0.341, \mathrm{p}<.001)$ which provides strong support for our hypothesis that integration of specific knowledge is positively associated with task effectiveness. The value of standardized $\beta$ coefficient between knowledge integration and task efficiency was positive and significant $(0.243, \mathrm{p}<.01)$ which provides strong support for our hypothesis that integration of specific knowledge is positively associated with task efficiency.

Further more we report an additional finding which was not in the original hypothesis, but is relevant to the research model and the path analysis. The value of standardized $\beta$ coefficient between task component complexity and knowledge integration was positive and significant $(0.187, \mathrm{p}<.05)$ which indicates that task component complexity is positively associated with integration of specific knowledge. The table below summarizes the hypotheses and our findings through path analyses. 


\begin{tabular}{|c|l|l|}
\hline \multicolumn{1}{|c|}{ Hypothesis } & \multicolumn{1}{|c|}{ Research Finding } \\
\hline H1a & $\begin{array}{l}\text { Component complexity of tasks is negatively } \\
\text { associated with task effectiveness }\end{array}$ & Strong support \\
\hline H1b & $\begin{array}{l}\text { Interactive complexity of tasks is negatively associated } \\
\text { with task effectiveness }\end{array}$ & Supported \\
\hline H1c & $\begin{array}{l}\text { Procedural rigidity of tasks is negatively associated } \\
\text { with task effectiveness }\end{array}$ & $\begin{array}{l}\text { Marginal support but } \\
\text { reverse direction }\end{array}$ \\
\hline H2a & $\begin{array}{l}\text { Component complexity of tasks is negatively } \\
\text { associated with task efficiency }\end{array}$ & Supported \\
\hline H2b & $\begin{array}{l}\text { Interactive complexity of tasks is negatively associated } \\
\text { with task efficiency }\end{array}$ & Strong support \\
\hline H2c & $\begin{array}{l}\text { Procedural rigidity of tasks is negatively associated } \\
\text { with task efficiency }\end{array}$ & $\begin{array}{l}\text { Supported but reverse } \\
\text { direction }\end{array}$ \\
\hline H3 & $\begin{array}{l}\text { Integration of specific knowledge is positively } \\
\text { associated with task effectiveness }\end{array}$ & Strong support \\
\hline H4 & $\begin{array}{l}\text { Integration of specific knowledge is positively } \\
\text { associated with task efficiency }\end{array}$ & Strong support \\
\hline & $\begin{array}{l}\text { Component complexity of tasks is positively } \\
\text { associated with knowledge integration }\end{array}$ & $\begin{array}{l}\text { Supported (not in } \\
\text { original hypothesis) }\end{array}$ \\
\hline
\end{tabular}

Table 15: Summary of hypotheses and findings 
Figure 13: Summary of path analyses

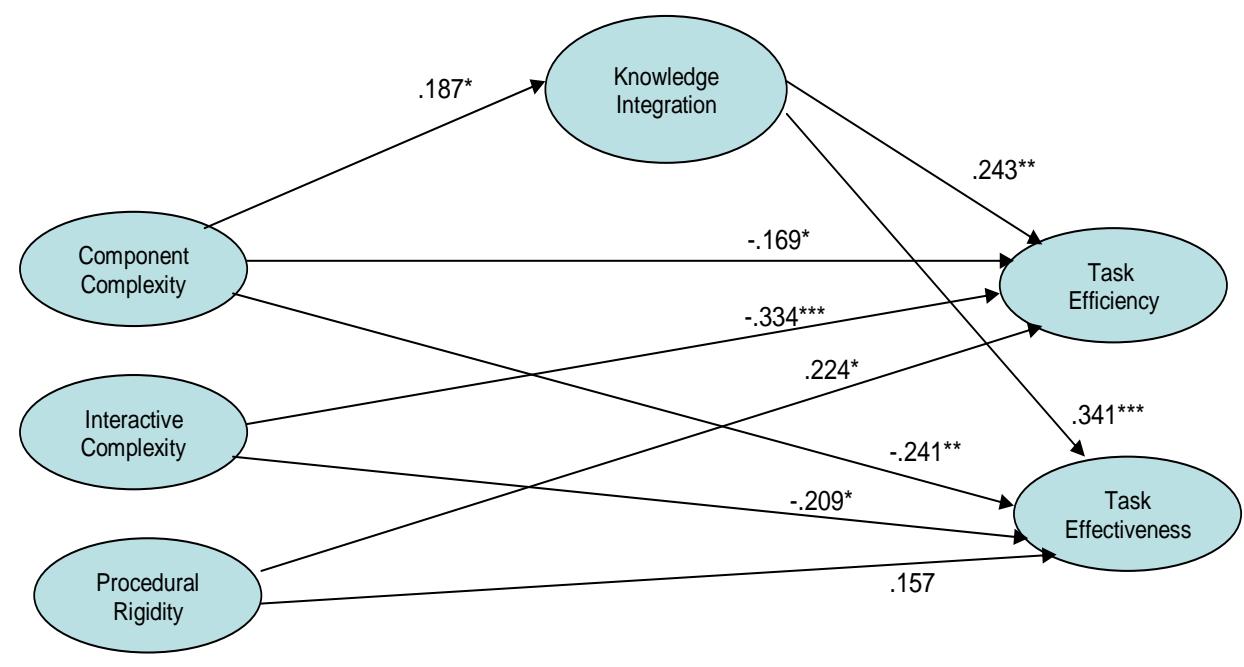

Task Complexity

$\longrightarrow \begin{aligned} & \text { Knowledge } \\ & \text { Integration }\end{aligned} \longrightarrow \begin{gathered}\text { Task } \\ \text { Performance }\end{gathered}$




\subsection{Summary of path analyses with control variables}

The following control variables are used in this part of the analysis representing some of the data corresponding to the respondent's demographic attributes:

1) Number of years worked in current organization: This is a measure of the knowledge and expertise of the respondent in the designated field (yrs-work)

2) Total number of years worked in emergency management: This is a measure of the knowledge and experience of the respondent in emergency management (yrs_tot)

In this section we describe the path analysis conducted for the main constructs task complexity, knowledge integration, task performance, and the control variables. Three sets of multiple regression tests were conducted to explore the relationships between task complexity, control variables, knowledge integration, and task performance. In the first set, the independent variables were task component complexity, task interactive complexity, task procedural rigidity, and the two control variables, while the dependent variable was knowledge integration. In the second set, knowledge integration was included as the independent variable along with the three constructs for task complexity and control variables, while the dependent variable was task efficiency. In the third set of regression testing, the independent variables were the same as the second set, while the dependent variable was task effectiveness.

1) Regression of Task Complexity, Control variables, and Knowledge Integration 2) Regression of Task Complexity, Control Variables, Knowledge Integration, and Efficiency 
3) Regression of Task Complexity, Control Variables, Knowledge Integration, and Effectiveness

as represented by the following equations:

$$
\begin{aligned}
& \mathrm{KI}=\mathrm{f}(\mathrm{CC}, \mathrm{IC}, \mathrm{PR}, \mathrm{CV} 1, \mathrm{CV} 2) \\
& \text { Efficiency = } \mathrm{f}(\mathrm{CC}, \mathrm{IC}, \mathrm{PR}, \mathrm{KI}, \mathrm{CV} 1, \mathrm{CV} 2) \\
& \text { Effectiveness = } \mathrm{f}(\mathrm{CC}, \mathrm{IC}, \mathrm{PR}, \mathrm{KI}, \mathrm{CV} 1, \mathrm{CV} 2)
\end{aligned}
$$

\begin{tabular}{|c|c|c|c|c|c|c|}
\hline Independent & \multicolumn{6}{|c|}{ Dependent Variable } \\
\hline & \multicolumn{2}{|c|}{$\mathrm{KI}$} & \multicolumn{2}{|c|}{ Efficiency } & \multicolumn{2}{|c|}{ Effectiveness } \\
\hline & $\begin{array}{l}\text { Standardized } \\
\beta \text { coefficient }\end{array}$ & t-statistic & $\begin{array}{l}\text { Standardized } \\
\beta \text { coefficient }\end{array}$ & t-statistic & $\begin{array}{l}\text { Standardized } \\
\beta \text { coefficient }\end{array}$ & t-statistic \\
\hline$C C_{1}$ & $0178^{+}$ & 19020 & $0107 *$ & 2218 & $0251 * *$ & 2009 \\
\hline $\mathrm{IC}$ & 0.058 & 0.601 & $-0.306^{\star \star \star}$ & -3.514 & $\frac{-0.251}{-0.199^{*}}$ & $\begin{array}{l}-2.009 \\
-2.225\end{array}$ \\
\hline PR & -0.015 & -0.155 & $0.206^{*}$ & 2.403 & $0.149^{+}$ & 1.691 \\
\hline CV1 & -0.020 & -0.216 & -0.045 & -0.538 & -0.042 & -0.482 \\
\hline CV2 & -0.087 & -0.927 & $-0.229^{* *}$ & -2.701 & -0.100 & -1.151 \\
\hline $\mathrm{KI}$ & -- & -- & $0.220^{\star *}$ & 2.613 & $0.330^{\star \star *}$ & 3.814 \\
\hline \multicolumn{7}{|c|}{ Adj $R^{2}=0.002 ; F=1.050$} \\
\hline
\end{tabular}

The following table summarizes the results of these analyses showing the individual values of standardized beta coefficients, t-statistic and the statistically significant level.

Table 16: Summary of path analyses with control variables 
Based on the results, we note that no major differences in the magnitude and direction of the relationships between the key constructs were noted after the control variables were included in the regression tests (in other words the story remains the same).

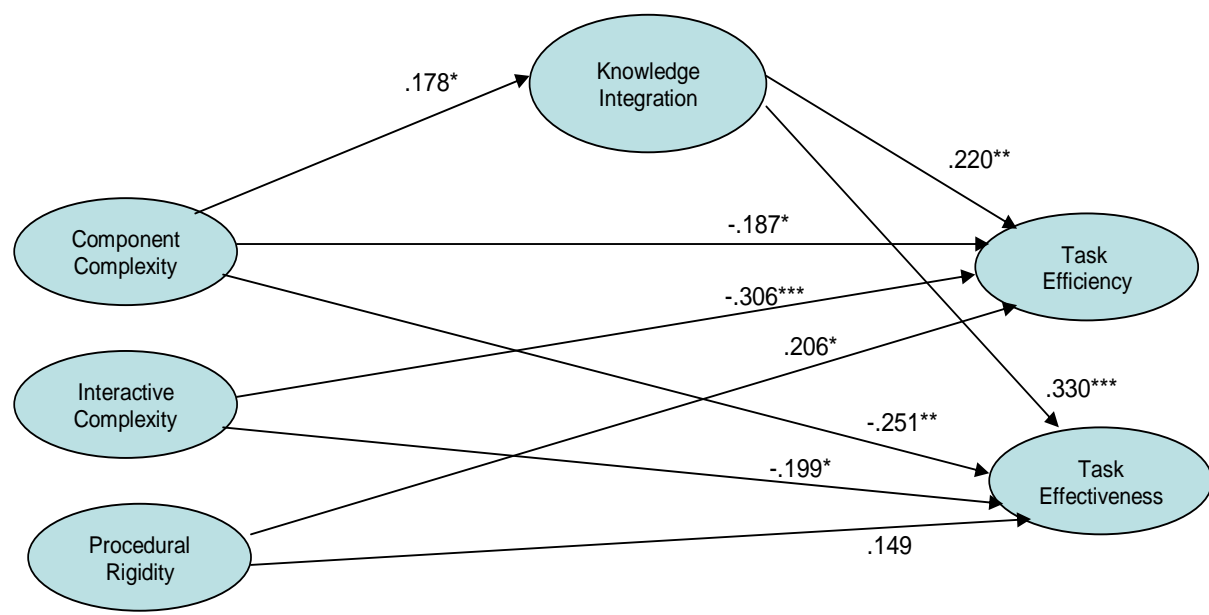

Control Variables

- Experience in current organization - Experience in emergency management

\begin{tabular}{|c|} 
Task \\
Complexity
\end{tabular}$\longrightarrow \begin{aligned} & \text { Knowledge } \\
& \text { Integration }\end{aligned}$

Figure 14: Summary of path analyses with control variables 


\subsection{Moderating effects of specific knowledge}

To evaluate the level of specific knowledge (context, technology, or context-and technology) that was required to execute a particular emergency task, we adopted a methodology based on the median values of each of the constructs for specific knowledge. The median values for context-specific knowledge and technology-specific knowledge as determined through Descriptive Statistics tests in SPSS, were each 5.33. We segregated the data into two groups: the first group contained the cases for which the values of the specific knowledge construct were less than the median value of 5.33 and the second group contained the cases for which the values of the specific knowledge construct were greater than or equal to the median value of 5.33 .

Subsequently, the first group represents the emergency tasks which were performed using a relatively low level of the specific knowledge and the second group represents those emergency tasks which required a relatively high level of specific knowledge. As explained in Section 3.5, the notion of a relatively low level of specific knowledge would imply a higher level of general knowledge required for the task. The regression path analyses described in the previous sections were again performed for each of the two groups of data, thus enabling us to examine any particular similarities or differences in the respective outcomes.

Our expectation is that the nature of the relationship between task complexity, knowledge integration, and task performance depends on the extent to which the area of knowledge is general (low specificity) or context-specific or technology-specific. For example, we can observe if the relationship between task component complexity and task 
efficiency remains the same or is different for the two levels of context-specific knowledge; furthermore in the latter case, we are interested in what the particular differences are and what can be inferred from these observations. In the following sections, the details of these tests, the analyses and our observations have been described.

\subsubsection{Moderating effects of context-specific knowledge}

For each of the two groups of data (Context-specific knowledge less/greater than median value 5.33), three sets of multiple regression tests were conducted to explore the relationships between task complexity, knowledge integration, and task performance. We are particularly interested in observing how the level of context-specific knowledge affects the strength and direction of the relationship between task complexity and task

performance. In the first set, the independent variables were task component complexity, task interactive complexity, and task procedural rigidity, while the dependent variable was knowledge integration. In the second set, knowledge integration was included as the independent variable along with the three constructs for task complexity, while the dependent variable was task efficiency. In the third set of regression testing, the independent variables were the same as the second set, while the dependent variable was task effectiveness. In summary,

1) Path analyses of task complexity and knowledge integration (2 groups for level of context-specific knowledge less/greater than 5.33) 
2) Path analyses of task complexity, knowledge integration, and efficiency (2 groups for level of context-specific knowledge less/greater than 5.33)

3) Path analyses of task complexity, knowledge integration, and effectiveness (2 groups for level of context-specific knowledge less/greater than 5.33)

We now discuss the results of regression of task complexity and knowledge integration as represented by the equation $\mathrm{KI}=\mathrm{f}(\mathrm{CC}, \mathrm{IC}, \mathrm{PR})$.

\begin{tabular}{|c|c|c|c|c|}
\hline \multirow{3}{*}{$\begin{array}{c}\text { Independent } \\
\text { Variable }\end{array}$} & \multicolumn{4}{|c|}{ Dependent Variable KI } \\
\hline & \multicolumn{2}{|c|}{ Context-specific knowledge $<5.33$} & \multicolumn{2}{|c|}{ Context-specific knowledge $>=5.33$} \\
\hline & $\begin{array}{l}\text { Standardized } \beta \\
\text { coefficient }\end{array}$ & t-statistic & $\begin{array}{l}\text { Standardized } \beta \\
\text { coefficient }\end{array}$ & t-statistic \\
\hline $\mathrm{CC}$ & 0.262 & 1506 & $0.208^{+}$ & 1694 \\
\hline IC & -0.105 & -0.558 & 0.098 & 0.786 \\
\hline PR & 0.112 & 0.635 & -0.134 & -1.105 \\
\hline \multicolumn{3}{|c|}{$\begin{array}{l}\text { Note: Adj } R^{2}=-.012 ; F=.846 \\
{ }^{* \star *} p<0.001 ;{ }^{* *} p<0.01 ;{ }^{*} p<0.05\end{array}$} & \multicolumn{2}{|c|}{$\operatorname{Adj} R^{2}=0.015 ; F=1.352$} \\
\hline
\end{tabular}

Table 17: Path analyses knowledge integration and context-specific knowledge

From the above table we see that the standardized $\beta$ coefficient between task component complexity and knowledge integration was positive and somewhat significant $(0.208, p<0.1)$ when the level of context-specific knowledge was greater than 5.33.

However when the level of context-specific knowledge was less than 5.33, this relationship was not significant. This result indicates that when the level of contextspecific knowledge is greater than the median value, the impact of component complexity 
is greater on knowledge integration as compared to the impact when the knowledge is more general. This implies that emergency operations managers need to invest in knowledge integration strategies even more so when there are many personnel and organizations involved in a task and thereby strive to reduce their dependence on the expertise and skills of few specialized personnel.

We now discuss the results of path analyses of task complexity, knowledge integration, and efficiency as represented by Efficiency $=\mathrm{f}(\mathrm{CC}, \mathrm{IC}, \mathrm{PR}, \mathrm{KI})$.

\begin{tabular}{|c|c|c|c|c|}
\hline Independent & \multicolumn{4}{|c|}{ Dependent Variable: Efficiency } \\
\hline & \multicolumn{2}{|c|}{ Context-specific knowledge $<5.33$} & \multicolumn{2}{|c|}{ Context-specific knowledge $>=5.33$} \\
\hline & $\begin{array}{l}\text { Standardized } \beta \\
\text { coefficient }\end{array}$ & t-statistic & $\begin{array}{l}\text { Standardized } \beta \\
\text { coefficient }\end{array}$ & t-statistic \\
\hline $\mathrm{CC}$ & -0.062 & -0.381 & -0.185 & -1565 \\
\hline IC & $-0.492^{* \star}$ & -2.861 & $-0.283^{*}$ & -2.393 \\
\hline PR & $0.320^{+}$ & 1.988 & -0.187 & 1.611 \\
\hline $\mathrm{KI}$ & 0.008 & 0.050 & $0.322^{* *}$ & 2.765 \\
\hline $\begin{array}{l}\text { Note: Adj } R^{2}= \\
{ }_{* * *} p<0.001\end{array}$ & $\begin{array}{l}161 ; F=2.866^{*} \\
p<0.01 ;{ }^{*} p<0.0\end{array}$ & & dj $R^{2}=0.119 ; F=3$ & \\
\hline
\end{tabular}

Table 18: Path analyses efficiency and context-specific knowledge

1) The value of the standardized $\beta$ coefficient between task interactive complexity and efficiency was negative and significant $(-0.492, \mathrm{p}<0.01)$ when the level of contextspecific knowledge was less than 5.33. It was also negative and significant $(-0.283, \mathrm{p}<$ 0.05 ) when the level of context-specific knowledge was greater than 5.33. These results indicate that task interactive complexity has significant negative effects on task efficiency when the integrative knowledge involved is general as well as context-specific; however, the results indicate that there is a greater negative effect on efficiency when the knowledge is more general. As explained in Section 5.6 the negative effect of task 
interactive complexity can be compensated by the integration of specific knowledge used in the task.

2) The value of the standardized $\beta$ coefficient between knowledge integration and efficiency was positive and significant $(0.322, \mathrm{p}<0.01)$ when the level of contextspecific knowledge was greater than 5.33. This indicates that the impact of knowledge integration on efficiency depends on the level of context-specific knowledge used for the task performance -- when the level of context-specific knowledge is high, then the impact is greater and significant. Hence when dealing with such tasks, it is beneficial to invest in knowledge integration to improve the task outcome in terms of efficiency. This also indicates that "one size does not fit all" and the same degree of knowledge integration need not be applied for all tasks.

3) From the standpoint of managerial implications, the results suggest that potentially higher benefits can be gained by being selective in knowledge integration strategies for tasks that require different levels of context-specific knowledge. Some tasks may require a particularly higher level of context-specific knowledge whereas more general knowledge is required for working other tasks. 
We now discuss the results of path analyses of task complexity, knowledge integration, and effectiveness as Effectiveness = $\mathrm{f}(\mathrm{CC}, \mathrm{IC}, \mathrm{PR}, \mathrm{KI})$.

\begin{tabular}{|c|c|c|c|c|}
\hline \multirow{3}{*}{$\begin{array}{c}\text { Independent } \\
\text { Variable }\end{array}$} & \multicolumn{4}{|c|}{ Dependent Variable: Effectiveness } \\
\hline & \multicolumn{2}{|c|}{ Context-specific knowledge $<5.33$} & \multicolumn{2}{|c|}{ Context-specific knowledge $>=5.33$} \\
\hline & $\begin{array}{l}\text { Standardized } \beta \\
\text { coefficient }\end{array}$ & t-statistic & $\begin{array}{l}\text { Standardized } \beta \\
\text { coefficient }\end{array}$ & t-statistic \\
\hline CC & 0.034 & 0.206 & $-0.379^{\star *}$ & -3.324 \\
\hline IC & $-0.327^{+}$ & -1.877 & $-0.210^{+}$ & -1.839 \\
\hline PR & -0.098 & -0.600 & $0.229^{*}$ & 2.051 \\
\hline $\mathrm{KI}$ & $0.315^{\star}$ & 2.051 & $0.325^{\star *}$ & 2.891 \\
\hline $\begin{array}{l}\text { Note: Adj } R^{2}= \\
{ }^{* * *} p<0.001\end{array}$ & $\begin{array}{l}138 ; F=2.567^{+} \\
0<0.05 ;{ }^{*} p<0.0\end{array}$ & & $R^{2}=0.181 ; F$ & $66^{* *}$ \\
\hline
\end{tabular}

Table 19: Path analyses effectiveness and context-specific knowledge

1) The value of the standardized $\beta$ coefficient between task component complexity and effectiveness was negative and significant $(-0.379, \mathrm{p}<0.01)$ when the level of contextspecific knowledge was greater than 5.33. Thus when the integrative knowledge was context-specific, the negative impact of component complexity on effectiveness is greater and significant. This also indicates that component complexity has significant negative effect on task effectiveness when the integrative knowledge is context-specific.

2) The value of the standardized $\beta$ coefficient between task procedural rigidity and effectiveness was positive and significant $(0.229, \mathrm{p}<0.05)$ when the level of contextspecific knowledge was greater than 5.33. Thus the impact of task procedural rigidity on task effectiveness becomes positive with higher specific knowledge. This seems to suggest that emergency organization planners have drawn elaborate and comprehensive 
policies and procedures for tasks that are dependent on a high level of context-specific knowledge for their execution.

3) The value of the standardized $\beta$ coefficient between task interactive complexity and effectiveness was negative and somewhat significant $(-0.327, \mathrm{p}<0.1)$ when the level of context-specific knowledge was less than 5.33. It was also negative and somewhat significant $(-0.210, \mathrm{p}<0.1)$ when the level of context-specific knowledge was greater than 5.33. These results indicate that task interactive complexity has negative effects on task effectiveness when the integrative knowledge involved is general as well as contextspecific; however, the results indicate that there is a greater negative effect on effectiveness when the knowledge is more general.

4) The value of the standardized $\beta$ coefficient between knowledge integration and effectiveness was positive and significant $(0.315, \mathrm{p}<0.05)$ when the level of contextspecific knowledge was less than 5.33; it was also positive and significant $(0.325$, $\mathrm{p}<$ 0.01) when the level of context-specific knowledge was greater than 5.33. This indicates that the impact of knowledge integration on effectiveness is significant for all levels of context-specific knowledge, but somewhat greater when the integrative knowledge is context-specific.

5) From a planning perspective for managerial implications, we use the analogy of "modularity" to explain a flexible design as a better alternative when the degree of component complexity in a task is high. Since when the knowledge is highly contextspecific it has a greater impact on effectiveness, the components should be more modular or general purpose to reduce this impact. In other words, the personnel and the organizations responsible for the task should try to share common knowledge and 
communicate across organizational or functional barriers to get the job done. The "stickiness" of the context-specific knowledge is important to correct the negative effects of complexity; for example by using more general knowledge to understand the other person's perspectives while focusing on the context-specific knowledge to solve a problem.

\subsubsection{Moderating effects of technology-specific knowledge}

For each of the two groups of data (Technology-specific knowledge less/greater than median value 5.33), three sets of multiple regression tests were conducted to explore the relationships between task complexity, knowledge integration, and task performance. In the first set, the independent variables were task component complexity, task interactive complexity, and task procedural rigidity, while the dependent variable was knowledge integration. In the second set, knowledge integration was included as the independent variable along with the three constructs for task complexity, while the dependent variable was task efficiency. In the third set of regression testing, the

independent variables were the same as the second set, while the dependent variable was task effectiveness.

1) Path analyses of task complexity and knowledge integration (2 groups for level of technology-specific knowledge less/greater than 5.33)

2) Path analyses of task complexity, knowledge integration, and efficiency (2 groups for level of technology-specific knowledge less/greater than 5.33) 
3) Path analyses of task complexity, knowledge integration, and effectiveness (2 groups for level of technology-specific knowledge less/greater than 5.33)

We now discuss the results of path analyses of task complexity and knowledge integration as represented by $\mathrm{KI}=\mathrm{f}(\mathrm{CC}, \mathrm{IC}, \mathrm{PR})$.

\begin{tabular}{|c|c|c|c|c|}
\hline \multirow{3}{*}{$\begin{array}{l}\text { Independent } \\
\text { Variable }\end{array}$} & \multicolumn{4}{|c|}{ Dependent Variable: KI } \\
\hline & \multicolumn{2}{|c|}{ Tech-specific knowledge $<5.33$} & \multicolumn{2}{|c|}{ Tech-specific knowledge $>=5.33$} \\
\hline & $\begin{array}{l}\text { Standardized } \beta \\
\text { coefficient }\end{array}$ & t-statistic & $\begin{array}{l}\text { Standardized } \beta \\
\text { coefficient }\end{array}$ & t-statistic \\
\hline $\mathrm{CC}$ & $0.249^{+}$ & 1.693 & 0.147 & 1130 \\
\hline IC & 0.039 & 0.256 & 0.016 & 0.122 \\
\hline PR & 0.175 & 1.168 & -0.240 & -1.862 \\
\hline \multicolumn{5}{|c|}{$\begin{array}{l}\text { Note: } \operatorname{Adj} R^{2}=0.038 ; F=1.614 \\
{ }^{* * *} p<0.001 ;{ }^{* *} p<0.01 ;{ }^{*} p<0.05\end{array}$} \\
\hline
\end{tabular}

Table 20: Path analyses knowledge integration and technology-specific knowledge

From the above table we see that the standardized $\beta$ coefficient between task component complexity and knowledge integration was positive and somewhat significant $(0.249, \mathrm{p}<0.1)$ when the level of technology-specific knowledge was less than 5.33 (indicating the integrative knowledge was general). However when the level of technology-specific knowledge was greater than 5.33, this relationship was not significant. This result seems to indicate that when the integrative knowledge is more general, the impact of component complexity is greater on knowledge integration as compared to the impact when the technology knowledge is more specific.

We note that these results would suggest that it is relatively more difficult to integrate knowledge when the level of technological specificity is high. Special effort 
would be required to share such type of knowledge among the responsible individuals and organizations assigned to these tasks (for example, FEMA courses and training) so that at the time of the emergency event it is easier for them to understand how to quickly apply and use the knowledge for solving a problem.

We now discuss the results of path analyses of task complexity, knowledge integration, and efficiency as represented by Efficiency $=\mathrm{f}(\mathrm{CC}, \mathrm{IC}, \mathrm{PR}, \mathrm{KI})$.

\begin{tabular}{|c|c|c|c|c|}
\hline \multirow{3}{*}{$\begin{array}{c}\text { Independent } \\
\text { Variable }\end{array}$} & \multicolumn{4}{|c|}{ Dependent Variable: Efficiency } \\
\hline & \multicolumn{2}{|c|}{ Tech-specific knowledge $<5.33$} & \multicolumn{2}{|c|}{ Tech-specific knowledge $>=5.33$} \\
\hline & $\begin{array}{l}\text { Standardized } \beta \\
\text { coefficient }\end{array}$ & t-statistic & $\begin{array}{l}\text { Standardized } \beta \\
\text { coefficient }\end{array}$ & t-statistic \\
\hline $\mathrm{CC}$ & $-0.326^{*}$ & -2.534 & 0.004 & 0.033 \\
\hline IC & $-0.456^{\star \star}$ & -3.524 & $-0.260^{+}$ & -1.931 \\
\hline PR & $0.258^{+}$ & 2.006 & 0.159 & 1.181 \\
\hline $\mathrm{KI}$ & $0.407^{\star *}$ & 3.197 & 0.023 & 0.173 \\
\hline $\begin{array}{l}\text { Note: Adj } R^{2} \\
{ }_{\star \star \star} p<0.001\end{array}$ & $\begin{array}{l}14 ; F=6.368^{* * *} \\
<0.01 ;{ }^{*} p<0.0\end{array}$ & & $\operatorname{dj} R^{2}=0.009 ; F=$ & \\
\hline
\end{tabular}

Table 21: Path analyses efficiency and technology-specific knowledge

1) From the above table we see that the standardized $\beta$ coefficient between task component complexity and efficiency was negative and significant $(-0.326, \mathrm{p}<0.05)$ when the level of technology-specific knowledge was less than 5.33. Also the standardized $\beta$ coefficient between task interactive complexity and efficiency was negative and significant $(-0.456, \mathrm{p}<0.01)$ when the level of technology-specific knowledge was less than 5.33. Thus when the task is characterized by interactive complexity and the integrative knowledge is general, there is a negative effect on task effectiveness. When the level of technology-specific knowledge was greater than 5.33, 
the standardized $\beta$ coefficient between task interactive complexity and efficiency was negative and somewhat significant $(-0.260, \mathrm{p}<0.1)$.

These results indicate that both task component complexity and interactive complexity have a negative effect on task efficiency when the integrative knowledge is more general. When the level of technology-specific knowledge is greater than the median value, the impact of component complexity on efficiency is not significant and the impact of interactive complexity on efficiency is reduced. The implications are that, the level of technology-specific knowledge is important to reduce the negative effect of task complexity on efficiency.

2) The standardized $\beta$ coefficient between knowledge integration and efficiency was positive and significant $(0.407, \mathrm{p}<0.01)$ when the level of technology-specific knowledge was less than 5.33. This indicates that the impact of knowledge integration on efficiency depends on the level of technology-specific knowledge used for the task performance -- when the integrative knowledge is more general, then the impact is greater and significant. Hence when dealing with such tasks, it is beneficial to invest in knowledge integration to improve the task outcome in terms of efficiency. This also indicates that "one size does not fit all" and the same degree of knowledge integration need not be applied for all tasks.

3) We reflect on this finding in conjunction with the earlier finding that it is relatively more difficult to integrate specific knowledge when the level of technological specificity is high. As suggested in (2) above we need to consider other types of complementary knowledge management systems when dealing with activities with a level of technologyspecific knowledge. 
We now discuss the results of path analyses of task complexity, knowledge integration, and effectiveness as represented by Effectiveness $=\mathrm{f}(\mathrm{CC}, \mathrm{IC}, \mathrm{PR}, \mathrm{KI})$.

\begin{tabular}{|c|c|c|c|c|}
\hline Independent & \multicolumn{4}{|c|}{ Dependent Variable: Effectiveness } \\
\hline & \multicolumn{2}{|c|}{ Tech-specific knowledge $<5.33$} & \multicolumn{2}{|c|}{ Tech-specific knowledge $>=5.33$} \\
\hline & $\begin{array}{l}\text { Standardized } \beta \\
\text { coefficient }\end{array}$ & t-statistic & $\begin{array}{l}\text { Standardized } \beta \\
\text { coefficient }\end{array}$ & t-statistic \\
\hline $\mathrm{CC}$ & $-0.411^{\star *}$ & -3.042 & 0.089 & 0.670 \\
\hline $\mathrm{IC}$ & $-0.296^{\star}$ & -2.178 & $-0.258^{+}$ & -1.918 \\
\hline PR & 0.147 & 1.089 & -0.015 & -0.109 \\
\hline $\mathrm{KI}$ & $0.427^{\star *}$ & 3.190 & 0.096 & 0.726 \\
\hline
\end{tabular}

Table 22: Path analyses effectiveness and technology-specific knowledge

1) From the above table we see that the standardized $\beta$ coefficient between task component complexity and effectiveness was negative and significant $(-0.411, \mathrm{p}<0.01)$ when the level of technology-specific knowledge was less than 5.33. Also the standardized $\beta$ coefficient between task interactive complexity and effectiveness was negative and significant $(-0.296, \mathrm{p}<0.05)$ when the level of technology-specific knowledge was less than 5.33. When the level of technology-specific knowledge was greater than 5.33, the standardized $\beta$ coefficient between task interactive complexity and effectiveness was negative and somewhat significant $(-0.258, \mathrm{p}<0.1)$.

These results indicate that both task component complexity and interactive complexity have a negative effect on task effectiveness when the integrative knowledge is more general. When the integrative knowledge is technology-specific, the impact of component complexity on effectiveness is not significant and the impact of interactive complexity on effectiveness is somewhat reduced. The implications are that the level of 
technology-specific knowledge is important to reduce the negative effect of task complexity on effectiveness.

2) The standardized $\beta$ coefficient between knowledge integration and effectiveness was positive and significant $(0.427, \mathrm{p}<0.01)$ when the level of technology-specific knowledge was less than 5.33. This indicates that the impact of knowledge integration on effectiveness depends on the level of technology-specific knowledge used for the task performance -- when the integrative knowledge is more general, then the impact is greater and significant. Hence when dealing with such tasks, it is beneficial to invest in knowledge integration to improve the task outcome in terms of effectiveness. This also indicates that "one size does not fit all" and the same degree of knowledge integration need not be applied for all tasks.

\subsubsection{Moderating effects of context-and-technology-specific knowledge}

For each of the two groups of data (context-and-technology-specific knowledge less/greater than median value 5.33), three sets of multiple regression tests were conducted to explore the relationships between task complexity, knowledge integration, and task performance. In the first set, the independent variables were task component complexity, task interactive complexity, and task procedural rigidity, while the dependent variable was knowledge integration. In the second set, knowledge integration was included as the independent variable along with the three constructs for task complexity, while the dependent variable was task efficiency. In the third set of regression testing, the independent variables were the same as the second set, while the dependent variable 
was task effectiveness. (In the following sections, the term "Context-and-technologyspecific knowledge" has been abbreviated to "C-and-T-specific knowledge").

In summary,

1) Path analyses of task complexity and knowledge integration (2 groups for level of C-and-T-specific knowledge less/greater than 5.33)

2) Path analyses of task complexity, knowledge integration, and efficiency (2 groups for level of C-and-T-specific knowledge less/greater than 5.33)

3) Path analyses of task complexity, knowledge integration, and effectiveness (2 groups for level of C-and-T-specific knowledge less/greater than 5.33)

We now discuss the results of path analyses of task complexity and knowledge integration as represented by $\mathrm{KI}=\mathrm{f}(\mathrm{CC}, \mathrm{IC}, \mathrm{PR})$.

\begin{tabular}{|c|c|c|c|c|}
\hline \multirow{3}{*}{$\begin{array}{c}\text { Independent } \\
\text { Variable }\end{array}$} & \multicolumn{4}{|c|}{ Dependent Variable: KI } \\
\hline & \multicolumn{2}{|c|}{ C-and-T-specific knowledge $<5.33$} & \multicolumn{2}{|c|}{ C-and-T-specific knowledge $>=5.33$} \\
\hline & $\begin{array}{l}\text { Standardized } \beta \\
\text { coefficient }\end{array}$ & t-statistic & $\begin{array}{l}\text { Standardized } \beta \\
\text { coefficient }\end{array}$ & t-statistic \\
\hline $\mathrm{CC}$ & 0.185 & 0.816 & 0.071 & 0.449 \\
\hline $\mathrm{IC}$ & -0.271 & -1.075 & 0.067 & 0.412 \\
\hline PR & $0.539^{*}$ & 2.260 & -0.254 & -1.623 \\
\hline $\begin{array}{l}\text { Note: } \operatorname{Adj} R^{2}= \\
* * * p<0.001 ;\end{array}$ & $\begin{array}{l}141 ; F=2.152 \\
<0.05 ;{ }^{*} p<0\end{array}$ & $0<0.1$ & dj $R^{2}=-0.004 ; F=$ & \\
\hline
\end{tabular}

Table 23: Path analyses knowledge integration and context-and-technology-specific knowledge

From the above table we see that the standardized $\beta$ coefficient between task procedural rigidity and knowledge integration was positive and significant $(0.539, \mathrm{p}<$ 0.05) when the level of C-and-T-specific knowledge was less than 5.33. This result 
seems to indicate that when the integrative knowledge is more general, the impact of procedural rigidity is greater on knowledge integration as compared to the impact when the $\mathrm{C}$-and-T knowledge has a higher level of specificity. This finding suggests that integration of specific knowledge is more difficult to accomplish when the levels of specificity of the two types of specific knowledge, context and technology are relatively high.

We now discuss the results of path analyses of task complexity, knowledge integration, and efficiency as represented by Efficiency = $\mathrm{f}(\mathrm{CC}, \mathrm{IC}, \mathrm{PR}, \mathrm{KI})$.

\begin{tabular}{|c|c|c|c|c|}
\hline \multirow{3}{*}{$\begin{array}{l}\text { Independent } \\
\text { Variable }\end{array}$} & \multicolumn{4}{|c|}{ Dependent Variable: Efficiency } \\
\hline & \multicolumn{2}{|c|}{ C-and-T-specific knowledge $<5.33$} & \multicolumn{2}{|c|}{ C-and-T-specific knowledge $>=5.33$} \\
\hline & $\begin{array}{l}\text { Standardized } \beta \\
\text { coefficient }\end{array}$ & t-statistic & $\begin{array}{l}\text { Standardized } \beta \\
\text { coefficient }\end{array}$ & t-statistic \\
\hline $\mathrm{CC}$ & 0.149 & 0.739 & $0.278^{+}$ & 1.809 \\
\hline $\mathrm{IC}$ & $-0.804^{\star *}$ & -3.528 & $-0.352^{*}$ & -2.245 \\
\hline PR & 0.301 & 1.270 & 0.020 & 0.126 \\
\hline $\mathrm{KI}$ & 0.120 & 0.582 & 0.095 & 0.623 \\
\hline \multicolumn{5}{|c|}{$\begin{array}{l}\text { Note: } \text { Adj } R^{2}=0.342 ; F=3.723^{\star} \\
{ }^{* * *} p<0.001 ;{ }^{* \star} p<0.05 ;{ }^{*} p<0.01 ;{ }^{+} p<0.1 \quad \text { Adj } R^{2}=0.068 ; F=1.789\end{array}$} \\
\hline
\end{tabular}

Table 24: Path analyses of task efficiency and context-and-technology-specific knowledge

From the above table we see that the standardized $\beta$ coefficient between task component complexity and efficiency was positive and somewhat significant $(0.278, \mathrm{p}<$ 0.1) when the level of C-and-T-specific knowledge was greater than 5.33. This result indicates that when the level of context-and-technology-specific knowledge is relatively high, task component complexity has a positive impact on efficiency.

The standardized $\beta$ coefficient between task interactive complexity and efficiency was negative and significant $(-0.804, \mathrm{p}<0.01)$ when the level of $\mathrm{C}$-and-T-specific 
knowledge was less than 5.33. Also the standardized $\beta$ coefficient between task interactive complexity and efficiency was negative and significant $(-0.352, \mathrm{p}<0.05)$ when the level of C-and-T-specific knowledge was greater than 5.33. These results indicate that when the integrative knowledge is both context and technology specific, the negative impact of task interactive complexity on efficiency is reduced.

Overall, these results are also in conformity with our earlier findings that the levels of context-specific and technology-specific knowledge are important to neutralize the impacts of task complexity in general on the task efficiency.

We now discuss the results of path analyses of task complexity, knowledge integration, and effectiveness as represented by Effectiveness $=\mathrm{f}(\mathrm{CC}, \mathrm{IC}, \mathrm{PR}, \mathrm{KI})$.

\begin{tabular}{|c|c|c|c|c|}
\hline \multirow{3}{*}{$\begin{array}{c}\text { Independent } \\
\text { Variable }\end{array}$} & \multicolumn{4}{|c|}{ Dependent Variable: Effectiveness } \\
\hline & \multicolumn{2}{|c|}{ C-and-T-specific knowledge $<5.33$} & \multicolumn{2}{|c|}{ C-and-T-specific knowledge $>=5.33$} \\
\hline & $\begin{array}{l}\text { Standardized } \beta \\
\text { coefficient }\end{array}$ & t-statistic & $\begin{array}{l}\text { Standardized } \beta \\
\text { coefficient }\end{array}$ & t-statistic \\
\hline $\mathrm{CC}$ & 0.153 & 0.674 & 0.133 & 0.842 \\
\hline $\mathrm{IC}$ & $-0.515^{+}$ & -2.009 & $-0.344^{*}$ & -2.139 \\
\hline PR & -0.092 & -0.346 & 0.020 & 0.126 \\
\hline $\mathrm{KI}$ & 0.298 & 1.282 & -0.014 & -0.091 \\
\hline $\begin{array}{l}\text { Note: Adj } R^{2} \\
* * * p<0.001\end{array}$ & $\begin{array}{l}67 ; F=2.049 \\
<0.05 ;{ }^{*} p<0 .\end{array}$ & & $\operatorname{Adj} R^{2}=0.018$ & \\
\hline
\end{tabular}

Table 25: Path analyses task effectiveness and context-and-technology-specific knowledge

The standardized $\beta$ coefficient between task interactive complexity and effectiveness was negative and somewhat significant $(-0.515, \mathrm{p}<0.1)$ when the level of C-and-T-specific knowledge was less than 5.33. Also the standardized $\beta$ coefficient between task interactive complexity and effectiveness was negative and significant (- 
$0.344, \mathrm{p}<0.05)$ when the level of $\mathrm{C}$-and-T-specific knowledge was greater than 5.33.

These results indicate that at relatively higher levels of context-and-technology-specific knowledge, the negative impact of task interactive complexity on effectiveness is reduced.

Again, these results are in conformity with our earlier findings that the levels of context-specific and technology-specific knowledge are important to neutralize the impacts of task complexity in general on the task effectiveness.

\subsubsection{Summary of moderating effects hypotheses}

We replicate below the hypotheses stated earlier for the research model (Chapter 3) for our expectations regarding the relationships between integration of specific knowledge and task performance. On the basis of the analyses and results discussed in the prior sections, we summarize our findings in the following table.

\begin{tabular}{|c|l|l|}
\hline & \multicolumn{1}{|c|}{ Hypothesis } & \multicolumn{1}{|c|}{ Research Finding } \\
\hline H3a & $\begin{array}{l}\text { Integration of context-specific knowledge is } \\
\text { positively associated with task effectiveness }\end{array}$ & $\begin{array}{l}\text { Strong support for both general and } \\
\text { context-specific knowledge }\end{array}$ \\
\hline H3b & $\begin{array}{l}\text { Integration of technology-specific knowledge is } \\
\text { positively associated with task effectiveness }\end{array}$ & Strong support for general knowledge \\
\hline H3c & $\begin{array}{l}\text { Integration of context-and-technology-specific } \\
\text { knowledge is positively associated with task } \\
\text { effectiveness }\end{array}$ & Results were not significant \\
\hline H4a & $\begin{array}{l}\text { Integration of context-specific knowledge is } \\
\text { positively associated with task efficiency }\end{array}$ & $\begin{array}{l}\text { Strong support for context-specific } \\
\text { knowledge }\end{array}$ \\
\hline H4b & $\begin{array}{l}\text { Integration of technology-specific knowledge is } \\
\text { positively associated with task efficiency }\end{array}$ & Strong support for general knowledge \\
\hline H4c & $\begin{array}{l}\text { Integration of context-and-technology-specific } \\
\text { knowledge is positively associated with task } \\
\text { efficiency }\end{array}$ & Results were not significant \\
\hline
\end{tabular}

Table 26: Summary of moderating effects hypotheses 


\subsection{Mediating effect of knowledge integration}

As explained in Section 3.6, the mediating variable (integration of specific knowledge) explains how or why the predictor or independent variable (task complexity dimensions -- component, interactive, procedural rigidity) affects the criterion or dependent variable (task performance dimensions -- efficiency, effectiveness). As shown in the figure below, there are two paths which feed into the outcome or dependent variable: the direct impact of the independent variable (path c) and the impact of the mediating variable (path b). In addition, there is also the path from the independent variable to the mediator (path a) which we consider.

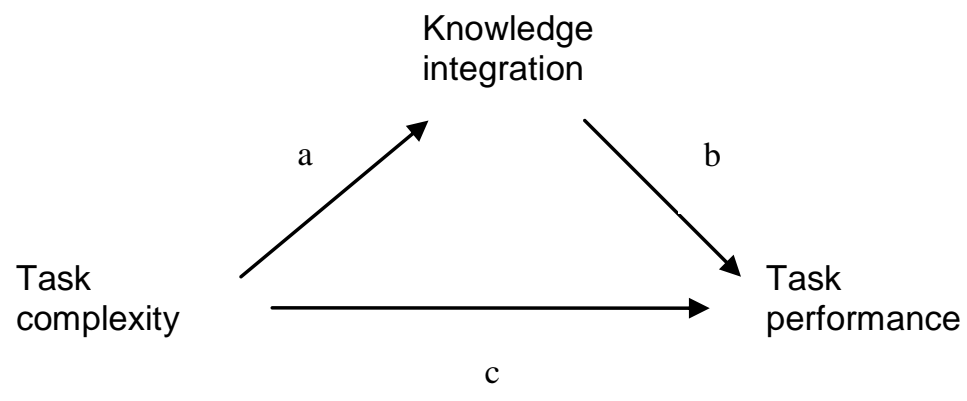

Figure 15: Mediating effect of knowledge integration

As explained in Section 5.6 (Summary of path analyses), we ran a series of regression models which allow us to test the linkages of the mediational models. To test for mediation, we look for the following conditions to be satisfied (Baron \& Kenny, 1986): First, the independent variable must affect the mediator; second, the independent variable must affect the dependent variable; third, the mediating variable must affect the dependent variable. 
An approximate significance test for the indirect effect of the independent variable on the dependent variable via the mediator was provided by Sobel (1982). The path from the independent variable to the mediator is denoted as $a$ and its standard error is $s_{a}$; the path from the mediator to the dependent variable is denoted as $b$ and its standard error is $s_{b}$. The formula for the standard error of the indirect effect or $a b$ is given by:

$$
\sqrt{\left(b^{2} s_{a}^{2}+a^{2} s_{b}^{2}+s_{a}^{2} s_{b}^{2}\right)}
$$

The significance of the indirect effect is given by:

$$
\mathrm{T}_{\mathrm{ab}}=\mathrm{ab} / \mathrm{s}_{\mathrm{ab}}
$$

Using this formulation, we derived the $\mathrm{T}$ values for the indirect effect between task component complexity and efficiency as 1.59 and the indirect effect between task component complexity and effectiveness as 1.77 . These results indicate that the mediating effect of knowledge integration on the relationship between task component complexity and task efficiency is significant. Also the mediating effect of knowledge integration on the relationship between task component complexity and task effectiveness is significant. The mediating effects of knowledge integration on the relationships between task interactive complexity and performance, and between procedural rigidity and performance were found to be not significant. In summary the following two hypotheses were supported:

H14a) Integration of specific knowledge mediates the relationship between task component complexity and efficiency.

H15a) Integration of specific knowledge mediates the relationship between task component complexity and effectiveness. 


\section{Discussion}

The original premise of this dissertation work was first to frame the inherent characteristics of emergency management tasks in terms of task component complexity, interactive complexity, and procedural rigidity. Based on prior research studies and our empirical observations, we proposed that organizational systems that depended on such tasks are prone to failure. This further motivated us to investigate the influence of knowledge integration as a particular knowledge management strategy on the dimensions of emergency task performance which we identified as task efficiency and effectiveness. In this study we also examine the three types of specific knowledge: context, technology, and context-and-technology for analysis of knowledge integration.

Unless otherwise cited, the examples and anecdotes in this section are drawn from field observations and meeting notes at the Miami-Dade EOC and transcripts of interviews and discussions with emergency officials and managers made by the author(s) and others in the research team over a two-year period. Researchers spent 4 to 6 hours/ day at the Miami-Dade EOC at any one time as invited observers during simulation and practice drills or actual activations in preparation for disaster events (for example Hurricane/Tropical Storm Ernesto in 2006). Depending on the nature of the event, observations were usually made from different vantage points as the events unfolded to cover the appropriate breadth and depth for the research. These observations were discussed by the members of the research team with the EOC branch managers and officials for relevance and clarity of meaning. Examples are also drawn from the EOC/EOM archives such as Incident Action Plans and Situation reports and SOPs. 


\subsection{Relationship between task complexity, knowledge integration and performance}

Our conceptualization of knowledge integration is based on the extent to which a specific area of knowledge is shared and applied across the organization that enables its members to better perform their tasks. We believe that this work provides one of the first research studies in proposing that knowledge integration in emergency management operations is necessary for improving the effectiveness and efficiency of the typical tasks undertaken in emergency operations centers. We have also demonstrated that there are three types of specific knowledge that are required in this work. Prior research in emergency management has typically focused on coordination mechanisms, technical elements, and behavioral factors -- mostly originating from a motivation to understand the vagaries of the question "what went wrong?" in adverse and unpredictable situations. Through this knowledge-based view of emergency management, we sought to understand the inherent nature of emergency tasks and how the integration of specific knowledge is essential for successful emergency management.

Overall, the results support our main propositions as depicted in the research model. Our research model seems stable and we have been able to support many of the hypotheses that we posited in order to address our research questions. We did the preliminary analyses on the partial dataset (about 70 responses) which included testing for reliability, validity, factor analysis, regression testing, control variables testing, and non-response bias tests. Similar tests on the complete dataset at the end of the data collection phase yielded results that in general were comparable to the prior results.

At the same time we have had some surprises and we have gained new insights based on our results and observations which we believe will further extend the theory 
related to task complexity, knowledge integration and emergency management performance. We attempted to explain the incongruity between our expectations and the results in various ways which included discussions with emergency managers experienced in specific areas of operations, observations of training drills and simulations at the EOC, and reviewing the notes and recordings from previous disaster incidents resulting in the activation of the EOC.

The results provide adequate support for the first two hypotheses about the relationship between task component complexity and task effectiveness and between task interactive complexity and task effectiveness. We had proposed that these two dimensions of task complexity will influence task effectiveness negatively expecting that a higher degree of task complexity will tend to reduce the task effectiveness.

However we were surprised with the results for the third dimension of task complexity, procedural rigidity, which indicate that a higher degree of procedural rigidity will tend to improve the task effectiveness. To explain this incongruity with our original hypothesis, we reflect upon the following quote from one of the senior emergency managers at the EOC:

"What I was trying to get was the fact that typically, EOC personnel, those assigned to sit in the Operations and especially members of our staff have all been trained under the National Incident Management System (NIMS) and Incident Command System (ICS) and understand the importance of following the structure of the two and also understand the value of a Incident Action Plan (IAP)." 
We theorize that EOC personnel are specially trained and prepared to handle the tasks that have been planned along the guidelines as provided by the (Incident Command System) $\mathrm{ICS}^{7}$. Hence it is plausible that those tasks which are particularly complex in terms of procedural rigidity (time rigidity and/or sequence rigidity) are planned in advance during the disaster preparation phase and the associated personnel and organizations notified and trained accordingly. This makes the activities and the interdependencies of these tasks less subtle, transparent, and therefore easier to foretell and execute during the emergency incident.

For example, such plans are laid out describing detailed steps, processes, dependencies, and resource and personnel requirements in the Standard Operating Procedures (SOP) for "Transportation ESF \# 1". According to the SOP, "ESF-1 provides for and coordinates the emergency transportation needs of Miami-Dade County and its municipalities during the preparedness, response and recovery phases of an incident or disaster. These needs include but are not limited to the following: Assist in the evacuation of vulnerable populations; assist the Public Safety Branch in traffic control..." The tasks outlined in ESF-1 require the coordination not only among the three functional branches, but also eleven other agencies which include Miami-Dade Transit, Florida DOT, Florida National Guard, Miami-Dade Aviation, Miami-Dade Public Schools, and others. The initiation of the evacuation tasks depend on several factors such as tropical storm force winds, flooding, debris collection, and so on. The task responsibilities also include evacuation support systems such as bridge lockdown and

\footnotetext{
${ }^{7}$ The ICS is a particular approach to management of highly reliable temporary organizations that has been employed by many public safety professionals in emergency response organizations. It has enabled the organizations to be flexible and reliable in complex and volatile task environments.
} 
traffic signal reprogramming procedures. Such a task would be categorized as having a high degree of procedural rigidity because of the stringent requirements for timing and sequence of activities as well as coordination between the team members. Through elaborate planning, preparation, and practice, the Miami-Dade EOC is able to execute such tasks successfully during disaster situations.

We were able to observe a demonstration of this aspect of emergency response during the drill and practice sessions of the EOC functional exercises. These sessions gave the EOC managers and the participants the opportunity to test, exercise, and practice their skills and coordination requirements for the tasks. The unexpected outcome in our research would underscore the importance of the principles of the ICS and its applicability to the improvement of emergency management performance. It further whets our academic interest in our conceptual idea regarding the adaptability of highreliability organizations when dealing with complex systems.

\subsection{Implications of moderating effects of specific knowledge}

We present a theoretical model of integration of specific knowledge touching upon the classification of types of knowledge and also the interrelationships between these types. Based on prior literature (Sabherwal \& Becerra-Fernandez 2005), our research model has proposed three types of specific knowledge in the realm of emergency management: context-specific, technology-specific, and context-andtechnology-specific.

We have discussed the detailed analyses for the moderating effects of specific knowledge on the relationships between task complexity, knowledge integration, and task 
performance in Section 5.8. We present below two perspectives of the same analyses which is a comprehensive view involving task efficiency, task effectiveness, contextspecific knowledge, and technology-specific knowledge. Besides giving us a basis for further reflection on the findings, these perspectives serve to reveal some interesting facets of our research which otherwise would not be easily discerned. The perspective in Table 27 is context and technology specific knowledge viewed within task performance dimensions of efficiency and effectiveness.

\begin{tabular}{|c|c|c|c|c|c|c|c|c|}
\hline \multirow{4}{*}{$\begin{array}{l}\text { Independent } \\
\text { Variable }\end{array}$} & \multicolumn{8}{|c|}{ Dependent Variables } \\
\hline & \multicolumn{4}{|c|}{ EFFICIENCY } & \multicolumn{4}{|c|}{ EFFECTIVENESS } \\
\hline & \multicolumn{2}{|c|}{ Context-specific } & \multicolumn{2}{|c|}{$\begin{array}{l}\text { Technology- } \\
\text { specific }\end{array}$} & \multicolumn{2}{|c|}{ Context-specific } & \multicolumn{2}{|c|}{$\begin{array}{l}\text { Technology- } \\
\text { specific }\end{array}$} \\
\hline & Low & High & Low & High & Low & High & Low & High \\
\hline & & & & & & & & \\
\hline $\mathrm{CC}$ & -0.062 & -0.185 & $-0.326^{\star}$ & 0.004 & 0.034 & $-0.379^{\star \star}$ & $-0.411^{\star \star}$ & 0.089 \\
\hline IC & $-0.492^{\star \star}$ & $-0.283^{*}$ & $-0.456^{\star \star}$ & $-0.260^{+}$ & $-0.327^{+}$ & $-0.210^{+}$ & $-0.296^{*}$ & $-0.258^{+}$ \\
\hline PR & $0.320^{+}$ & -0.187 & $0.258^{+}$ & 0.159 & -0.098 & $0.229^{*}$ & 0.147 & -0.015 \\
\hline $\mathrm{KI}$ & 0.008 & $0.322^{* *}$ & $0.407^{\star *}$ & 0.023 & $0.315^{\star}$ & $0.325^{* *}$ & $0.427^{\star *}$ & 0.096 \\
\hline
\end{tabular}

Table 27: Context and technology specific knowledge within task performance

We present our findings of the moderating effects of specific knowledge on the relationship between task complexity, knowledge integration, and task performance from the perspective of task performance. This perspective enables us to view the moderating effects of context-specific and technology-specific knowledge on task efficiency on one side and on task effectiveness on the other. We clarify the terminology for levels of specific knowledge as follows: Low level and high level of specific knowledge represent 
a level of the specific knowledge less than the median value (5.33) and greater than or equal to the median value (5.33) respectively.

We note that in general the negative impact of task complexity on task efficiency is reduced by a higher level of specific knowledge: context-specific and technologyspecific. The impact of procedural rigidity on efficiency is greater for lower levels of specific knowledge (or general knowledge). However there is a difference in the relationship between knowledge integration and efficiency for the different levels of each type of specific knowledge. The impact of knowledge integration on efficiency is greater for higher levels of context-specific knowledge, and lower levels of technology-specific (or general) knowledge. The relationship between knowledge integration and efficiency is more pronounced in tasks when the integrative knowledge used is context-specific knowledge. At the same time, the relationship between knowledge integration and efficiency is more pronounced in tasks with relatively lower levels of technology-specific knowledge. Management needs to be aware of the extent and type of specific knowledge used for the task since performance can be ameliorated through the use of different types of integrative knowledge.

The impact of component complexity on effectiveness is different for each type of specific knowledge. The impact of component complexity on effectiveness is reduced by lower level of context-specific and higher levels of technology-specific knowledge. In general the moderating effects of specific knowledge on interactive complexity and effectiveness are similar. The moderating effect of technology-specific knowledge on procedural rigidity is not significant, but has a positive impact on effectiveness for higher levels of context-specific knowledge. The impact of knowledge integration on 
effectiveness is greater when higher levels of context-specific knowledge were used, and lower levels of technology-specific (or more general) knowledge were used.

From the standpoint of practical implications, the findings suggest that potentially higher benefits can be gained by being selective in knowledge integration strategies for tasks that require different levels of context-specific knowledge. Depending on the complexity characteristics, some tasks may require a particularly higher level of contextspecific knowledge whereas more general knowledge is required for accomplishing other tasks. This is evident from the example given by a senior level emergency coordinator about locking down drawbridges in preparation for a hurricane event, which we would classify as being high in its degree of component complexity requiring a relatively high level of context-specific knowledge:

"There are 23 movable bridges that we are responsible for which are owned by five organizations -- CSX Railroad, Florida East Coast Railroad, Florida DOT, Miami-Dade County, and Town of Bay Harbor Islands. It takes approximately 6 to 8 hours to lock down and secure all the bridges and the task needs to be coordinated between ten organizations. There may be ships in the river at the time and some ships have unique requirements like they need a high tide... so the timing is critical! If there is a problem then they notify (me)... There was a case once when one of the motors for a bridge was burnt out and they needed to bring in a crane to close the bridge...". 
The perspective in Table 28 is task performance dimensions viewed within specific knowledge types context-specific and technology-specific.

\begin{tabular}{|c|c|c|c|c|c|c|c|c|}
\hline Independent & \multicolumn{8}{|c|}{ Dependent Variables: Efficiency and Effectiveness } \\
\hline & \multicolumn{4}{|c|}{ CONTEXT-SPECIFIC } & \multicolumn{4}{|c|}{ TECHNOLOGY-SPECIFIC } \\
\hline & \multicolumn{2}{|c|}{ Efficiency } & \multicolumn{2}{|c|}{ Effectiveness } & \multicolumn{2}{|c|}{ Efficiency } & \multicolumn{2}{|c|}{ Effectiveness } \\
\hline & Low & High & Low & High & Low & High & Low & High \\
\hline CC & -0.062 & -0.185 & 0.034 & $-0.379^{* *}$ & $-0.326^{*}$ & 0.004 & $-0.411^{* *}$ & 0.089 \\
\hline IC & $-0.492^{* *}$ & $-0.283^{*}$ & $-0.327^{+}$ & $-0.210^{+}$ & $-0.456^{\star *}$ & $-0.260^{+}$ & $-0.296^{*}$ & $-0.258^{+}$ \\
\hline PR & $0.320^{+}$ & -0.187 & -0.098 & $0.229^{*}$ & $0.258^{+}$ & 0.159 & 0.147 & -0.015 \\
\hline $\mathbf{K I}$ & 0.008 & $0.322^{* *}$ & $0.315^{\star}$ & $0.325^{\star \star}$ & $0.407^{\star \star}$ & 0.023 & $0.427^{* *}$ & 0.096 \\
\hline
\end{tabular}

Table 28: Task performance within specific knowledge

We present our findings of the moderating effects of specific knowledge on the relationship between task complexity, knowledge integration, and task performance from the perspective of specific knowledge types. This perspective enables us to view the moderating effects of specific knowledge on task efficiency and effectiveness with context-specific knowledge on one side and technology-specific knowledge on the other. We clarify the terminology for levels for specific knowledge as follows: Low level and high level of specific knowledge represent a level of the specific knowledge less than the median value (5.33) and greater than or equal to the median value (5.33) respectively.

We point out an important consideration when dealing with emergency tasks that are characterized by a particularly high degree of component complexity. We use the analogy of "modularity" to explain a flexible design as a better alternative when the degree of component complexity in a task is high. Since when the knowledge is highly 
context-specific it has a greater impact on effectiveness, the components should be more modular or general purpose to reduce this impact. In other words, the personnel and the organizations responsible for the task should try to share common knowledge and communicate across organizational or functional barriers to get the job done. The "stickiness" of the context-specific knowledge is important to correct the negative effects of complexity; for example by using more general knowledge to understand the other person's perspectives while focusing on the context-specific knowledge to solve a problem.

The Miami-Dade EOC is organized along the guidelines provided by ICS. One of the management characteristics of the ICS is modular organization, an organizational structure which develops in a top-down modular fashion based on the size and complexity of the incident (Anderson et al., 2004). When situational complexity increases, the organization is able to respond by expanding from the top down adding functional responsibilities as required. Communication and coordination is achieved by a governance structure which involves all three functional branches (infrastructure, human services and public safety). As explained by a senior emergency manager:

"Mother nature does not read the rule book! The planned activities in a task change, all agencies have to change to get back on track so everyone needs to react the same way. The Lead Agency is responsible for a given task, the Duty Officer (DO) is the central point to be notified, which rotates, and there is also a manager on call..."

In general, the level of technology-specific knowledge is important to reduce the negative effect of task complexity on the efficiency and the opportunity to introduce knowledge 
management systems (technologies as well as processes) when dealing with high complexity tasks needs to be considered.

For example, the Miami-Dade EOC is developing the Emergency Incident Management GIS Tool along with the Miami-Dade Enterprise Technology Services Department (ETSD). This system will enable information sharing with many municipalities and partner agencies in disaster situations (including hurricane, fire, mass migration) in terms of critical facilities and their locations. It is designed to be a webbased application which can be used anywhere and is easily expandable for additional data and functionality. The GIS Manager states:

"The purpose of this technology is to make available as much information as possible about the location and surrounding areas of where an emergency incident has occurred in order to give the emergency managers the ability to assess situations in a timely and effective manner. It is simple and user-friendly and provides accurate, reliable, and linked data...".

In the frameworks below we summarize the knowledge areas classified according to the type of specificity at the EOC and the findings that we have discussed about the moderating effects of the levels of specific knowledge on the relationship between task complexity and task performance. We have used the original framework described by Sabherwal and Becerra-Fernandez (2005) for knowledge specificity as the basis for these analyses where each of the four quadrants represents the combination of low/high specificity of contextual knowledge and low/high specificity of technical knowledge. 
The quadrant where the levels of both types of specific knowledge are low represents general knowledge.

Key: $\quad$ CC - Task Component Complexity

IC - Task Interactive Complexity

PR - Task Procedural Rigidity

KI - Knowledge Integration

In Figure 16, we present the conceptual framework for the moderating effects of specific knowledge on task efficiency. In summary, the positive impact of knowledge integration on efficiency is significant when the integrative knowledge is contextspecific. To reduce the negative impact of interactive complexity on task efficiency, the integrative knowledge should be both context and technology specific. To reduce the negative impact of component complexity on task efficiency, the integrative knowledge should be technology-specific.

In Figure 17, we present the conceptual framework for the moderating effects of specific knowledge on task effectiveness. In summary, the positive impact of knowledge integration on effectiveness is significant when the integrative knowledge is contextspecific or general. However, this impact is more pronounced for the quadrant where the integrative knowledge is context specific (denoted by*). The positive impact of procedural rigidity on task effectiveness is significant when the integrative knowledge is context-specific. To reduce the negative impact of interactive complexity on task effectiveness, the integrative knowledge should be technology-specific. To reduce the negative impact of component complexity on task effectiveness, the integrative knowledge should be technology-specific. 


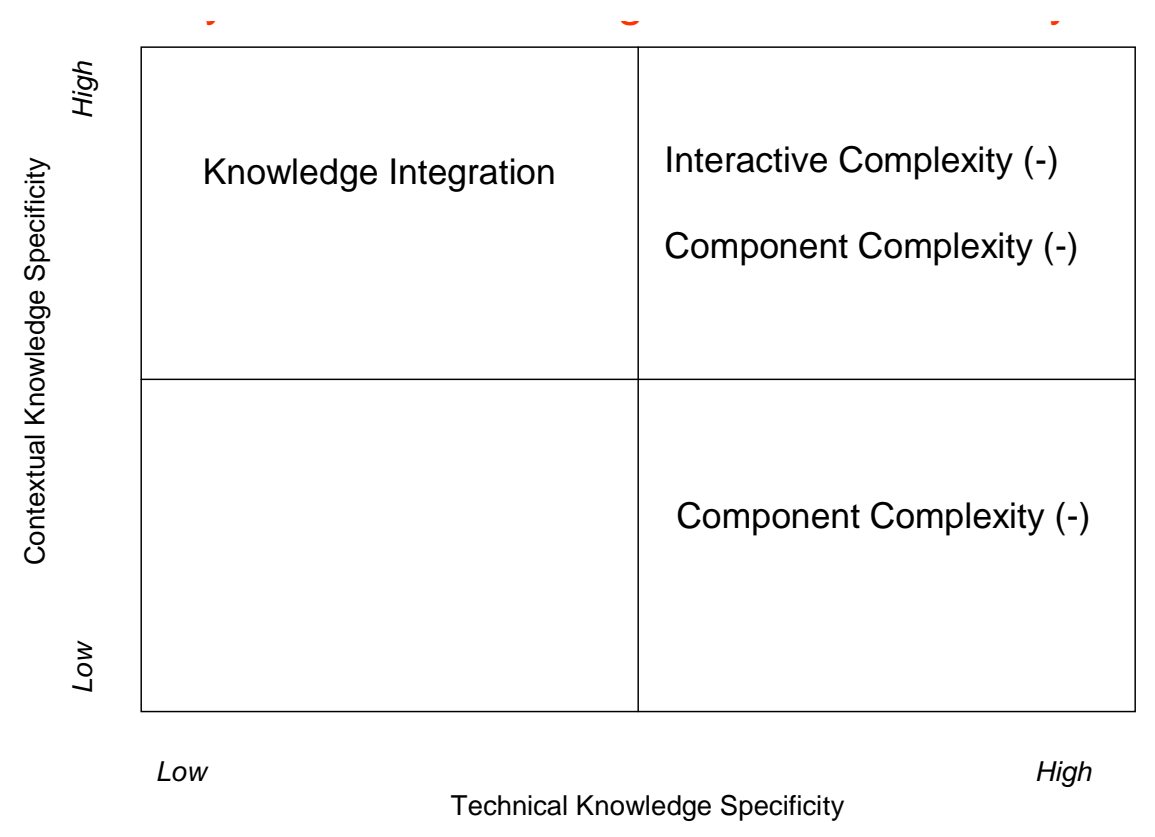

Figure 16: Conceptual framework moderating effects on efficiency (adapted from Sabherwal \& Becerra-Fernandez 2005, p. 302)

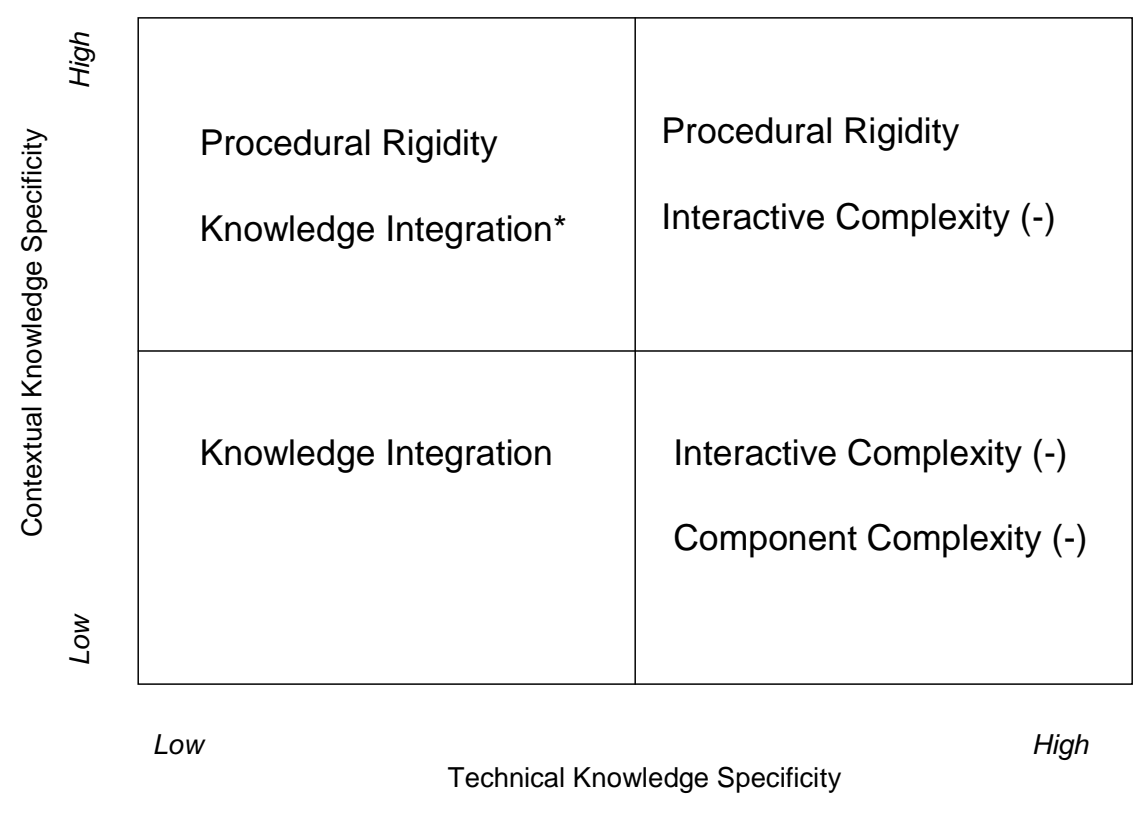

Figure 17: Conceptual framework moderating effects on effectiveness (adapted from Sabherwal \& Becerra-Fernandez 2005, p. 302) 


\subsection{Knowledge integration at Emergency Operations Center}

When reflecting upon the challenges of an emergency response organization, one might wonder how it could be possible to go through a disaster situation if the MiamiDade EOC did not exist. The EOC functioning as the "coordinating organization" makes it possible for all the individuals, private firms, and government agencies to come together and start functioning very quickly to respond to a particular disaster. To a certain extent, well established policies and procedures enable the smooth working of the EOC. For example, activation levels can be ramped up from three to one based on the severity level of the disaster -- three indicating a lower level of severity and one indicating the highest severity. For a lower level of severity, the urgency is understandably less -- so fewer individuals would be called in physically for the activation and many more would be "on call" (or stand-by status). For the highest severity level, all the participants would be expected to be present at the EOC.

We have been able to demonstrate that many of the EOC tasks are inherently difficult and this study has proposed a methodology for assessing the dimension and degree of complexity of the tasks in terms of component complexity, interactive complexity, and procedural rigidity. Further, we have shown that knowledge integration is the means to turn things around so that the tasks can be completed successfully. Most importantly, the structure, the technology, and the resources at the EOC provide the necessary conditions and the environment for effective knowledge integration.

Our findings in the empirical study and field observations allow us to offer further insights about knowledge integration at the Miami-Dade EOC. Although the integration of technology-specific knowledge provides the required basis for solving the problems in 
the emergency tasks, the integration of context-specific knowledge is critical for the successful execution of the tasks. In other words, the integration of context-specific knowledge is required over and above the integration of technology-specific knowledge for working emergency management tasks failing which the task will not be successfully completed.

We have defined knowledge integration as the extent to which the specific area of knowledge is shared and applied across the organization and enables its members to better perform their tasks. We argue that the nature of planning, preparation and execution of knowledge integration for each of the two types of specific knowledge are different and contingent upon the disaster event that the EOC is responding to.

Discussions with one of the branch managers at the EOC helps further clarify this notion. He explained that the Storm Action Lead Time (SALT) is an electronic checklist of tasks that have evolved over time based on the experiences of past incidents.

"SALT deals with the 'known'. There may be situations which nobody can think of before hand. Preparation and planning goes during the time of the year when it is not the hurricane season. Previous year tasks are evaluated, lessons learned are studied, and built in for the next year... this is a constant cycle. But every scenario can be different! So we need to be resilient. Storms can speed up, slow down, change directions ... always changing. For our operations we have different considerations depending on whether it is mid-week or week-end..." During the months which are not part of the Hurricane season (typically November through May), the EOC professionals are engaged in planning and review activities. This is the time for activities such as reviewing previous plans and procedures, 
modifying them as needed by newer experiences and lessons learned, designing and developing new technologies, and establishing new feeds to information systems. The model for integration of technology-specific knowledge incorporates such activities which prepare the foundation for the next Hurricane season (typically June through November). Based on this body of (integrated) knowledge, the EOC is now prepared to handle the emergency events in the coming season. For this purpose the next stage is the integration of context-specific knowledge which depends on the nature and location of a particular event.

Thus we highlight two important contingent aspects of integration of specific knowledge other than the type of the specific knowledge itself. First, the integration of specific knowledge includes a component for technology-specific knowledge which is driven by the organizational and political initiatives to plan and prepare for emergency events. It is characterized by rigorous planning and review concerned with systematized methodologies. Second, it includes an element of improvisation that can change over time, based on experience and on the particular organizational characteristics (contextspecific) and depends on the emergency response criteria for new events. Since some of these tasks might not have been required earlier, it often entails creative dynamism and spontaneity to deal with the new event.

The best professionals know much more than what they can easily express through written or oral communication (Schon 1983). Our empirical observations lead us to believe that to meet the challenges of their work at the EOC, the emergency professionals in being "reflective practitioners" rely not only on what they learned in training institutions, but on improvisation which they gain through their experience and 
reflection. In our attempt to conceptualize and explain this vital element of emergency management, we adopted the notion of integration of context-specific knowledge. This represents the capacity of the emergency manager to quickly grasp the nuances of an unfamiliar situation, reflect upon past situations, communicate with other officials and agencies, and the cumulative effort to bring the past knowledge and experience to bear on the unique task.

According to Donald Schon (p. 242):

"...managers live in an organizational system which may promote or inhibit reflection-in-action. Organizational structures are more or less adaptable to new findings, more or less resistant to new tasks. ... The scope and direction of a manager's reflection-in-action are strongly influenced, and may be severely limited, by the learning system of the organization in which he practices".

Our results suggest overall that the Miami-Dade EOC organizational structure, managerial inter-relationships, and technological infrastructure provide the coordinating capabilities that enable effective knowledge integration. In this regard, the Miami-Dade EOC environment offers a fertile organizational learning system to the emergency managers allowing them to be creative and resourceful amidst the constrained and harsh limitations of emergency events.

\subsection{Mediation of knowledge integration}

In this study we view knowledge integration as an important knowledge management strategy which creates a generative capability, allowing the Miami-Dade 
EOC to organize its structural, managerial, technological, and contextual expertise into integrated sets of decision-making processes.

The results indicate that support was found for the mediating effect of knowledge integration on the relationship between task component complexity and each of the two dimensions of task performance: task efficiency and task effectiveness. Thus, integration of specific knowledge plays an important role in improving the task efficiency and task effectiveness of emergency tasks that are characterized by component complexity (number of personnel, organizations, machines, computer systems, etc.). In other words, the Miami-Dade EOC can reduce the negative impact of task component complexity on performance by knowledge integration.

We note the comments of a senior emergency coordinator when he narrated the key points of Initial Damage Assessment (IDA) and Rapid Impact Assessment Team (RIAT) immediately after an emergency incident such as a hurricane and how personnel from many different organizations need to interact -- which requires the integration of various areas of knowledge they represent:

"Several areas of specific knowledge are required to be used to make an assessment of how severe the impact is. The people who are called for activation are senior enough in their organizations to make their own decisions. There is a high level of trust...Debris assessment is done. Technology-specific knowledge involves deciding the right equipment, how to operate the equipment, how to prevent possible damage to other equipment (e.g. FPL); engineers need to decide what kind of damage was experienced, how many roofs were damaged, whether they can be immediately repaired, and so on. Rain can be an important factor 
(context-specific)... if there is flooding, then the hydrological experts need to decide how quickly the water can be drained, since if the water stays too long it can cause interior damage. Further, if the ground is saturated, this will lead to flooding. The situation can be further complicated if there is any hazardous material involved...Boil water orders may need to be given based on health and medical considerations".

We have discussed earlier that knowledge integration does have a strong positive impact on task efficiency as well as task effectiveness. However, the support for the mediating effects of knowledge integration on the relationships for task interactive complexity and procedural rigidity were not as strong as expected. A possible explanation is that there may be other factors besides knowledge integration that may be important mediators for the effects of task interactive complexity, procedural rigidity on task efficiency and effectiveness. When the EOC is dealing with complex interactive tasks (uncertain and inter-related), a possible influence they need to contend with is the political pressure and the related media coverage of the events as they unfold. Political pressures stemming from political goals and agendas might tend to intervene with the EOC operations and in some cases might be imposed on them. A senior emergency manager explained that the EOC personnel are trained under the National Incident Management System (NIMS) and the Incident Command System (ICS). He continued: "...County bureaucrats on the other hand try to deal with emergencies similar to how they run government on a day-to-day basis. The two are not the same. Case studies have shown that the system (NIMS/ICS) does not fail...it fails because people try to deviate or change NIMS/ICS for their own reasons. When politics 
come into play, it does indeed pull EOC personnel away from the objectives set forth in the IAP".

Overall, we see that the performance measures of emergency management tasks (efficiency and effectiveness) may rest in part to the extent to which the specific areas of knowledge required in the task are successfully integrated. 


\section{Conclusions}

\subsection{Research contributions}

The proposed research study has several contributions to academic researchers as well as practitioners. Although a rich body of literature is available in emergency management studies and knowledge management, little research is found on how to combine both in an effort to understand how knowledge management initiatives can improve emergency management. This work attempts to integrate the two bodies of emerging literature in emergency management studies and knowledge management. We believe this "cross-fertilization" of research streams is important to provide scholars a more balanced and comprehensive view and strategically address the persistent issues that are encountered in this field.

Hardly any studies were found which analyze task complexity and examine relationships to knowledge integration and task performance. One of the major contributions of this work will be the "unbundling" of the concept of task complexity in the realm of emergency management. We view this as an important concept, which having understood will allow us to develop further understanding of involved issues. Emergency operations are organized around tasks and hence the task becomes the nexus for their operations and useful as a unit of analysis. This study will propose a useful method to analyze and measure task complexity and its dimensions. By building on the general task complexity concepts, research on emergency management may provide new insights that will contribute to the general task complexity literature and to emergency 
task management practices. We expect to open further avenues for prospective theoretical and empirical research in this area.

Overall, this work intends to develop and test a model to enrich our understanding of the problems indicated in earlier sections. The concepts developed and explained in this work are intended to shed light on the link between task complexity, knowledge integration, and task performance in emergency operations. By applying perspectives of how system accidents occur and how specific knowledge is integrated, we expect to tap into a solution space which otherwise would not be self-evident in this field.

The perspective that integration of specific knowledge in emergency management operations can greatly facilitate activities through which the outcome can be improved is a novel knowledge-based view which adds to the literature on the improvement of emergency management. Our results show that by understanding the nature of task complexity and the required expertise in terms of specific knowledge, emergency managers and personnel can selectively try to improve the performance outcome of their operations.

In this study we have examined three types of specific knowledge: technology, context, and context-and-technology. We extend the research on general knowledge and the typology of specific knowledge by providing a useful and effective method for measuring the constructs for the extent of context-specific knowledge and technologyspecific knowledge. We see this as an important contribution which will allow the further development of conceptualizations about knowledge specificity. Knowledge integration is organized around the sharing and application of different areas of specific 
knowledge and this study provides a method to analyze and measure specific knowledge and its dimensions.

We propose a new emergent phenomenon related to the contingency of integration of specific knowledge which extends prior theories of knowledge integration particularly in the realm of emergency management. Through our findings in the empirical study and field observations, what emerged is an appreciation of the view that the integration of context-specific knowledge is required over and above the integration of technology-specific knowledge for working emergency management tasks. We argue that in emergency management the integration of context-specific knowledge and the integration of technology-specific knowledge have different characterizations. The integration of technology-specific knowledge deals more with planning, preparation, methodologies, systems, and training. The integration of context-specific knowledge is facilitated by the integration of technology-specific knowledge and entails improvisation and spontaneity.

\subsection{Implications for practice}

For practitioners, this research provides a unique perspective in knowledge management, namely integrating specific knowledge in the contingent context of emergency management. Current research has attempted to touch upon broad concepts that apply to emergency environments in different organization settings but may not have reached the heart of the issues that we contemplate in this study. We expect that when policy-makers and managers are responsible for making crucial decisions, the outcome of this work will provide useful insight and guidelines. It should help them evaluate their 
options, so that the choices they make are informed and deliberate instead of being simply repetitious based on past experiences.

The tasks undertaken at the EOC are inherently complex and depend on many personnel representing a variety of organizations. Our data conveys and confirms this observation. The complexity of emergency tasks is represented along three dimensions: task component complexity, task interactive complexity, and task procedural rigidity. In general, our results suggest that EOC personnel use three types of knowledge: contextspecific, technology-specific, and context-and-technology-specific knowledge. This indicates that the successful execution of the tasks requires both formal education (technology-specific) and on-the-job training (context-specific). In addition, turnover of personnel may compromise the EOC's ability to utilize and integrate the specific knowledge residing in those personnel, which in turn poses a significant concern for effective emergency response.

Despite the high levels of complexity, EOC tasks are completed successfully because of the effective integration of specific knowledge carried out by the individuals assigned to the tasks. When the degree of task complexity is high, the task is more difficult to manage and execute, which in turn makes it more difficult to succeed. The ability of the EOC personnel and their corresponding organizations to effectively integrate specific knowledge is essential for improving the task performance in these circumstances. The EOC organizational structure (modeled along ICS guidelines), technological infrastructure, and coordinators provide a fertile environment that enables effective knowledge integration across the personnel and organizations who are assigned to the EOC during the response and recovery efforts in a disaster situation. 
However, emergency managers need to be aware that "one size does not fit all" and the same degree of knowledge integration need not be applied for all tasks. Our results suggest that potentially higher benefits can be gained by being selective in knowledge integration strategies for tasks that require different levels of context-specific knowledge and different levels of technology-specific knowledge. The proposed framework for specificity of knowledge is a useful tool in this decision-making process.

We also propose possible future work to advance the requirements for systematically developing knowledge integration systems based on the findings of this study. These systems can include technologies and information systems that support gaining experiential knowledge. For example, experience may be gained via simulated events as well as virtual environments such as implementing a virtual EOC infrastructure (Becerra-Fernandez et al. 2007).

\subsection{Research limitations}

There are some inherent limitations in this study due to which the interpretation of the findings and the conclusions should be treated with caution. We focused on one large emergency response organization, the Miami-Dade Emergency Operations Center which might limit the extent to which the results can be generalized. Since Hurricane Andrew in 1992, the Miami-Dade EOC has been particularly acclaimed to have emerged as a well-organized, mature, and sophisticated EOC as compared to other emergency operations centers in the nation. Over the years, this organization has garnered the respect of neighboring municipalities, government agencies, local businesses, and research and training institutions. 
Due to the peculiar geographical location of South Florida, it is particularly vulnerable to tropical storms and hurricanes in the late summer and fall season. The Miami-Dade EOC is prepared to deal with a variety of possible natural disasters and man-made threats, nonetheless its planning and operations are generally fashioned with a heightened emphasis on dealing with preparation and response for tropical storms and hurricanes. Hence, emergency operations centers can vary in their structural and cultural attributes as well as their coordination and learning capabilities.

In the research design, we chose to focus on the inherent attributes of emergency management tasks (task complexity) and the influence of knowledge integration on the relationship between task complexity and task performance. In the research model we have excluded other factors, which might be potentially important but this was necessary to keep the research focused and prevent the data acquisition and analysis from becoming overwhelmingly complex. We concentrated on the task complexity dimensions as were relevant to this study from the theoretical perspectives of how systems accidents can occur, and knowledge integration from the practical perspective of emergency operations centers. Some factors that are important and can impact the task performance are the extent of prior planning and the available support from local and state governments.

Our motivation to approach this research from a knowledge-based perspective led us to study the influence of integration of specific knowledge on task performance. Our expectation was that integration of specific knowledge is an important mediating factor on the relationship between task complexity and performance. Other potentially important considerations which were excluded from this study can be the role that the 
political leaders and local media coverage play in influencing the outcome of some critical emergency operations.

Finally the use of a self-report measure for the dimensions of task performance, efficiency and effectiveness might be considered a limitation of this study. We attempted to capture additional information related to the task performance which can be considered objective -- for example traditional questions about completion time and planned time for the task as well as actual and planned budget considerations. However many participants were unable to respond to these questions either because they did not have access to the information or simply because it was not relevant to emergency tasks. For several emergency tasks, there is no initially planned budget for completing the task. We decided to use the questions related to each of the task performance constructs for the measurement of efficiency and effectiveness which were intended to capture the participant's perception concerning the items. As discussed earlier, the statistical internal reliability and validity test results for these constructs were satisfactory.

\subsection{Future research directions}

We identify and describe some important potential directions for future research. This study was based on the workings of one organization and the personnel who are called in to participate during activations of the Miami-Dade emergency operations center. Further research is required to be conducted in more emergency operations centers to see whether the results of this study can be further generalized. It will also be interesting to compare the results from studies in emergency operations centers in different geographical locations; for example the centers that are located in the hurricane 
belt might have different characteristics and priorities than the centers located in areas that are prone to earthquakes.

A different research methodology such as detailed case studies might help in expanding the research model presented in this study. For example we have investigated three types of specific knowledge which can be part of the knowledge integration process in emergency response operations. A detailed case-study might help to unravel exactly how the different types of specific knowledge are shared and applied for solving a given problem. Such studies can also explore the mediating effects on task performance of other factors besides knowledge integration. These can possibly be intra-organizational factors such as a particular organizational structure (e.g. the ICS structure) or factors external to the EOC organization (e.g. coordination support from private organizations).

This research was motivated by an interest in the study of complex systems as applied to the domain of emergency management tasks. Future work can include task characteristics that are not directly related to task complexity, for example the concepts of task novelty and task newness. Certainly, these task characteristics can also be important antecedents to the task performance construct.

Finally this research stream involving task complexity and knowledge integration can be extended beyond the domain of emergency management. For example we proposed the contingency aspects of integration of specific knowledge in the realm of emergency response organizations. This phenomenon might also be applicable in other environments such as firms characterized by highly complex projects or research and development institutions, albeit in different ways. 
We believe that this study will provide a good basis as a starting point for several of the research initiatives that we discussed above. Particularly we are hopeful that such a knowledge-based perspective will shed more light on understanding the complexities of emergency management operations and this research stream will prove to be a promising direction for future studies. 


\section{BIBLIOGRAPHY}

Ackoff, R. L. (1967). Management Misinformation Systems. Management Science, 14(4: B147-56).

Allen, P. M., \& Strathern, M. (2003). Evolution, emergence, and learning in complex systems. Emergence: Complexity and organization, 5(4), 8-33.

Anderson, A. I., Compton, D., \& Mason, T. (2004). Managing in a dangerous world: The National Incident Management System. Engineering management journal, 16(4), 3-9.

Anderson, J. C., \& Gerbing, D. W. (1988). Structural equation modeling in practice: A review and recommended two-step approach. Psychological Bulletin, 103(3), 411-423.

Anderson, P. (1999). Complexity theory and organization science. Organization science, 10(3), 216-232.

Baccarini, D. (1996). The concept of project complexity - a review. International journal of project management, 14(4), 201-204.

Banker, R. D., \& Slaughter, S. A. (2000). The moderating effects of structure on volatility and complexity in software enhancement. Information Systems Research, 11(3), 219.

Baron, R. M., \& Kenny, D. A. (1986). The Moderator-Mediator Variable Distinction in Social Psychological Research: Conceptual, Strategic, and Statistical Considerations. Journal of Personality and Social Psychology, 51(6), 1173.

Bar-Yam, Y. (2003). Dynamics of complex systems. Oxford: Westview press.

Becerra-Fernandez, I., Gonzalez, A., \& Sabherwal, R. (2004). Knowledge Management: Challenges, solutions, and technologies. New Jersey: Pearson Prentice Hall.

Becerra-Fernandez, I., \& Prietula, M. (2006). Project Ensayo: Integrating simulation, training, discovery, and support. Paper presented at the Proceedings of the North American Association for Computational Social and Organizational Science (NAACSOS 2006), Notre Dame, Indiana.

Becerra-Fernandez, I., Prietula, M., Madey, G., Rodriguez, D., Gudi, A., \& Rocha, J. (2007). Project Ensayo: A Virtual Emergency Operations Center. Paper presented at the The 16th International Conference on Management of Technology, Miami Beach, Florida. 
Becerra-Fernandez, I., Prietula, M., Madey, G., Rodriguez, D., Valerdi, R., \& Wright, T. (2008). Design and development of a Virtual Emergency Operations Center for disaster management research, training, and discovery. Paper presented at the Presentation and proceedings of 41st Hawaii International Conference on System Science (HICSS 2008), Big Island, Hawaii.

Becerra-Fernandez, I., \& Sabherwal, R. (2001). Organizational knowledgement management processes: A contingency perspective. Journal of Management information systems, 18(1), 23-55.

Becerra-Fernandez, I., Xia, W., Gudi, A., \& Rocha, J. (2008). Emergency management task characteristics, knowledge sharing and integration, and task performance: Research agenda and challenges. Paper presented at the Presentation and proceedings of the 5th International ISCRAM Conference 2008, Washington D.C. USA.

Belout, A. (1998). Effects of human resource management on project effectiveness and success: Toward a new conceptual framework. International Journal of Project Management, 16(1), 21.

Bhatt, G. D., \& Troutt, M. D. (2005). Examining the relationship between business process improvement initiatives, information systems integration and customer focus: an empirical study. Business Process Management Journal, 11(5), 532.

Bigley, G. A., \& Roberts, K. H. (2001). The incident command system: High-reliability organizing for complex and volatile task environments. Academy of Management Journal, 44(6), 1281.

Boer, M. d., Bosch, F. A. J. V. d., \& Volberda, H. W. (1999). Managing organizational knowledge integration in the emerging multimedia complex. The Journal of Management Studies, 36(3), 379.

Brass, D. J. (1995). A social network perspective on human resources management. Research in personnel and human resources management, 13, 39-79.

Brown, J. S., \& Duguid, P. (2002). The social life of information. Boston, Massachusetts: Harvard Business School Press.

Brusoni, S., Prencipe, A., \& Pavitt, K. (2001). Knowledge specialization, organizational coupling, and the boundaries of the firm: Why do firms know more than they can make? Administrative science quarterly, 46, 597-621.

Campbell, D. J. (1988). Task Complexity: A Review and Analysis. Academy of Management. The Academy of Management Review, 13(1), 40. 
Carlile, P. R. (2004). Transferring, Translating, and Transforming: An Integrative Framework for Managing Knowledge Across Boundaries. Organization Science, 15(5), 555.

Carver, L., \& Turoff, M. (2007). Human-computer interaction. Association for Computing Machinery. Communications of the ACM, 50(3), 33.

Choudhury, V., \& Sampler, J. L. (1997). Information specificity and environmental scanning: An economic perspective. MIS Quarterly, 21(1), 25.

Churchman, C. W. (1971). The design of inquiring systems: Basic concepts of systems and organizations. New York: Basic Books Inc.

Coakes, E., Willis, D., \& Clarke, S. (Eds.). (2002). Knowledge management in the Sociotechnical world: The graffiti continues. London: New York: Springer.

Cohen, J., \& Cohen, P. (1983). Applied Multiple Regression/Correlation Analysis for the Behavioral Sciences: Lawrence Erlbaum Associates, Inc.

Coleman, L. (2006). Frequency of Man-Made Disasters in the 20th Century. Journal of Contingencies and Crisis Management, 14(1), 3.

Comfort, L. K., Dunn, M., Johnson, D., Skertich, R., \& Zagorecki, A. (2004).

Coordination in complex systems: Increasing efficiency in disaster mitigation and response. International Journal of Emergency Management, 2(1-2), 62-80.

Comfort, L. K., Ko, K., \& Zagorecki, A. (2004). Coordination in Rapidly Evolving Disaster Response Systems: The Role of Information. The American Behavioral Scientist, 48(3), 295.

Cooke, D. L., \& Rohleder, T. R. (2006). Learning from incidents: From normal accidents to high reliability. System Dynamics Review, 22(3), 213.

Creswell, J. W. (2003). Research design: Qualitative, quantitative and mixed methods approaches. Thousand Oaks, California: Sage publications, Inc.

Creswell, J. W., Clark, P., Gutmann, M., \& Hanson, W. (2003). Advances in mixed method design. In A. Tashakkori \& C. Teddlie (Eds.). In Handbook of mixed methods in the social and behavioral sciences: Thousand Oaks, CA: Sage.

Cross, R., Parker, A., Prusak, L., \& Borgatti, S. P. (2001). Knowing what we know: Supporting knowledge creation and sharing in social networks. Organizational Dynamics, 30(2), 100.

Currion, P., De Silva, C., \& Van De Walle, B. (2007). Open source software for disaster management. Communications of the ACM, 50(3), 61-65. 
Daft, R. L., \& Lewin, R. L. (1993). Where are the theories of the "new" organizational forms? An editorial essay. Organization Science, 4(4), i-vi.

DeSanctis, G., \& Poole, M. (1994). Capturing the complexity in advanced technology use: Adaptive structuration theory. Organization Science, 5(2), 121-147.

DHS. (2004). Emergencies and disasters: Planning and prevention: Department of Homeland Security.

Eisenhardt, K. M. (1989). Building theories from case study research. Academy of management review, 14(4), 532-550.

Fiedrich, F., \& Burghardt, P. (2007). Agent-based systems for disaster management. Association for Computing Machinery. Communications of the ACM, 50(3), 41.

Field, A. P. (2005). Discovering statistics using SPSS (2nd edition). London: Sage.

Fong, P. S. W. (2005). Managing knowledge in project-based professional services firms: an international comparison. Oxford: Elsevier Butterworth-Heinemann.

Freeman, M., \& Beale, P. (1992). Measuring Project Success. Project Management Journal, 23(1), 8.

French, S., \& Turoff, M. (2007). Decision support systems. Association for Computing Machinery. Communications of the ACM, 50(3), 39.

Fryer, P. (2003). A brief description of complex adaptive systems and complexity theory

GAO, G. A. O. (2006). Hurricane Katrina: GAO's preliminary observations regarding preparedness, response, and recovery.

Grant, R. (1996). Prospering in dynamically competitive environment: organizational capability as knowledge integration. Organization Science, 7(4), 375-387.

Green, S. B., \& Salkind, N. J. (2005). Using SPSS for Windows and Macintosh: Analyzing and Understanding Data. New Jersey: Pearson Prentice Hall.

Grimaldi, R., \& Torrisi, S. (2001). Codified-tacit and general-specific knowledge in the division of labour among firms -- A study of the software industry. Research Policy, 30(9), 1425.

Haeckel, S. H. (1999). Adaptive enterprise. Boston, Massachusetts: Harvard business school press.

Haeckel, S. H., \& Nolan, R. L. (1993). Managing by wire. Harvard Business Review, $71(5), 122$. 
Hansen, M. T., Nohria, N., \& Tierney, T. (1999). What is your strategy for managing knowledge? Harvard business review, 106-116.

Harris, P. (2005). Emergency training takes center stage. Training and Development.

Hayek, F. A. (1945). The use of knowledge in society. American Economic Review, $X X X V(4), 519-530$.

Huang, J. C., \& Newell, S. (2003). Knowledge integration processes and dynamics within the context of cross-functional projects. International journal of project management, 21, 167-176.

Jensen, M. C., \& Meckling, W. H. (1996). Specific and general knowledge, and organizational structure. In P. S. Myers (Ed.), Knowledge management and organizational design (pp. 17-38). Newton, MA: Butterworth-Heinemann.

Jick, T. D. (1979). Mixing qualitative and quantitative methods: Triangulation in action. Administrative science quarterly, 24, 602-611.

Kernick, D. P. (2005). Facilitating resource decision making in public organizations drawing upon insights from complexity theory. Emergence: Complexity and organization, 7(1), 23-28.

Kuhn, T. S. (1996). The structure of scientific revolutions. Chicago: University of Chicago Press.

La Porte, T., \& Consolini, P. (1998). Theoretical and operational challenges of "highreliability organizations": Air-traffic control and aircraft carriers. International Journal of Public Administration, 21(6-8), 847.

Lagadec, P. (1997). Learning Processes for Crisis Management in Complex Organizations. Journal of Contingencies and Crisis Management, 5, 24-31.

Liebowitz, J. (2005). Conceptualizing and implementing knowledge management. Oxford: Elsevier Butterworth-Heinemann.

Lucas, H. C. (1975). Why information systems fail. New York: Columbia University Press.

Majchrzak, A., Cooper, L. P., \& Neece, O. E. (2004). Knowledge reuse for innovation. Management science, 50(2), 174-188.

Manoj, B. S., \& Baker, A. H. (2007). Communication challenges in emergency response. Association for Computing Machinery. Communications of the ACM, 50(3), 51. 
Marais, K., Dulac, N., \& Leveson, N. (2004). Beyond Normal Accidents and High Reliability organizations: The need for an alternate approach to safety in complex systems. Paper presented at the Engineering Systems division symposium, MIT Cambridge, MA.

March, J. G. (1991). Exploration and exploitation in organizational learning. Organization Science, 2(1), 71-87.

McElroy, M. W. (2003). The new knowledge management: Complexity, learning, and sustainable innovation. New York: Knowledge management consortium international.

Mendonça, D., Jefferson, T., \& Harrald, J. (2007). Collaborative adhocracies and mixand-match technologies in emergency management. Association for Computing Machinery. Communications of the ACM, 50(3), 44.

Moore, G. C., \& Bebasat, I. (1991). Development of an instrument to measure the perceptions of adopting an information technology innovation. Information Systems Research, 2(3), 192-222.

Mullins, N. C. (1971). The art of theory: Construction and use. New York: Harper and Row, Publishers.

Mushkatel, A. H., \& Weschler, L. F. (1985). Emergency Management and the Intergovernmental System. Public Administration Review, 45, 49.

Myers, P. S. (Ed.). (1996). Knowledge management and organization design. Boston: Butterworth-Heinemann.

Nonaka, I., \& Takeuchi, H. (1995). The knowledge-creating company: How Japanese companies create the dynamics of innovation. Oxford: Oxford university press.

Orton, D. J., \& Weick, K. E. (1990). Loosely coupled systems: A reconceptualization. Academy of management review, 15(2), 203-223.

Palen, L., Hiltz, S. R., \& Liu, S. B. (2007). Online forums supporting grassroots participation in emergency preparedness and response. Association for Computing Machinery. Communications of the ACM, 50(3), 54.

Pearson, C. M., \& Clair, J. A. (1998). Reframing crisis management. Academy of Management. The Academy of Management Review, 23(1), 59.

Perrow, C. (1984). Normal Accidents: Living with high-risk technologies. Princeton, New Jersey: Princeton University Press.

Perrow, C. (2004). A personal note on Normal Accidents. Organization \& Environment, $17(1), 9,6$. 
Polanyi, M. (1966). Tacit dimension. New York: Doubleday \& Co.

Rijpma, J. A. (1997). Complexity, Tight-Coupling and Reliability: Connecting Normal Accidents Theory and High Reliability Theory. Journal of Contingencies and Crisis Management, 5, 15-23.

Roberts, K. H., \& Bea, R. (2001). Must accidents happen? Lessons from high-reliability organizations. Academy of Management Executive, 15, 70-79.

Sabherwal, R., \& Becerra-Fernandez, I. (2003). An empirical study of the effect of knowledge management processes at individual, group, and organizational levels. Decision sciences, 34(2), 225-261.

Sabherwal, R., \& Becerra-Fernandez, I. (2005). Integrating Specific Knowledge: Insights From the Kennedy Space Center. IEEE Transactions on Engineering Management, 52(3), 301.

Sagan, S. D. (1993). The limits of safety: Organizations, accidents, and nuclear weapons. Princeton: Princeton University Press.

Saks, A. M. (1995). Longitudinal field investigation of the moderating and mediating effects of self-efficacy on the relationship between training and newcomer adjustment. Journal of Applied Psychology, 80(2), 211.

Samii, R., Van Hassenhove, L., Kumar, K., \& Becerra-Fernandez, I. (2002a). IFRC: Choreographer of disaster management - The Gujarat Earthquake. Fontainebleau, France: INSEAD.

Samii, R., Van Hassenhove, L., Kumar, K., \& Becerra-Fernandez, I. (2002b). IFRC: Choreographer of disaster management - Preparing for tomorrow's disasters. Fontainebleau, France: INSEAD.

Sanchez, R., \& Mahoney, J. T. (1996). Modularity, flexibility, and knowledge management in product and organization design. Strategic management journal, 17(Winter specis), 63-76.

Schellong, A., \& Langenberg, T. (2007). Managing Citizen Relationships: Hurricane Wilma, 311 and Miami-Dade County. Paper presented at the Proceedings of HICSS 40, Waikoloa, Hawaii.

Schon, D. A. (1983). The reflective practitioner: How professionals think in action. Cambridge, MA: Basic Books, Inc.

Schulman, P., Roe, E., Eeten, M. v., \& Bruijne, M. d. (2004). High Reliability and the Management of Critical Infrastructures. Journal of Contingencies and Crisis Management, 12(1), 14. 
Senge, P. (1990). The fifth discipline. New York: Doubleday.

Shenhar, A. J., \& Dvir, D. (1996). Toward a typological theory of project management. Research Policy, 25, 607-632.

Simon, H. A. (1996). The Sciences of the Artificial (3rd ed. ed.). Cambridge, MA: MIT Press.

Sobel, M. E. (Ed.). (1982). Asymptotic confidence intervals for indirect effects in structural equation models. San Francisco: Jossey-Bass.

Stanton, T. H. (2007). Delivery of benefits in an Emergency: Lessons from hurricane Katrina. Washington, D.C.: IBM Center for the Business of Government.

Steckler, A., McLeroy, K. R., Goodman, R. M., Bird, S. T., \& McCormick, L. (1992). Toward integrating qualitative and quantitative methods: An intruduction. Health Education Quarterly, 19(1), 1-8.

Sutton, R., \& Staw, B. (1995). What theory is not. Administrative Science Quarterly, 371-384.

Tabachnick, B. G., \& Fidell, L. S. (1996). Using Multivariate Statistics: Harper Collins College Publishers.

Tashakkori, A., \& Teddlie, C. (1998). Mixed methodology: Combining qualitative and quantitative approaches: Thousand Oaks, CA: Sage.

Tenner, E. (1996). Why things bite back: Predicting the problems of progress. London: Fourth Estate.

Thompson, D. (1967). Organizations in Action. New York: McGraw-Hill.

Truex, D. P., Baskerville, R., \& Klein, H. (1999). Growing systems in emergent organizations. Communications of the ACM, 42(8).

Turkle, S. (2003). Technology and human vulnerability. Harvard Business Review, 81(9), 7.

Turner, J. R., \& Cochrane, R. A. (1993). Goals-and-methods matrix: coping with projects with ill defined goals and/or methods of achieving them. International journal of project management, 11, 93-102.

Vivekananda, S. (1985). The complete works of Swami Vivekananda (Vol. VI). Calcutta: Advaita Ashram.

Walle, B. V. d., \& Turoff, M. (2007). Introduction. Association for Computing Machinery. Communications of the ACM, 50(3), 29. 
Weber, R., Aha, D. W., \& Becerra-Fernandez, I. (2001). Intelligent lessons learned. Expert systems with applications, 17, 17-34.

Weick, K. (1995). What theory is not, theorizing IS. Administrative Science Quarterly, 40(3), 385-390.

Weick, K. E., \& Sutcliffe, K. M. (2001). Managing the unexpected: Assured high performance in an age of complexity. San Francisco: Jossey-Bass.

Wenger, E. (1998). Communities of practice: learning, meaning, and identity. Cambridge: Cambridge university press.

Williams, T. M. (1999). The need for new paradigms for complex projects. International journal of project management, 17(5), 269-273.

Wood, R. E. (1986). Task Complexity: Definition of the Construct. Organizational Behavior and Human Decision Processes, 37(1), 60.

Xia, W., \& Lee, G. (2005). Complexity of Information Systems Development Projects: Conceptualization and Measurement Development. Journal of Management Information Systems, 22(1), 45.

Zhu, D., Prietula, M. J., \& Hsu, W. L. (1997). When processes learn: Steps toward crafting an intelligent organization. Information Systems Research, 8(3), 302. 


\section{APPENDICES}

Appendix A: EOC Survey Questionnaire 


\section{A Study of Task Complexity, Inter-organizational Knowledge Management, and Emergency Management Performance}

Arvind Gudi, Florida International University, email: agudi@aol.com

Dr. Irma Becerra-Fernandez, Florida International University, email: becferi@ fiu.edu

Dr. Weidong Xia, Florida International University, email: xiaw@fiu.edu

Emergency management tasks are increasingly complex and inter-organizational. Effectively managing various knowledge areas and organizations has become a critical emergency management success factor. However, there is a lack of theory and tools that organizations can use to assess task complexity and improve emergency management success. This survey is the first-part of a study that examines how organizations can better assess and manage task complexity and knowledge sharing to enhance emergency management effectiveness.

Because of your extensive experience in emergency management, your input is critical to the success of our research. We assure you that all information you provide will be treated as confidential. We will not reveal the identities of individuals or organizations in any reports, only aggregated results will be analyzed and reported.

The survey has three sections: (1) characteristics of an emergency management task in which you were recently involved; (2) characteristics of a relevant knowledge area that was used to accomplish the task; and (3) background information that will help us segment and analyze the data. Our pilot tests with experienced emergency managers suggest that it would take about 20 minutes to complete the questionnaire.

URL to access web-based online version of the survey: https://www.surveymonkey.com/s.aspx?sm=17zs4eQdKelpnNF_2f53skqQ_3d_3d 


\section{Section 1: Characteristics of an Inter-organizational Task}

1.1. Please identify one task that you were recently involved in and were responsible for as a representative of your organization. The following is a list of typical EOC tasks related to response and recovery efforts during an incident, such as a hurricane. The list is not meant to be exhaustive -- it only provides some sample tasks. If the task you were recently involved in is on the list, please check it. If not, please specify the task (similar in nature to the sample tasks) in the space provided. We intend to study the tasks in a range with variations in the degree of complexity (relatively high to low). All tasks at the EOC are important; however we expect them to vary in terms of number of people, number of organizations, degree of interactions, and rigidity of processes.

Tasks with relatively low complexity

Open 311 Center/ Update web page Accomplish EEAP Registry call down

Repair air-conditioning unit at a given

Special Needs shelter

- Deliver mattresses to a given SNEC shelter, 300 needed

- Supply 2 traffic display signs to FHP due to accidents which require diversion of traffic

- Comply with City request to enhance flashlight supply request of 600 units - Other
Tasks with relatively high complexity

- Close schools

- Evacuate MMF (Medical Management Facility) clients via STS (Special Transport Service)

- Activate $\mathrm{DoH} /$ Dialysis command centers

- Accomplish drawbridge lockdown

- Activate/ accomplish debris clearance procedures

- Inspect critical facilities for integrity

o Other 
1.2. Background of the task. Please provide your best approximate estimates.

1. How many people were assigned to this task

2. How many machines were used to execute this task

(Please indicate the actual number for your scoring)

3. How many computer systems were used to execute this task

4. How many organizations were involved in this task

(These are organizations you represent. Please indicate the actual number for your scoring)

5. Which agency was leading this task

6. What was the planned time for the task completion (in hours)

7. What was the actual time required for completing the task (in hours)

8. What was the planned budget/cost for the task

9. What was the actual budget/cost for the task 
1.3. Characteristics of the task that you identified in the previous section. Please indicate the extent to which you disagree or agree with each of the following statements by CIRCLING the appropriate number from 1 to 7 . If you think the response is "do not know" or "not applicable", then circle 4 or neutral.

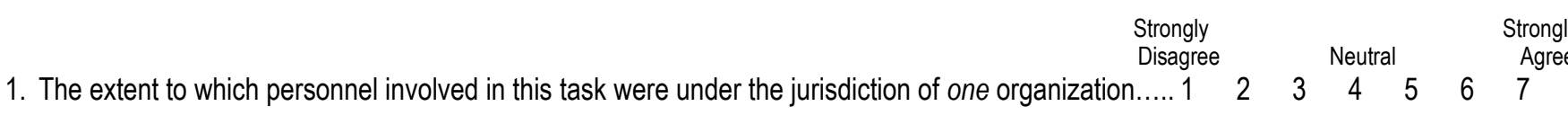

2. The different activities in the task interacted with each other in unpredictable ways during the

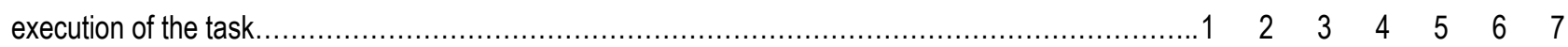

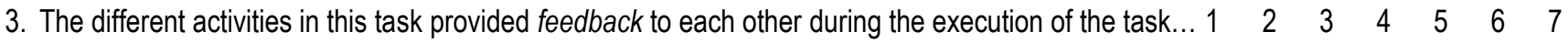

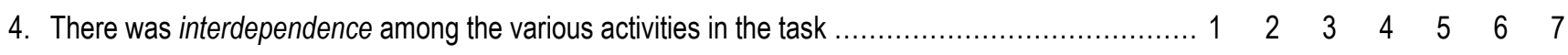

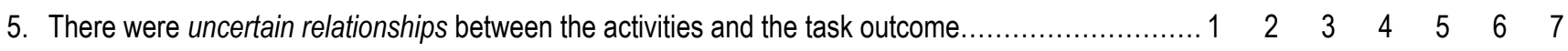

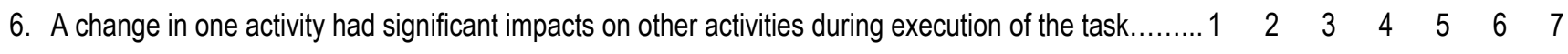

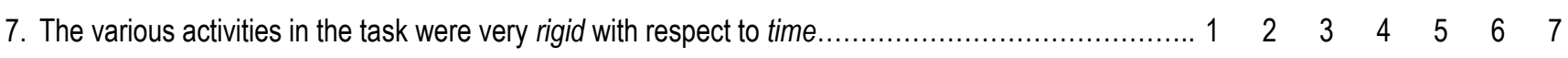

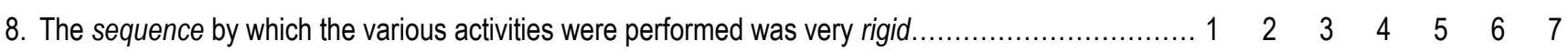

9. There were sufficient backup personnel in the executions of the task

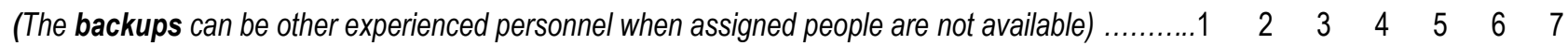

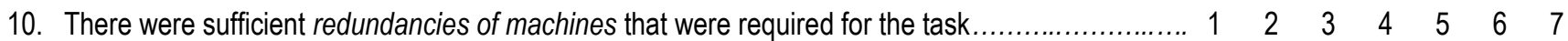
(These were machines that could be used in case of failure)

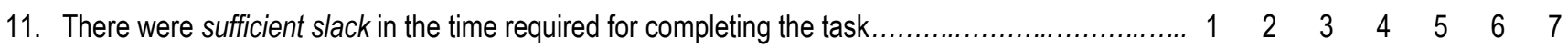

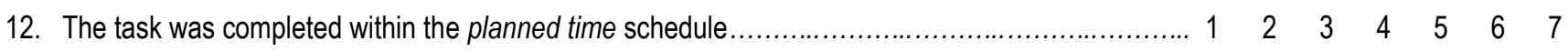

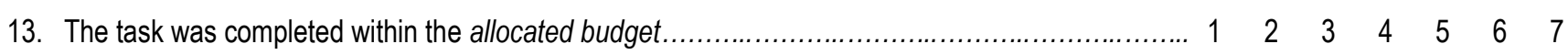

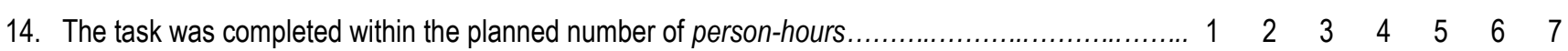

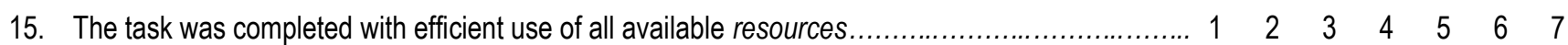


16. The task was completed satisfactorily for all participants.

$\begin{array}{llllll}2 & 3 & 4 & 5 & 6 & 7\end{array}$

17. All incident requirements were met when the task was completed.

$\begin{array}{llllll}2 & 3 & 4 & 5 & 6 & 7\end{array}$

18. The task was completed successfully without negatively impacting other tasks.........

$\begin{array}{llllll}2 & 3 & 4 & 5 & 6 & 7\end{array}$

19. The task was effectively completed despite any conflicting task requirements.

$\begin{array}{llllll}2 & 3 & 4 & 5 & 6 & 7\end{array}$ 


\section{Section 2: Evaluation of One Area of Knowledge}

2.1. Please identify one specific area of knowledge that you consider to be critical for performing the task that you identified in the previous section. We intend to study three categories of knowledge: Context-specific (knowledge of particular circumstances of time and place in which work is performed), Technology-specific (knowledge of a particular scientific or theoretical field, which includes the rules, tools and techniques that may be used to solve problems in that area), and Contextand-Technology-specific knowledge (knowledge that is both context-specific and technology-specific).

Examples: The following are few examples of knowledge areas for each of the three categories. If appropriate for the task that you identified in the previous section, you may select any one of them; otherwise provide a brief description of your specific knowledge area required for your task:

Examples of Context-specific knowledge areas:

- The planned evacuation routes in a given location in M-D County before a hurricane

How to locate receiving facilities for medical facilities whose prearranged plans failed

Experience in implementation of mutual aid agreements for the continued supply of fuel for the county after an incident or disaster

Experience in prioritizing a resource request based on relative urgency

Experience in estimating the completion time (of resource request), and advising the originator and the Infrastructure Branch Director via E-Team

Other

Examples of Technology-specific knowledge areas:

Expertise in draw-bridge lockdown procedures based on different bridge design types \& technology

Technical skill in operating particular equipment, tool, or machine to clear debris (RIAT)

How to use the High Frequency Radio System (this is the secondary communication system in case of failure of the primary telephone system)

Expertise in determining when to issue boil water orders

Calculating how loss of feeder lines and/or substations will impact consumption of electricity

Determining which additional medicines and medical supplies will be required based on new patient arrivals

$\circ$ Other 
Examples of Context-and-Technology specific knowledge areas:

Experience about estimating curfew times based on projection of arrival of tropical storm force winds

Priorities related to individuals and groups that are electrically dependent and will require preferential electrical restoration services

Procedures for shutdown of power grids to facilitate search and rescue efforts (also debris removal and road repair)

Experience in coordination and repair of the fuel supply infrastructure for different forms of transport

Procedures for staging and transportation of fuel for government vehicles and aircraft

How to coordinate tank farms in accordance with hurricane lock-down procedures

Other 
2.2. Characteristics of the knowledge that you just identified. Please indicate the extent to which you disagree or agree with each of the following statements by CIRCLING the appropriate number from 1 to 7 .

\begin{tabular}{|c|c|c|c|c|c|c|}
\hline $\begin{array}{l}\text { Strongly } \\
\text { Disagree }\end{array}$ & & & & leutra & & $\begin{array}{l}\text { Strongly } \\
\text { Agree }\end{array}$ \\
\hline 1 You depended on other departments for this knowledge to complete your tasks...................... & 2 & 3 & 4 & 5 & 6 & \\
\hline 2 You depended on other organizations for this knowledge to complete your tasks........................ 1 & 2 & 3 & 4 & 5 & 6 & 7 \\
\hline 3 There was a written manual describing the knowledge in this area..................................... 1 & 2 & 3 & 4 & 5 & 6 & 7 \\
\hline 4 This knowledge could be easily expressed in the form of notes and documents........................ 1 & 2 & 3 & 4 & 5 & 6 & 7 \\
\hline 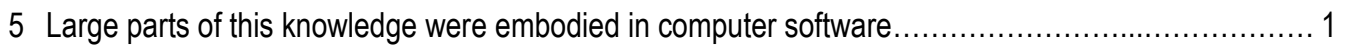 & 2 & 3 & 4 & 5 & 6 & 7 \\
\hline 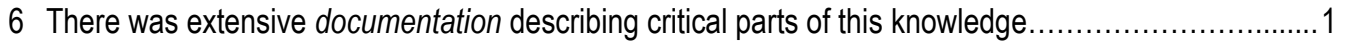 & 2 & 3 & 4 & 5 & 6 & 7 \\
\hline 7 New personnel were able to easily acquire this knowledge by talking to skilled employees............. 1 & 2 & 3 & 4 & 5 & 6 & 7 \\
\hline 8 Educating and training new employees was a quick, easy job................. & 2 & 3 & 4 & 5 & 6 & 7 \\
\hline 9 New personnel was able to easily acquire this knowledge by studying written documents ............... 1 & 2 & 3 & 4 & 5 & 6 & 7 \\
\hline 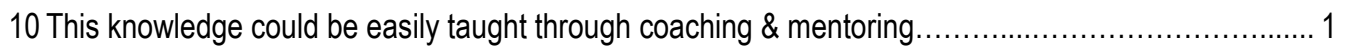 & 2 & 3 & 4 & 5 & 6 & 7 \\
\hline 11 This knowledge was frequently used by yourself in performing your tasks............. & 2 & 3 & 4 & 5 & 6 & 7 \\
\hline 12 This knowledge was frequently used by your organization in performing its tasks... & 2 & 3 & 4 & 5 & 6 & 7 \\
\hline 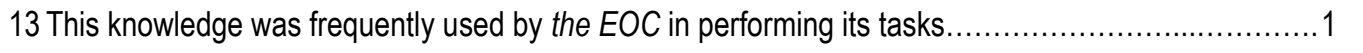 & 2 & 3 & 4 & 5 & 6 & 7 \\
\hline 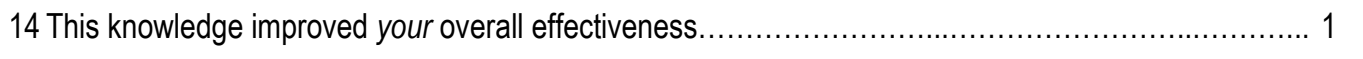 & 2 & 3 & 4 & 5 & 6 & 7 \\
\hline 15 This knowledge improved the overall effectiveness of your organization............................... 1 & 2 & 3 & 4 & 5 & 6 & 7 \\
\hline 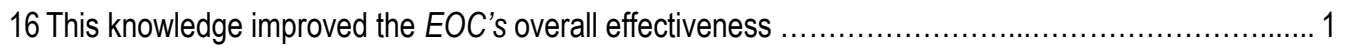 & 2 & 3 & 4 & 5 & 6 & 7 \\
\hline 17 This knowledge can be taught through formal training \& education..................... & 2 & 3 & 4 & 5 & 6 & 7 \\
\hline 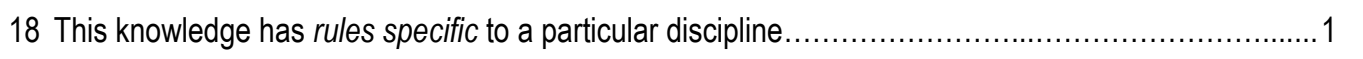 & 2 & 3 & 4 & 5 & 6 & 7 \\
\hline 19 This knowledge makes use of tools \& techniques specific to a particular discipline. & 2 & 3 & 4 & 5 & 6 & 7 \\
\hline
\end{tabular}


20 This knowledge can be applied regardless of situational context

21 This knowledge is related to particular circumstances of time.

22 This knowledge is related to particular situations and place......

23 This knowledge can be acquired only through on-the-job experience

24 Application of this knowledge is contingent upon particular circumstances \& events

25 Individuals in the EOC shared a common language \& vocabulary related to this area of knowledge...

26 Individuals in the EOC recognized other individuals' knowledge related to this area of knowledge...... 1

27 Individuals in the EOC shared common models related to this area of knowledge.

28 Individuals in the EOC shared norms/ rules related to this area of knowledge.

29 Individuals in the EOC recognized who has expertise in this knowledge area.

\section{Section 3: Background Information}

Please provide the following background information, which will help us segment the sample to understand how the relationship between task complexity, knowledge management and task performance varies according to the specific context of the task. Once again we assure you that your input will be treated as confidential and no personal information will be reported.

1 Name of your organization:

2 Your title:

3 How long have you worked at your current organization? Years

4 Did you work in another organization involved in emergency management? Yes No 
5 If yes, which organization?

6 How long have you been assigned at the EOC?

Years

7 In total, how long have you been working in the emergency management field? Years

8. Your educational degrees and corresponding fields:

Degree:

Degree:

Degree:

Field:

Field

Field:

We will email you an Executive Summary of our study. Please provide your contact information below or attach your business card.

Name:

Phone:

Email address: 
Appendix B: QSorting EOC instructions 


\section{Sorting procedure for construct validity in EOC survey}

Purpose: To qualitatively assess the face validity and the construct validity of the initial measurement items proposed in the survey instrument.

EOC Survey: A study on the relationships between task complexity, inter-organizational knowledge management and emergency management performance

Each measurement item has been printed on one index card. Please read each card carefully and place it in one of the six categories based on the definition/ explanation given below. If you feel any item does not belong to these predefined categories, then place it in the category "too ambiguous/ unclear".

1. Task component complexity: This construct will capture the magnitude, number, and variety of the task components. It is represented by items such as number of personnel and teams assigned to the task, number of machines and computer systems being used, and the number of organizational units involved in the task.

2. Task interactive complexity refers to the extent to which the different people and activities can interact with each other. It is represented by the number of relationships between all the elements, the number of feedback loops through which they interact, conflicting interdependencies, uncertain links, and the speed at which a change in one activity of the task will cascade through the system and impact other activities.

3. Task procedural rigidity refers to the tightness or looseness in the process. It is represented by rigidity in terms of time and sequence, the extent of component redundancy, backups available, resource buffer/ slack and process flexibility.

4. Integration of knowledge: Integration of a particular area of knowledge represents the extent to which that knowledge is shared and applied across the organization and enables its members to better perform their tasks. It is represented by the extent to which the specific area of knowledge is frequently used and how it is able to improve the effectiveness at individual and organizational levels.

5. Task efficiency refers to the extent to which the task was completed in the required time frame and within the allocated budget and resources.

6. Task effectiveness refers to the extent to which the emergency incident requirements were met. It represents the extent to which the task outcome was satisfactory to the participants, and the task was successfully completed without impacting other tasks. 
Appendix C: QSorting procedure sample results 


\section{Sorting procedure for construct validity in EOC survey: Results}

Name of judge:

Date:

\begin{tabular}{|c|c|c|c|c|c|c|c|c|c|}
\hline No & Measurement item & 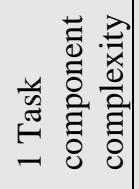 & 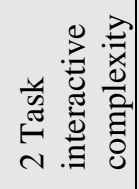 & 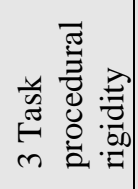 & 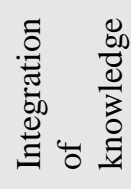 & 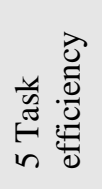 & 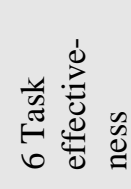 & 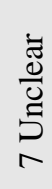 & $\begin{array}{l}\text { Com } \\
\text { ment }\end{array}$ \\
\hline 1 & How many people were assigned to this task & & & & & & & & \\
\hline 2 & How many machines were used to execute this task & & & & & & & & \\
\hline 3 & How many computer systems were used to execute this task & & & & & & & & \\
\hline 4 & How many organizations were involved in this task & & & & & & & & \\
\hline 5 & What was the planned time for the task completion (in hours) & & & & & & & & \\
\hline 6 & What was the actual time required for completing the task (in hours) & & & & & & & & \\
\hline 7 & What was the planned budget/cost for the task & & & & & & & & \\
\hline 8 & What was the actual budget/cost for the task & & & & & & & & \\
\hline 9 & $\begin{array}{l}\text { The extent to which personnel involved in this task were under the } \\
\text { jurisdiction of one organization }\end{array}$ & & & & & & & & \\
\hline 10 & $\begin{array}{l}\text { The different activities in the task interacted with each other in } \\
\text { unpredictable ways during the execution of the task }\end{array}$ & & & & & & & & \\
\hline 11 & $\begin{array}{l}\text { The different activities in this task provided feedback to each other during } \\
\text { the execution of the task }\end{array}$ & & & & & & & & \\
\hline 12 & $\begin{array}{l}\text { There was conflicting interdependence among the various activities in the } \\
\text { task }\end{array}$ & & & & & & & & \\
\hline 13 & $\begin{array}{l}\text { There were uncertain relationships between the activities and the task } \\
\text { outcome }\end{array}$ & & & & & & & & \\
\hline 14 & $\begin{array}{l}\text { A change in one activity had significant impacts on other activities during } \\
\text { execution of the task }\end{array}$ & & & & & & & & \\
\hline 15 & The various activities in the task were very rigid with respect to time & & & & & & & & \\
\hline
\end{tabular}




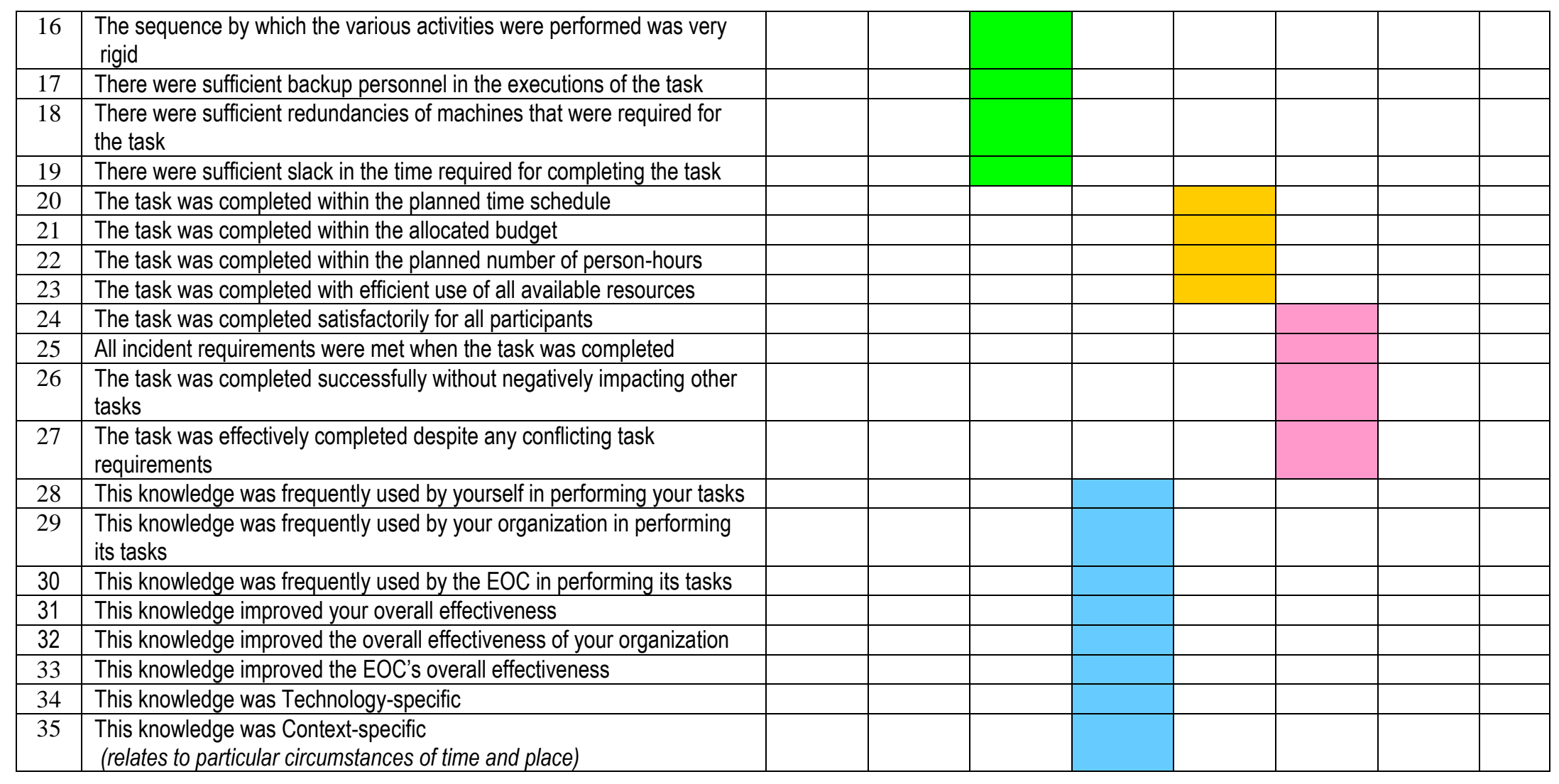




\section{Sorting procedure for construct validity in EOC survey: Results}

Name of judge: Judge01

Date:

$07 / 25 / 2007$

\begin{tabular}{|c|c|c|c|c|c|c|c|c|c|}
\hline No & Measurement item & 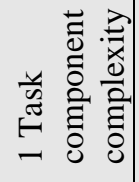 & 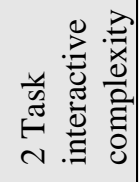 & 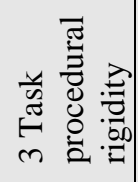 & 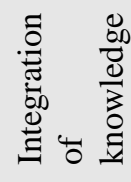 & 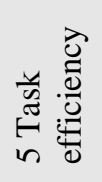 & 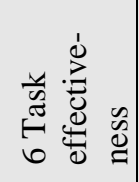 & 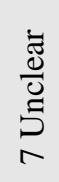 & $\begin{array}{l}\text { Com } \\
\text { ments }\end{array}$ \\
\hline 1 & How many different people were assigned to this task & & & & & & & & \\
\hline 2 & How many machines/ computer systems were used to execute this task & & & & & & & & \\
\hline 3 & How many organizations were involved in this task & & & & & & & & \\
\hline 4 & What was the planned time schedule for the task completion (in hours) & & & $\mathrm{X}$ & & & & & 1.1 \\
\hline 5 & What was the actual time required for completing the task (in hours) & & & & & & & & \\
\hline 6 & What was the planned budget/cost for the task & & & & & & & & \\
\hline 7 & What was the actual budget/cost for the task & & & & & & & & \\
\hline 8 & $\begin{array}{l}\text { All personnel/teams involved in this task were under the jurisdiction of } \\
\text { one organization }\end{array}$ & & & & & & & & \\
\hline 9 & $\begin{array}{l}\text { The different activities in the task interacted with each other in } \\
\text { unpredictable ways during the execution of the task }\end{array}$ & & & & & & & & \\
\hline 10 & $\begin{array}{l}\text { The different activities in this task provided feedback to each other during } \\
\text { the execution of the task }\end{array}$ & & & & & & & & \\
\hline 11 & $\begin{array}{l}\text { There was conflicting interdependence among the various activities in the } \\
\text { task }\end{array}$ & & & & & & & & \\
\hline 12 & $\begin{array}{l}\text { There were uncertain relationships between the activities and the task } \\
\text { outcome }\end{array}$ & & & & & & & & \\
\hline 13 & $\begin{array}{l}\text { A change in one activity had significant impacts on other activities during } \\
\text { execution of the task }\end{array}$ & & & $\mathrm{X}$ & & & & & 1.2 \\
\hline 14 & The various activities in the task were very rigid with respect to time & & & & & & & & \\
\hline
\end{tabular}




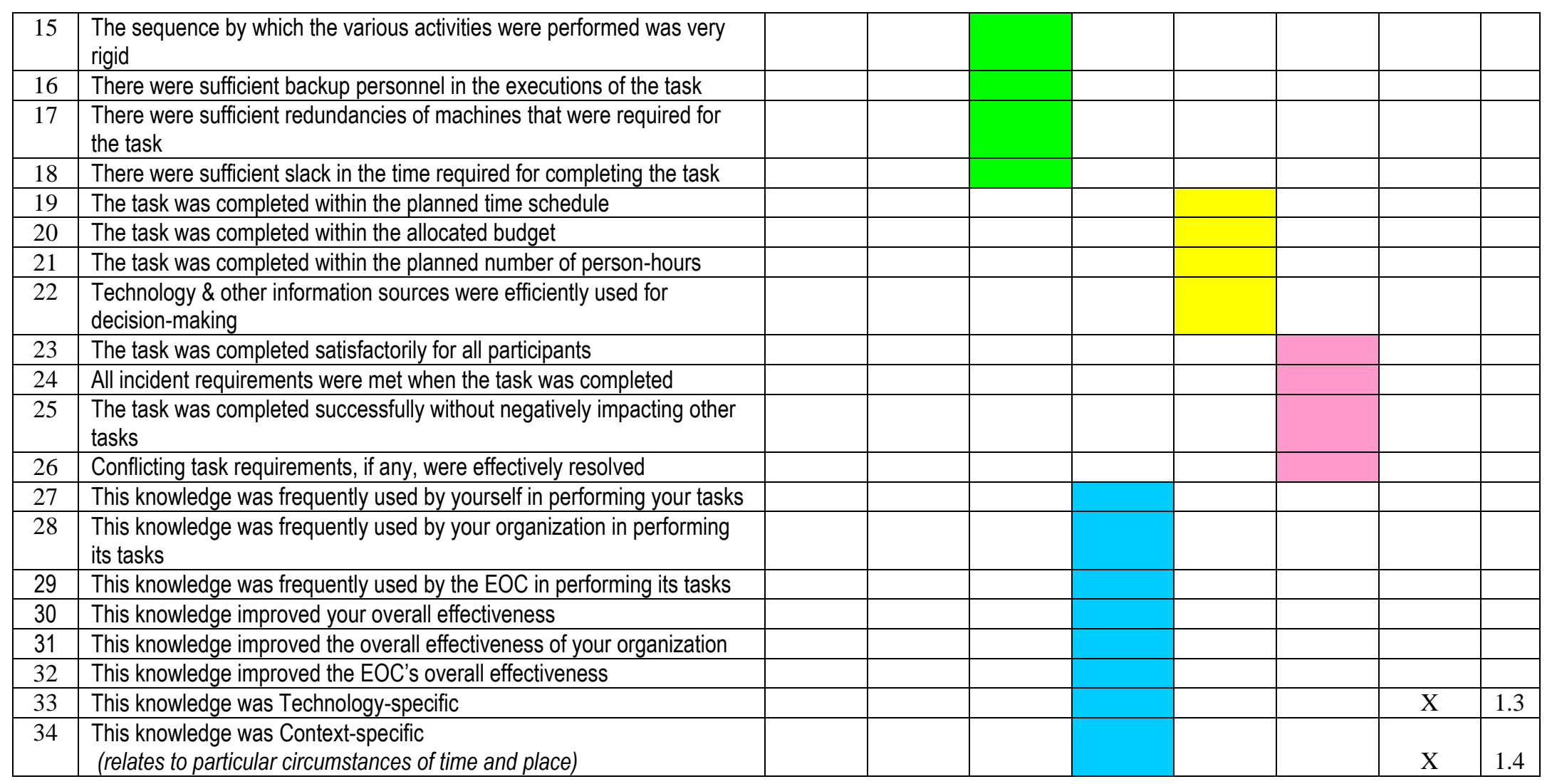




\section{Comments from Judge 01}

1.1 This question by itself appears to be an item for "Task procedural rigidity".

Observation: In the $Q$-sorting procedure, the questions were presented at random and the judge did not have the benefit of the context of the entire survey. This will not be the case when the actual survey will be conducted.

The Judge and I agreed that this discrepancy is not an issue.

1.2 This question could also be under "Task procedural rigidity".

Observation: This item was originally shifted from "Task procedural rigidity".

This is how we categorized the items based on "unbundling" the Complexity

construct.

We will observe how other judges will sort this item.

1.3 The question by itself is not clear what it will measure.

Observation: This question is an assessment of the survey participant's perception regarding specific knowledge. The observation here is similar to 1.1 above.

The Judge and I agreed that this is not an issue.

1.4 Same comments as (1.3) above. 


\section{Sorting procedure for construct validity in EOC survey: Results}

Name of judge: Judge02

Date:

07/26/2007

\begin{tabular}{|c|c|c|c|c|c|c|c|c|c|}
\hline No & Measurement item & 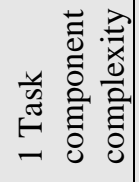 & 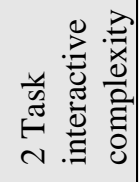 & 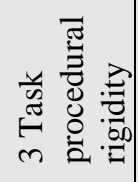 & 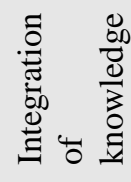 & 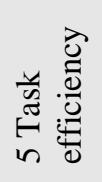 & 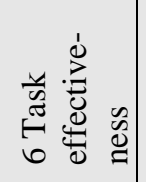 & 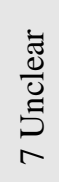 & $\begin{array}{l}\text { Com } \\
\text { ments }\end{array}$ \\
\hline 1 & How many different people were assigned to this task & & & & & & & & \\
\hline 2 & How many machines/ computer systems were used to execute this task & & & & & & & & \\
\hline 3 & How many organizations were involved in this task & & & & & & & & \\
\hline 4 & What was the planned time schedule for the task completion (in hours) & & & & & & & & \\
\hline 5 & What was the actual time required for completing the task (in hours) & & & & & & & & \\
\hline 6 & What was the planned budget/cost for the task & & & & & & & & \\
\hline 7 & What was the actual budget/cost for the task & & & & & & & & \\
\hline 8 & $\begin{array}{l}\text { All personnel/teams involved in this task were under the jurisdiction of } \\
\text { one organization }\end{array}$ & & $\mathrm{X}$ & & & & & & 2.1 \\
\hline 9 & $\begin{array}{l}\text { The different activities in the task interacted with each other in } \\
\text { unpredictable ways during the execution of the task }\end{array}$ & & & & & & & & \\
\hline 10 & $\begin{array}{l}\text { The different activities in this task provided feedback to each other during } \\
\text { the execution of the task }\end{array}$ & & & & & & & & \\
\hline 11 & $\begin{array}{l}\text { There was conflicting interdependence among the various activities in the } \\
\text { task }\end{array}$ & & & & & & & & \\
\hline 12 & $\begin{array}{l}\text { There were uncertain relationships between the activities and the task } \\
\text { outcome }\end{array}$ & & & & & & & & \\
\hline 13 & $\begin{array}{l}\text { A change in one activity had significant impacts on other activities during } \\
\text { execution of the task }\end{array}$ & & & & & & & & \\
\hline 14 & The various activities in the task were very rigid with respect to time & & & & & & & & \\
\hline
\end{tabular}




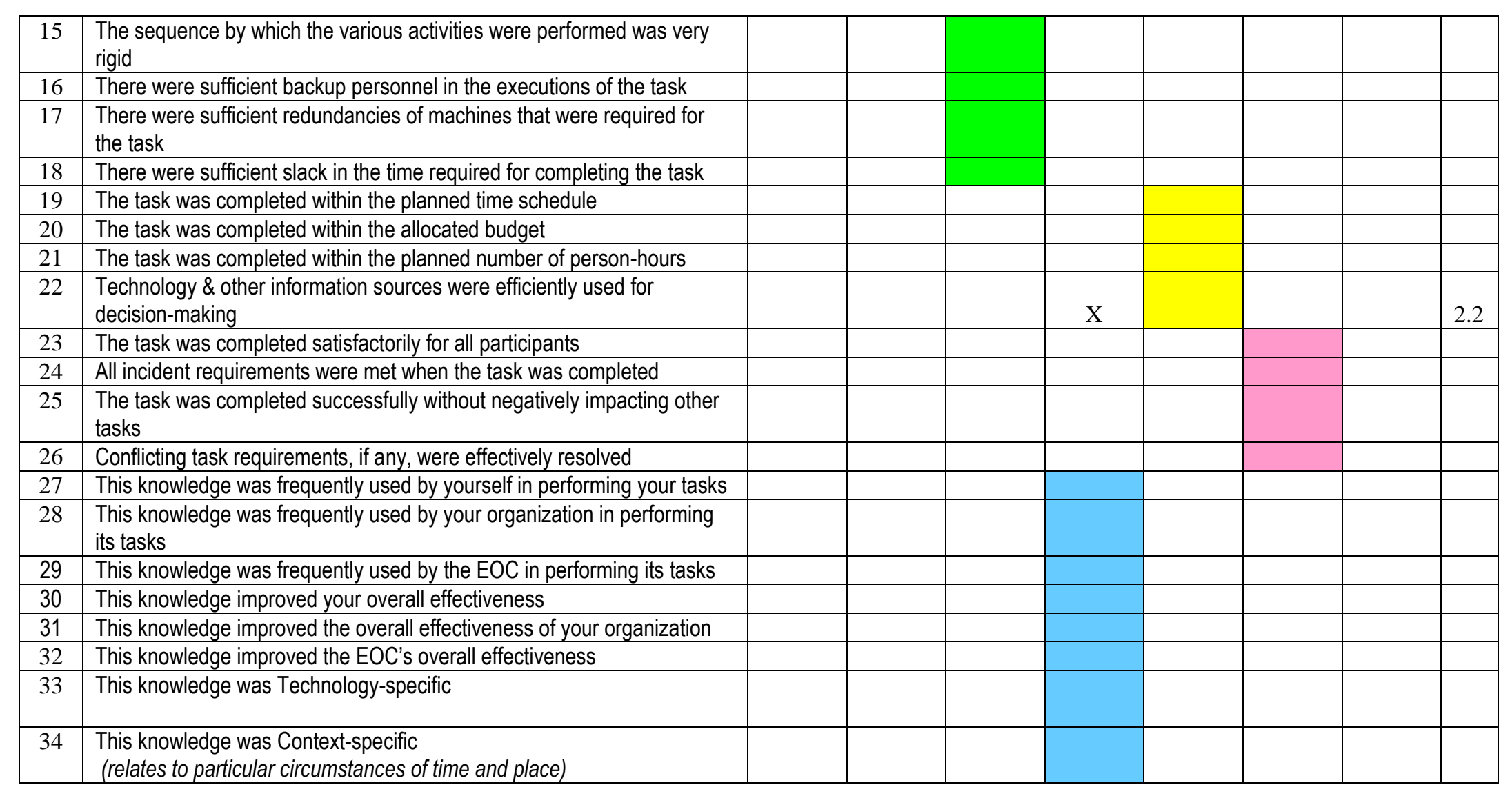




\section{Comments from Judge 02}

2.1 This question could also be under "Task interactive complexity".

Observation: This item was originally shifted as a result of unbundling the "Complexity" construct.

We will observe how other judges will sort this item.

2.2 The use of the word "technology" keyed in the Judge to the construct related to Integration of Knowledge.

Observation: When the survey participants have the context of the entire survey questionnaire, this will not be the case.

The Judge and I agreed that this is not an issue. 
Appendix D: Sample Miami-Dade County Situation Report 


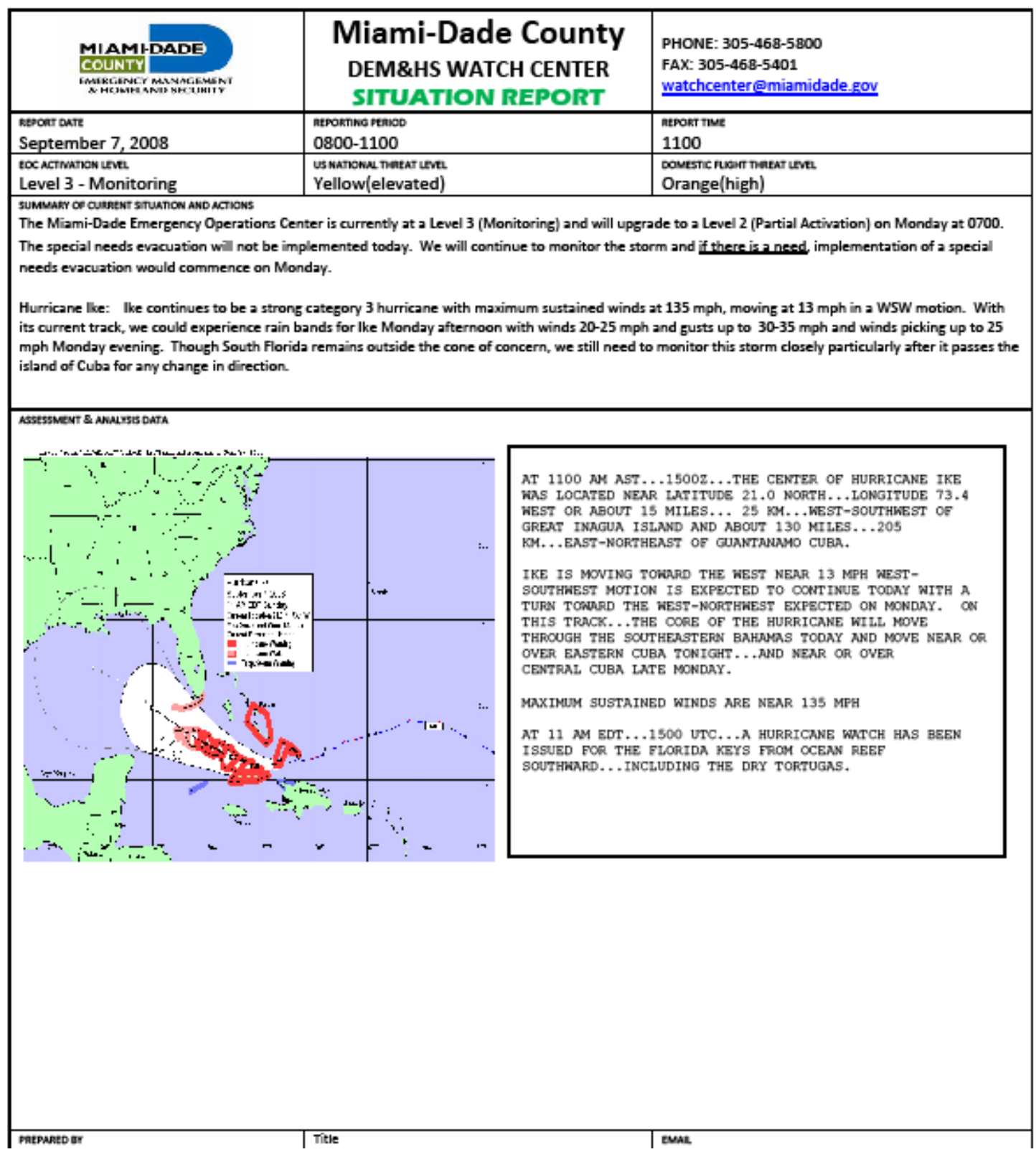


VITA

\section{ARVIND GUDI}

1980

B.E. Electronics and Telecommunications

College of Engineering, Pune, India

1980-1984

Tata Consultancy Services

Bombay, India

1984-1986

American Express - TCS

Fort Lauderdale, Florida

1986-1993

Computer Dynamics, Florida Power and Light

Miami, Florida

1992

M.S. Management Information Systems

Florida International University

Miami, Florida

1993-2003

American Bankers Insurance Group

Miami, Florida

2003-2008

Doctoral Candidate, Business Administration

Florida International University

Miami, Florida

\section{PUBLICATIONS AND PRESENTATIONS}

Arvind Gudi and Becerra-Fernandez, I. (2005). Role of Knowledge Management in Project Management of Complex Systems Organizations. Presentation at the Association for Global Business (International academy of linguistics behavioral and social sciences) Annual Conference 2005, November 17-20, 2005, Miami, Florida.

Arvind Gudi and Becerra-Fernandez, I. (2006). Effective Knowledge Management for Successful Project Operations. Presentation at the Knowledge Management and Successful Mission Operations Conference, March 2-3, 2006, NASA Johnson Space Center, Houston, Texas.

Becerra-Fernandez, I. Prietula, M., Madey, G. , Rodriguez, D., Gudi, A., and Rocha, J. (2007). Project Ensayo: A Virtual Emergency Operations Center. Presentation at the $16^{\text {th }}$ International Conference on Management of Technology, May 2007, Miami Beach, Florida. 
Gudi, A., Becerra-Fernandez, I. (2007). Effective knowledge management strategies in emergency response organizations. Presentation at the $16^{\text {th }}$ International Conference on Management of Technology, May 2007, Miami Beach, Florida.

Becerra-Fernandez, I., Xia, Weidong, Gudi, Arvind, Rocha, Jose. (2008). Emergency management task characteristics, knowledge sharing and integration, and task performance: Research agenda and challenges. Presentation and proceedings of ISCRAM $20085^{\text {th }}$ International Conference on Information Systems for Crisis Response and Management, May 4-7 2008 Washington DC, USA.

Becerra-Fernandez, I. and Gudi, A. (2008) 'An experiential approach to teaching Knowledge Management', Int. J. Teaching and Case Studies, Vol. 1, No. 3, pp. 171-188.

Gudi, A., Becerra-Fernandez, I., Xia, W. When Things go Right in Disasters: The Moderating Effect of Specific Knowledge -- Working paper targeting publication in Management Science.

Gudi, A., Becerra-Fernandez, I., Xia, W. Managing emergency task characteristics: A knowledge-based approach -- Working paper targeting publication in American Management Review. 